\title{
Pressure Control in Hydraulic Power Steering Systems
}

\section{Alessandro Dell'Amico}

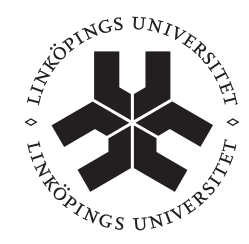

\section{Linköping University INSTITUTE OF TECHNOLOGY}

\author{
LIU-TEK-LIC-2013:60
}

Division of Fluid and Mechatronic Systems Department of Management and Engineering Linköping University, SE-581 83 Linköping, Sweden 
Copyright @ ( Alessandro Dell'Amico, 2013

Pressure Control in Hydraulic Power Steering Systems

ISBN 978-91-7519-476-9

ISSN 0280-7971

LIU-TEK-LIC-2013:60

Distributed by:

Division of Fluid and Mechatronic Systems

Department of Management and Engineering

Linköping University

SE-581 83 Linköping, Sweden

Printed in Sweden by LiU-Tryck, Linköping 2013. 
Per Barbara e Leonardo

No pain, no gain

Noin, no gain 



\section{Abstract}

There is a clear trend in the vehicle industry to implement more safetyrelated functions, where the focus is on active safety systems and today the steering system is also involved. Steering-related active safety functions can only be realised with a steering system that allows electronic control of either the road wheel angle or the torque required to steer the vehicle, called active steering. The high power requirement of heavy vehicles means they must rely on hydraulic power to assist the driver. The system is a pure hydro-mechanical system with an open-centre circuit activated by the driver's steering action and suffers from poor energy efficiency. The main task of the hydraulic system is to control the pressure in the assistance cylinder in such a way that it eases the load on the driver.

This work suggests a way to design and evaluate a self-regulating pressure control valve for use as actuator in the steering system. This valve can be made small and fast and is electronically controlled to enable active steering. It is based on a closed-centre circuit and has therefore the potential to improve energy efficiency. The aim of this work has been to investigate the possibility for the valve to perform as the original open-centre valve. The suggested approach is a model-based design and evaluation process where an optimisation routine is used to design the valve. Together with a validated model of the steering system, the new concept is compared with the original system. A hardware-inthe-loop simulation test rig has also been designed and built with the possibility to test a closed-centre steering system. It has partly been used to support the modelling process and partly to verify that a closedcentre steering system is a feasible solution. The simulation results have shown that the designed valve can perform sufficiently well compared to the original system. 


\section{Acknowledgements}

The work presented in this thesis has been carried out at the Division of Fluid and Mechatronic Systems (Flumes) at Linköping University, with Scania AB as industrial partner.

I want to thank my supervisor, Prof. Petter Krus, for his supervision and valuable conversations we had during this work. I also want to thank the former head of division, Prof. Jan-Ove Palmberg, for giving me the opportunity to be part of this division, and shearing his knowledge about pressure control. I also want to thank Dr. Jochen Pohl, for helping me in the initial part of the work and for shearing his experience of power steering systems. I am very grateful to all my colleagues at the division. Thank you for making this a great place to work. I also wish to thank Ulf Bengtsson and the workshop guys for their support with the test rig.

Finally, I want to thank my family for their support during this time. Barbara and Leonardo, you are the most important things in my life.

Linköping, November 2013

Alessandro Dell'Amico 


\title{
Abbreviations
}

\author{
ABS Anti-lock Brake System \\ EHPAS Electro Hydraulic Power Assisted Steering \\ EPAS Electric Power Assisted Steering \\ ESP Electronic Stability Program \\ HPAS Hydraulic Power Assisted Steering
}




\section{Nomenclature}

Bulkmodulus

Flow angle

Equivalent hydraulic damping

Mechanical damping

$\omega_{c}$

Resonance of control chamber

$[\mathrm{rad} / \mathrm{s}]$

$\omega_{h}$

Hydraulic breakfrequency

$[\mathrm{rad} / \mathrm{s}]$

$\omega_{m}$

Mechanical resonance

$[\mathrm{rad} / \mathrm{s}]$

$\omega_{s}$

System volume resonance

$[\mathrm{rad} / \mathrm{s}]$

$\omega_{v}$

Valve breakfrequency

$[\mathrm{rad} / \mathrm{s}]$

$\rho$

Density

$\left[\mathrm{kg} / \mathrm{m}^{3}\right]$

Step time

Steering wheel angle

Area opening

Area opening

Control pressure area

Piston area 
$b_{v} \quad$ Damping coefficient of valve spool

$b_{r w} \quad$ Equivalent damping of the rack

$b_{s w} \quad$ Equivalent damping of steering wheel and column

$C_{q} \quad$ Flow coefficient

$C_{s} \quad$ Capacitance of volume $\left[\mathrm{m}^{3} / \mathrm{Pa}\right]$

$C_{r w}$

Equivalent spring stiffness of the rack

$[\mathrm{N} / \mathrm{m}]$

$d_{a}$

Diameter of opening area of valve

[m]

$d_{c}$

Diameter of pressure area

[m]

Control signal

$e_{1 . . n} \quad$ Weight functions

F $\quad$ Force

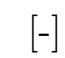

$f \quad$ Frequency

$f_{0} \quad$ Spring preload

$f_{s} \quad$ Flow forces

$f_{1 . . n} \quad$ Optimisation objectives

$G_{c} \quad$ Closed loop transfer function

$G_{o} \quad$ Loop gain transfer function

$J_{s w} \quad$ Inertia of steering wheel and column

$K_{1} \quad$ Pressure-flow coefficient of damping orifice $\left[\mathrm{m}^{3} / \mathrm{sPa}\right]$

$K_{c} \quad$ Flow-pressure coefficient $\left[\mathrm{m}^{3} / \mathrm{sPa}\right]$

$K_{e} \quad$ Equivalent spring stiffness

$K_{h} \quad$ Equivalent hydraulic spring stiffness

$K_{s} \quad$ Closed loop gain

$K_{T} \quad$ Spring stiffness of torsion bar and column 
$\begin{array}{lll}k_{1 . . n} \quad \text { Normalising factors } & {[-]}\end{array}$

$K_{C_{O C}} \quad$ Flow-pressure coefficient of open-centre valve $\quad\left[\mathrm{m}^{2} / \mathrm{s}\right]$

$K_{p 0} \quad$ Control gain

$K_{q_{O C}} \quad$ Flow gain of open-centre valve $\left[\mathrm{m}^{2} / \mathrm{s}\right]$

$m_{v} \quad$ Mass of spool $\quad[\mathrm{Kg}]$

$\begin{array}{lll}M_{r w} & \text { Total mass of rack }\end{array}$

$\begin{array}{lll}p_{c} & \text { Control chamber pressure } & {[\mathrm{Pa}]}\end{array}$

$\begin{array}{lll}P_{L} & \text { Load pressure } & {[\mathrm{Pa}]}\end{array}$

$\begin{array}{lll}p_{s} & \text { System pressure } & {[\mathrm{Pa}]}\end{array}$

$\operatorname{pen}_{1 . . n} \quad$ Penalty functions [-]

$q_{c} \quad$ Flow into control chamber $\quad\left[\mathrm{m}^{3} / \mathrm{s}\right]$

$q_{l} \quad$ Load flow $\quad\left[\mathrm{m}^{3} / \mathrm{s}\right]$

$q_{p} \quad$ Pump flow $\quad\left[\mathrm{m}^{3} / \mathrm{s}\right]$

$q_{s} \quad$ System flow $\quad\left[\mathrm{m}^{3} / \mathrm{s}\right]$

qus $\quad$ Flow from supply side $\left[\mathrm{m}^{3} / \mathrm{s}\right]$

$q_{v t} \quad$ Flow to tank $\quad\left[\mathrm{m}^{3} / \mathrm{s}\right]$

$\begin{array}{lll}R_{T} & \text { Steering system gear ratio } & {[\mathrm{rad} / \mathrm{m}]}\end{array}$

$R_{v} \quad$ Static characteristic of the valve $\quad\left[\mathrm{Ns} / \mathrm{m}^{5}\right]$

$T_{d} \quad$ Driver's torque $\quad[\mathrm{Nm}]$

$\begin{array}{lll}T_{s w} & \text { Steering wheel torque } & \end{array}$

$V_{c} \quad$ Control chamber volume $\quad\left[\mathrm{m}^{3}\right]$

$V_{p} \quad$ Chamber volume of cylinder $\quad\left[\mathrm{m}^{3}\right]$

$V_{s} \quad$ System volume $\left[\mathrm{m}^{3}\right]$

$w \quad$ Area gradient [m]

$\begin{array}{lll}x_{p} & \text { Piston position } & \text { [m] }\end{array}$

$\begin{array}{lll}x_{v} & \text { Spool position } & {[\mathrm{m}]}\end{array}$ 


\section{Papers}

The work in this thesis is presented as a monograph. Parts of the work are based on the following publications.

[I] Alessandro Dell'Amico, Jochen Pohl, and Petter Krus. "Conceptual evaluation of closed-centre steering gears in road vehicles". In: The 7th FPNI PhD Symposium on Fluid Power. 2012.

[II] Alessandro Dell'Amico and Petter Krus. "A Test rig for Hydrauilc Power Steering Concept Evaluation using Hardware-in-the-loop Simulation". In: The 8th International Conference on Fluid Power Transmission and Control (ICFP13). Hangzhou, China, 2013.

[III] Alessandro Dell'Amico, Jochen Pohl, and Petter Krus. "Modeling and Simulation for Requirement Generation of Heavy Vehicles Steering Gears". In: Fluid Power and Motion Control (FPMC 2010). Bath, UK, 2010.

[IV] Alessandro Dell'Amico, Magnus Sethson, and Jan-Ove Palmberg. "Modeling, Simulation and Experimental Verification of a Solenoid Pressure Control Valve". In: The 11th Scandinavian Conference on Fluid Power (SICFP09). Linköping, Sweden, 2009. 


\section{Contents}

1 Introduction 1

1.1 Future demands . . . . . . . . . . . . . . . . . 2

1.2 Formulating the research question $\ldots \ldots \ldots \ldots$

1.3 Limitations . . . . . . . . . . . . . . . . 4

1.4 Contributions . . . . . . . . . . . . . . 4

1.5 Outline ..................... 5

2 The steering system $\quad 7$

2.1 Hydraulic power assisted steering . . . . . . . . . . 8

3 Test rig 13

3.1 Hardware description . . . . . . . . . . . . . . . . 14

3.2 Test rig measurements . . . . . . . . . . . . . . 16

4 Modelling of the steering system 23

4.1 Mechanical modelling . . . . . . . . . . . . . . . 24

4.2 Hydraulic modelling . . . . . . . . . . . . . . . 26

4.3 Linear modelling . . . . . . . . . . . . . . . . . . 28

4.4 Simulation . . . . . . . . . . . . . . . . . 32

4.5 Validation of steering system model . . . . . . . . . 33

5 Pressure control $\quad 37$

5.1 Mathematical modelling of the pressure control valve . . . 38

5.1 .1 Static characteristic . . . . . . . . . . . 39

5.1.2 Linearisation of the pressure control valve . . . . . 40

6 Closed-centre power steering system $\quad 45$

6.1 Valve design by optimisation . . . . . . . . . . . . 47

6.1.1 Characteristics of the valve design . . . . . . 5 50 
6.2 Controller design . . . . . . . . . . . . . . . . 52

6.3 Closed-centre system evaluation . . . . . . . . . . . . 54

7 Hardware-in-the-loop simulation $\quad 59$

7.1 Force control . . . . . . . . . . . . . . 60

7.2 Pressure control with servo valves . . . . . . . . . . 61

$\begin{array}{lll}8 & \text { Results } & \mathbf{7 1}\end{array}$

8.1 Results from controller design . . . . . . . . . . . . . 71

8.2 Results from closed-centre steering system simulation . . . 72

8.3 Results from closed-centre steering in the test rig . . . . . 76

8.3 .1 Step response . . . . . . . . . . . 76

8.3 .2 On-centre driving . . . . . . . . . . . . . 77

$\begin{array}{lll}9 & \text { Discussion } & 79\end{array}$

10 Conclusions $\quad 83$

$\begin{array}{ll}11 \text { Outlook } & 85\end{array}$

$\begin{array}{ll}\text { Bibliography } & 87\end{array}$ 


\section{1}

Introduction

The demand for higher safety on our roads is constantly increasing and the trend within the vehicle industry is going in the same direction with more advanced systems being introduced to the market. Safety systems can be divided into passive and active safety systems. A typical passive safety system is the seat belt. Active safety systems refers to systems that provide assistance to the driver in more or less critical situations in order to avoid accidents. Typical active safety systems include the Anti-lock Brake System (ABS), Electronic Stability Program (ESP), and traction control. These systems use the brakes or engine control to increase safety by stabilising the vehicle when necessary. To further meet the demand for more safety, the latest trend within the vehicle industry is to also incorporate the steering system. Examples of functions that use the steering system are lane keeping assist, emergency lane assist [1], collision avoidance [2], [3], [4], roll-over prevention [5], yaw disturbance attenuation to stabilise the vehicle [6], and jackknife avoidance [7] (trucks with semitrailers). To enable this functionality, the steering system, or the steering gear, must allow for a modification of the steering wheel torque to turn the wheels or the road wheel angle by means of an external signal. This is here referred to as active steering. Another aspect within the industry is to also look at comfort functions that in some way could improve the steering feel ${ }^{1}$ or reduce the work load of the driver, e.g. by variable steering ratio [8], [9]. In a much wider perspective, active steering is a step towards automatic driving where the engine, brakes,

\footnotetext{
${ }^{1}$ The term steering feel summarises a number of characteristics such as on-centre torque built up, steering wheel return ability as well as torque levels during off centre handling and low speed manoeuvring/shunting.
} 
and steering system are all controlled by computer, [10], [11].

A traditional power-assisted steering system uses hydraulic power to assist the driver, referred to as Hydraulic Power Assisted Steering (HPAS). This system is a pure hydro-mechanical system and lacks the possibility to be activated other than by driver input. Compromised by an open-centre circuit and a constant flow pump, one of the major drawbacks with this system concerns energy efficiency [12]. Within the passenger car industry, Electric Power Assisted Steering (EPAS) has been implemented in recent years, which inherently gives the possibility to control the torque to turn the wheels by means of an external signal, though the main objective has been to decrease energy consumption. Here the hydraulic system is replaced with an electric motor that helps the driver turn the wheels. For heavy vehicles, such as trucks and to some extent premium cars, pure EPAS is not available today, mainly due to high power requirements during low speed manoeuvring. Hydraulic power is still needed. The steering gear or hydraulic system needs to be modified in order to open up the possibility to implement active safety functions. Several different solutions exist already that address both the problem of reducing the energy consumption and increasing the functionality of the steering system. Different solutions of the supply system was investigated in [13], and the so called Electro Hydraulic Power Assisted Steering (EHPAS) was investigated in [14], [15], [16], [17]. The EHPAS refer to systems where the supply pump is driven by an electric motor instead of the engine. A closed-centre power steering system for both increased functionality and reduced power consumption was investigated in [18], [19], [20], [21]. A hybrid steering system for commercial vehicles which uses both electric and hydraulic power to assist the driver was investigated in [22]. Solutions to increase functionality by overlaying the torque or steering angle were presented in [23] and [24].

\subsection{Future demands}

An attempt to phrase the requirements for future commercial vehicles might result in the list below, (compare to [25] for passenger cars):

1. Possibility to realise steering-related active safety and comfort functions.

2. Enabling the possibility to design the change of steering feel with load and predictable steering feel for a broad range of vehicle con- 
figurations.

3. Increased directional stability.

4. Significant reduction in fuel consumption compared to present hydraulic power-steering systems.

5. Sufficient power capacity for all vehicle classes.

6. Providing means for safe operation during failure modes of the system and fulfilling legal requirements for steering wheel torques for a wide range of vehicle configurations.

7. Reduced system costs, improved packaging capabilities, including potential weight savings, and improved NVH (Noise, vibration, and harshness) performance.

\subsection{Formulating the research question}

The aim of the work is to investigate how a steering gear can be modified in order to open up the possibility to implement active steering functions. The focus is on the actuator controlling the assistance pressure. The design of the actuator must reflect the future demands concerning steering systems in commercial vehicles. This means that the actuator must be electronically controlled, have the same performance as today's actuator, and reduce energy consumption. Research has shown that a closed-centre system has the greatest impact on energy consumption. Cost and packaging are also important aspects. A self-regulating pressure control valve is therefore the actuator chosen for the design. The research question can then be formulated as:

Can a self-regulating pressure control valve be used as an actuator in a closed-centre circuit for a power-assisted steering system with preserved performance compared to the open-centre actuator?

This includes studying the design of the valve and controller design. Another aim is to investigate whether a closed-centre power steering system can be evaluated in a test rig. A further research question can therefore be formulated as:

Can a proof of concept be stated through hardware-in-the-loop simulation of a closed-centre steering system? 


\subsection{Limitations}

This work has only focused on the actuator of the hydraulic power steering system, i.e. the element that controls the pressure in the assistance cylinder. The steering system itself and any models are only considered to be tools in the evaluation process of the actuator. The vehicle model used is arbitrary and is only used for a complete simulation environment and is not part of the research. Any aspects concerning steering feel or on-centre handling are not dealt with other than as valuable knowledge when understanding the application or system. No possible failure modes are considered, nor are legal requirements. It is, however, assumed that if the closed-centre actuator has similar performance and characteristics to the open-centre actuator, the steering feel should be the same. The valve is assumed to be actuated by a solenoid. This is not part of the work at this point, but it is rather assumed that a small solenoid is fast. For a better overview of the work and to better support the modelling and design process, the system studied is the designed test rig with dimensions for a passenger car. Although the functionality of the steering system is the same for a heavy vehicle, the requirements differ somewhat. However, the aim of the design process is to be functional on any vehicle configuration and this is the more important aspect of this work. All aspects of this work concerns the operating range related to on-centre driving, which indicates moderate steering action around centre position of the steering wheel, with an amplitude of not higher than $\pm 30^{\circ}$. This region is where the performance of the steering system is most evident for a driver.

\subsection{Contributions}

This work suggests a way to design and evaluate a self-regulating pressure control valve for use as an actuator in the steering system loop. The suggested approach is a model-based design and evaluation process where an optimisation routine is used to design the valve. A complete simulation model of the suggested design, together with a validated model of the steering system and a vehicle model, is used to compare the closed-centre system with the original system.

A hardware-in-the loop simulation test rig was also designed and built with the possibility to test a closed-centre steering system. It is partly used to support the modelling process and partly to verify that a closed- 
centre steering system is a feasible solution.

\subsection{Outline}

The outline of the thesis begins with describing the steering system in chapter 2, with intention to give the reader an overview of the application. Chapter 3 describes the test rig, that is developed for evaluation of steering system actuator concepts, but also to support the modelling of the steering system in chapter 4 . Chapter 5 deals with pressure control and the analysis of the intended valve in this work. The outcomes of chapters 4 and 5 are linked together in chapter 6 , where the closedcentre power steering system is analysed and evaluated. How the test rig is used for hardware-in-the-loop simulation is dealt with in chapter 7. Chapter 8 presents the most important results from chapter 6 and 7 . The thesis ends with discussion, conclusions and outlook in chapters 9 , 10 and 11. 


\section{The steering system}

The steering system has the purpose of giving the driver a tool to control the direction of motion of the vehicle. An interpretation of the driversteering system/vehicle by [12] is a closed loop system where the driver wants to control the direction of the vehicle. The reference input to the system is the direction of the vehicle and one feedback channel is the actual direction, which is a visual channel. The direction is changed by the driver through the steering system by controlling the steering wheel angle. The torque required by the driver is another feedback channel provided by the steering system. This channel gives important information about the road conditions. The steering system affects the direction of the vehicle, which in turn provides yet another feedback channel, namely the lateral acceleration, which is felt by the driver. Historically, as the front axle load increased, tyres grew larger and front wheel drive was introduced, power steering was introduced to meet demands for low steering wheel torque and comfort. Traditionally, this is done by hydraulic means, referred to as HPAS. In recent years, EPAS has also been introduced, where an electric motor assists the driver. However, for heavy vehicles and some premium cars HPAS is still in use due to the power requirement casued by high front axle loads. This work focuses only on HPAS.

There are two types of steering system arrangement: the rack-andpinion and the worm gear steering box. The rack-and-pinion system is mostly found in lighter vehicles and passenger cars while the worm gear steering box is found in heavy vehicles. The rack-and-pinion steering system is lighter, more compact, has higher efficiency and gives the driver a more accurate feeling of the tyre-ground interaction,[26] and [27]. The 
most common worm gear today is the recirculating ball screw, [28], that utilizes a closed helical channel inside the gear where balls rotate and move. In this way the friction is kept to a minimum. Regardless of the arrangement the principal function is the same. A schematic figure of the rack-and-pinion steering system is shown in Fig. 2.1.

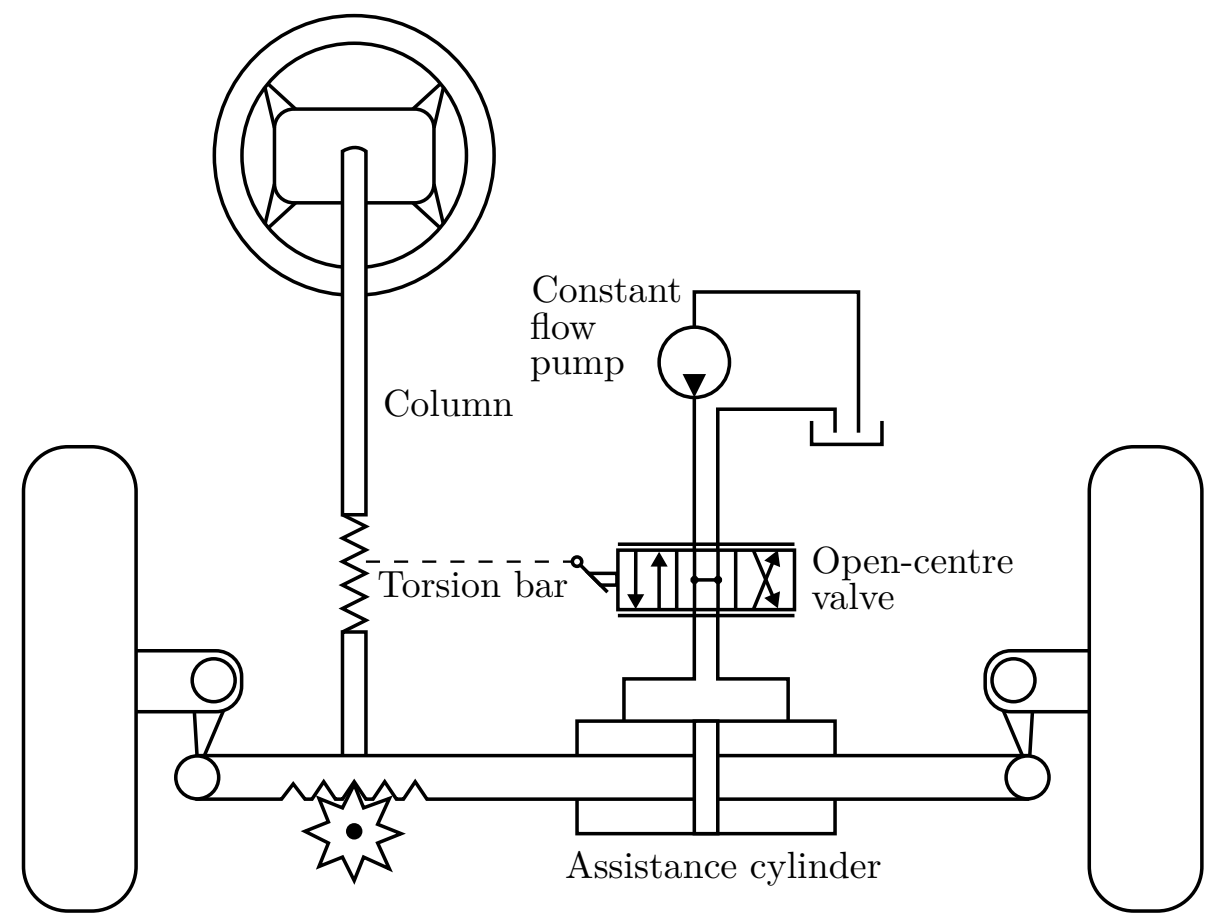

Figure 2.1 Schematic picture of a rack-and-pinion steering system.

\subsection{Hydraulic power assisted steering}

A detailed analysis of the HPAS can be found [12]. The hydraulic system is parallel to the mechanical system. There is a legal requirement that the vehicle is steerable in case of hydraulic loss, but the mechanical connection also ensures the haptic feedback from the tyre-road interaction to the driver. The main components of the hydraulic system are a constant flow pump and a rotational open-centre valve. The valve is actuated by a torsion bar attached to the spool at the upper end and to the pinion at the lower end, where the valve body is also attached. The valve consists of several parallel control edges, making up several 
parallel-connected Wheatstone bridges. These are preferably described as one lumped Wheatstone bridge. At centre position, the valve is fully open. The valve is activated by the twisting of the torsion bar, which occurs when the driver applies a torque to the steering wheel. When twisted, the control edges close on one side, thus increasing the pressure on that side, and open on the other side. The purpose of the hydraulic system is thus to control the differential pressure in the assistance cylinder. The steering system itself is actually a position servo where the twist of the torsion bar corresponds to the control error. A perfect position controller would therefore not provide any feedback to the driver. A schematic of the hydraulic system is shown in Fig. 2.2. The pump is usually driven by the engine and the flow control function is only effective above a certain rotational speed. Due to the open-centre characteristic the pressure build up characteristic is dependent on the pump flow. The pump flow is therefore dimensioned for a very low rotational engine speed in order to ensure assistance even at low velocities, such as during parking manoeuvres. This means that at high velocities, when the need for assistance is usually low, the pump flow is very high and excessive flow is surplussed to tank. This is of course a waste of energy and one of the main reasons for the low energy efficiency of the traditional HPAS.

The steering system is usually characterized as the assistance pressure vs. the torsion bar torque. This is called the boost curve and a typical boost curve is shown in Fig. 2.3. The shape of the curve depends on the geometry of the valve and the pump flow. Different driving scenarios can be identified from the boost curve. During parking manoeuvres, a high level of assistance is needed while during high speed manoeuvres a little assistance is needed. The compromise with the boost curve is that a high level of assistance also means less feedback to the driver, where road disturbances are suppressed. This is usually not a problem during parking, while at high speed the driver wants more information from the road, which is achieved with low assistance. 


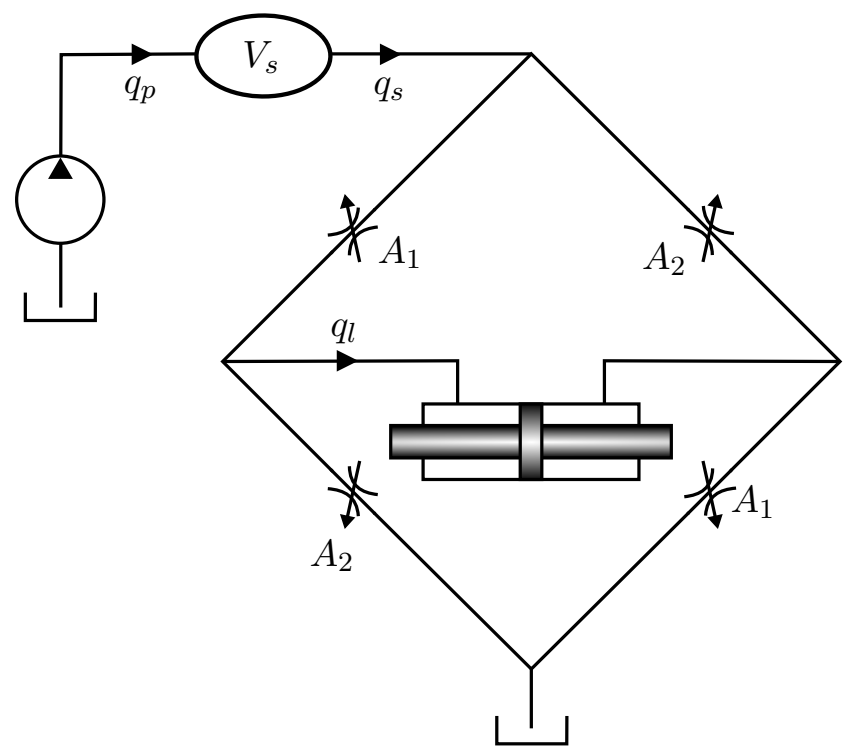

Figure 2.2 A schematic of the hydraulic system. The valve is seen as a lumped Wheatstone bridge.

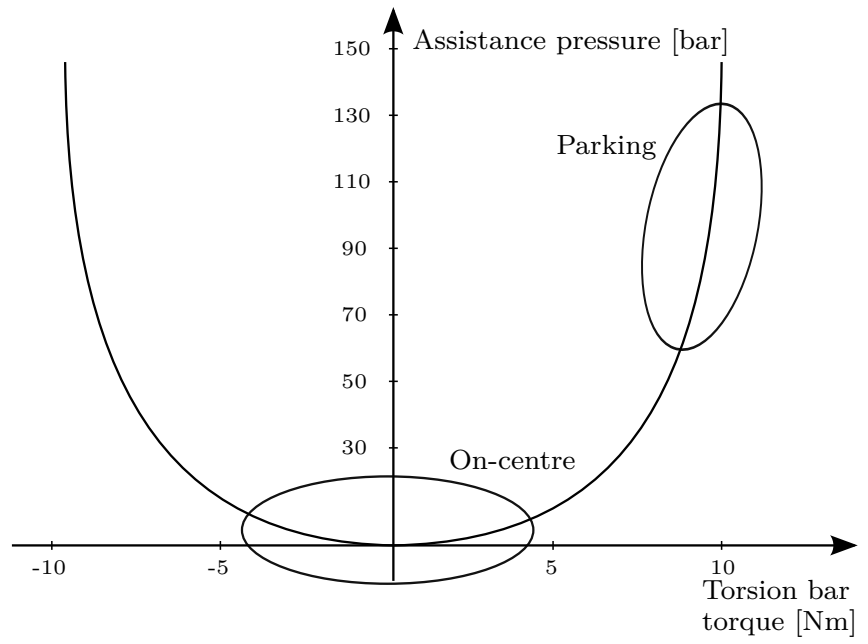

Figure 2.3 A typical boost curve. Values represent a heavy vehicle.

Phenomenona such as hydraulic lag and chattering were studied by [12]. Hydraulic lag has both a static and a dynamic part. The static lag is when the pump flow is not sufficient, i.e. the assistance cylinder's piston moves faster than the delivered flow, causing the assistance pressure to 
drop. Chattering is an instability problem. Since the steering system is a position servo, it constitutes a closed loop, which can become unstable if the loop gain is too high. The loop gain is defined by the boost curve, which can generate too high gain due to geometric tolerances. Another cause of too high gain is when the piston moves towards the direction of the assistance pressure. When moving in the same direction the pressure decreases, but when moving towards the direction of the assistance, the pressure increases and a higher gain is produced. 


\section{3 \\ Test rig}

The test rig used in this work has been developed for several reasons. First of all, the test rig is used to support the development of a simulation model of the steering system. With a test rig available it is much easier to measure all necessary states and perform tests, which would be difficult to do when installed in a vehicle. The test rig also provides a clear boundary of the system studied. The other purpose of the test rig is to evaluate different closed-centre actuators with hardware-in-the-loop simulation, described in chapter 7 . The present chapter describes the hardware of the test rig and the measurements performed for system modelling. A layout of the test rig and the interaction between the hardware and the software is shown in Fig. 3.1. The rack-and-pinion with steering wheel and column constitutes the hardware. A vehicle model is implemented in the software. To evaluate actuator concepts, a model of the concept studied is also implemented in the software. 


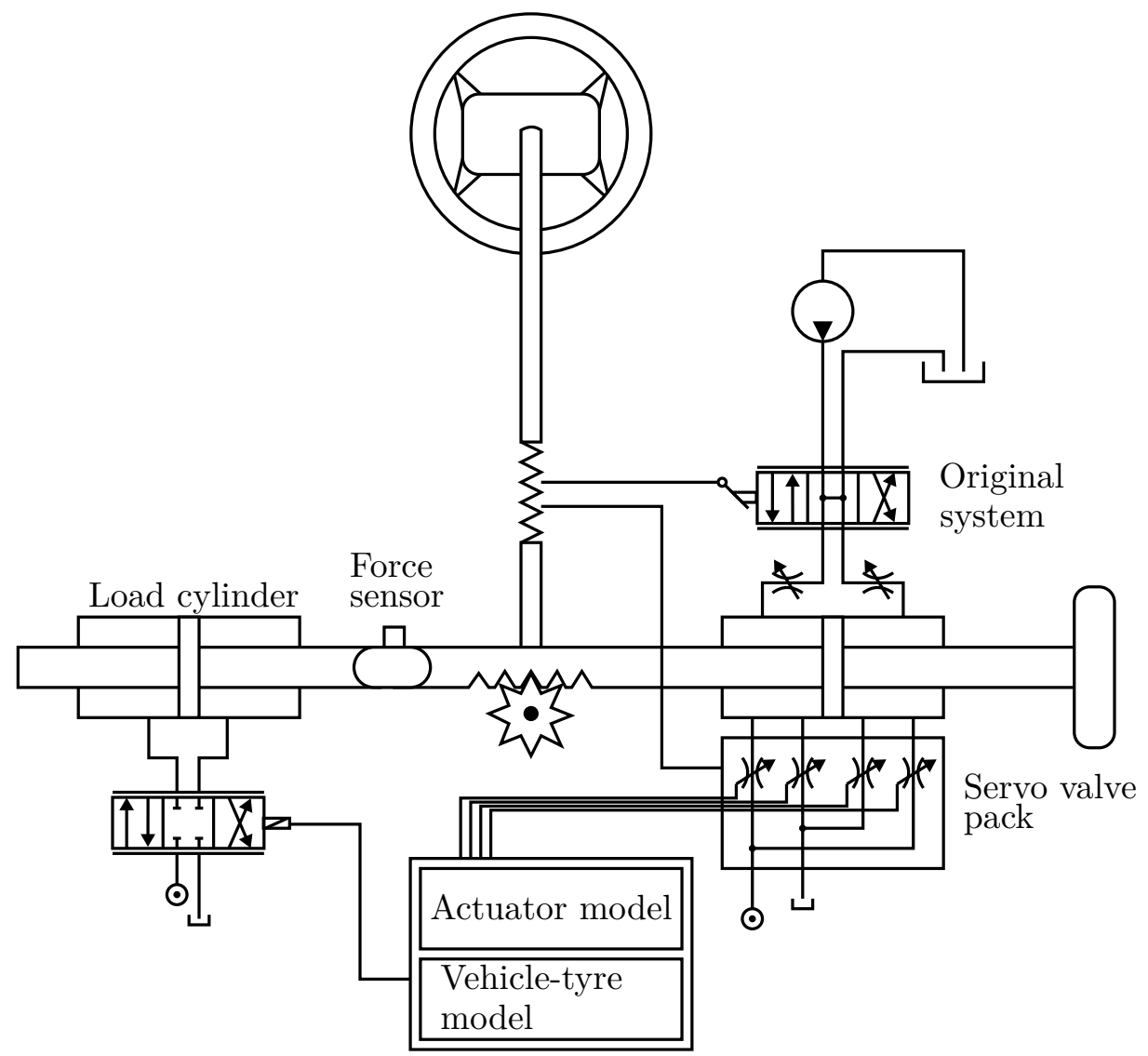

Figure 3.1 A schematic of the test rig. A model of the actuator under study, as well as a vehicle model, are implemented in the software.

\subsection{Hardware description}

The test rig is built up around a rack-and-pinion steering system. A fixed displacement pump is driven by an electric motor. Sensors are used to measure the pump pressure as well as the chamber pressures. To measure the torque applied by the driver, strain gauges are attached directly to the torsion bar. This means that the actual torsion bar torque is measured instead of the steering wheel torque and an additional torsion bar is not needed. Since the torsion bar torque is linear to the twist of the torsion bar, hence the twist of the open-centre valve, the measurement of the torque gives a direct measure of the valve actuation. The steering wheel angle and rack position are measured with potentiome- 
ters. A weight of $20 \mathrm{~kg}$ is attached to one end of the rack to give the system the right inertia. At the other end of the rack, a load cylinder is attached to generate the load experienced by the steering system due to the tyre-ground interaction. Between the load cylinder and the rack, a force sensor measures the force applied by the load cylinder and is used in a closed loop controller. Parallel to the original system, four high performance servo valves from Moog (bandwidth is approx. $250 \mathrm{~Hz}$ at $10 \%$ stroke) control the meter-in and meter-out flow to each chamber of the assistance cylinder. These valves are over-dimensioned for the application, but the result is that they work with very small movements, which should be beneficial from a performance point of view. A Moog servo valve is also used with the load cylinder. All servo valves use an external supply system of 200 bar. Argus valves are used to switch between the original system and the servo valve system. The reason for keeping the original system is to always have the reference system available for a qualitative comparison between the open-centre and closed-centre systems. The test rig is shown in Fig. 3.2 and a closer view of the servo valve pack is shown in Fig. 3.3.

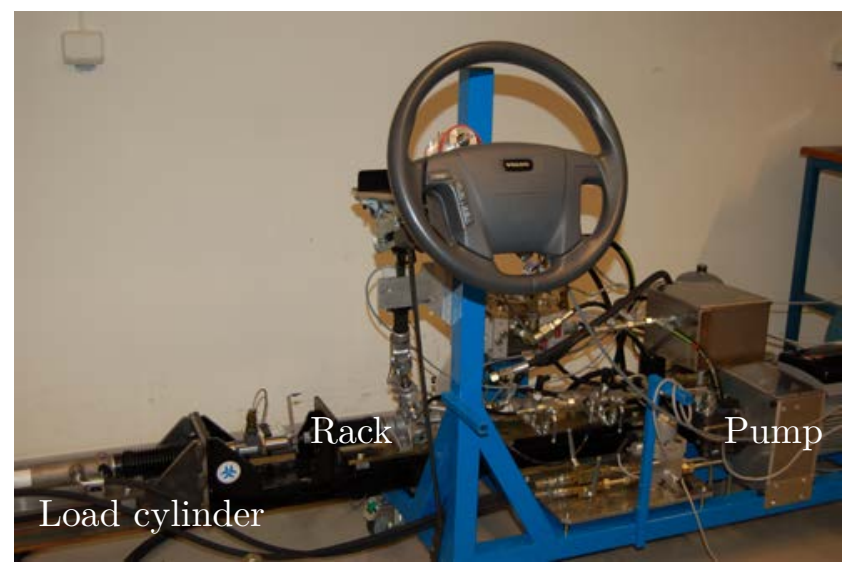

Figure 3.2 The test rig constituted of a rack-and-pinion steering system. 


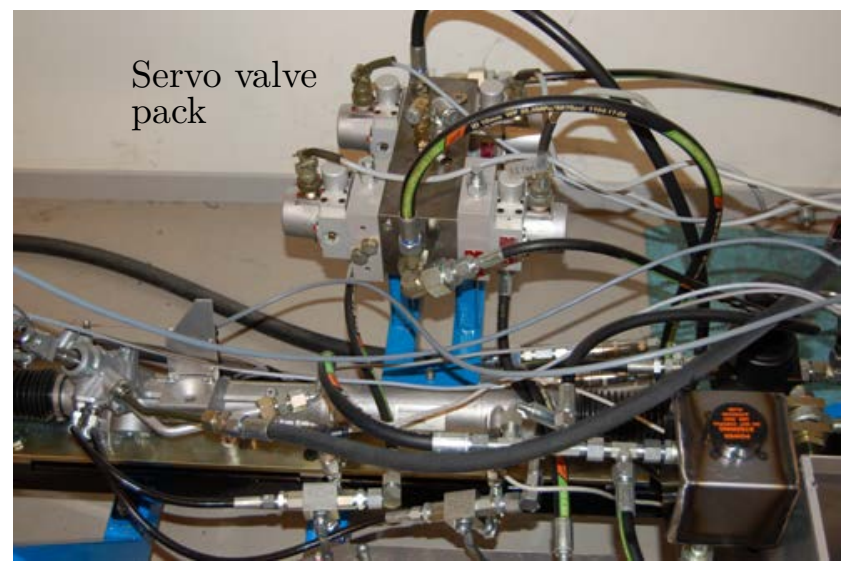

Figure 3.3 Four servo valves from Moog control the meter-in and meter-out flow of each chamber of the assistance cylinder.

\subsection{Test rig measurements}

Several tests have been conducted to derive parameters for the model. Subparts of the steering system were tested separately. Each test is further explained in the following subsections.

\section{Boost curve}

The boost curve is measured by clamping the rack. A steering wheel torque is applied slowly in both directions. Pump and cylinder pressures are recorded together with the torsion bar torque. The measured boost curve is shown in Fig. 3.4.

From the boost curve the opening areas of the valve can be calculated using equations 4.7 and 4.8, shown in Fig. 3.5. 


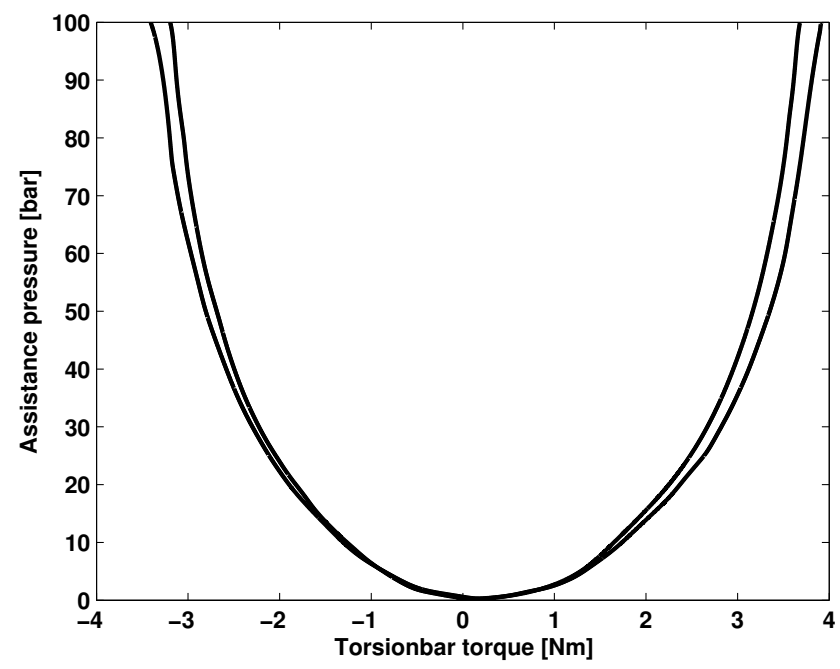

Figure 3.4 The measured boost curve of the test rig shows differential cylinder pressure vs. torsion bar torque.

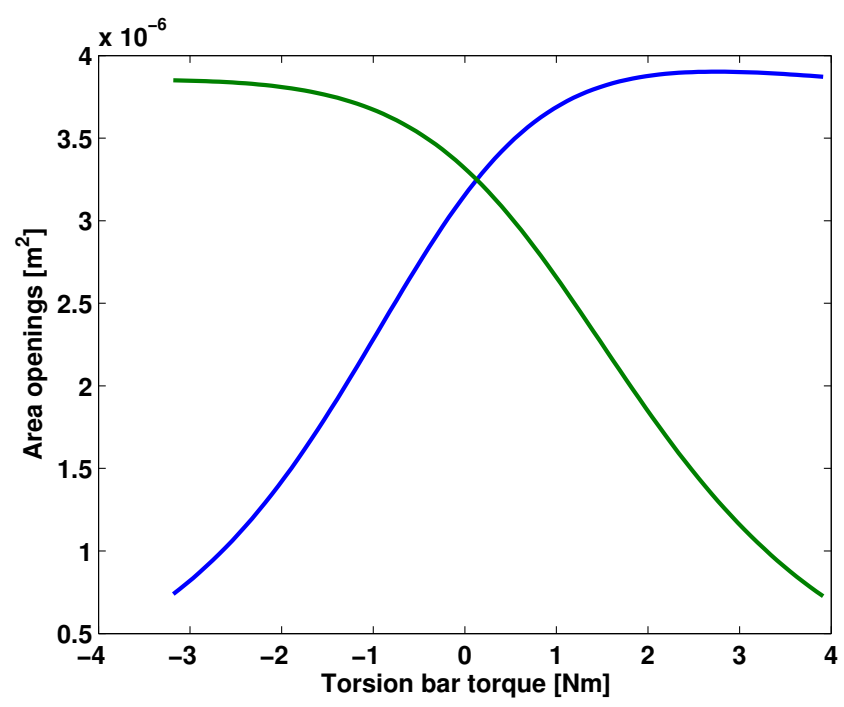

Figure 3.5 The calculated opening areas of the open-centre valve.

\section{Rack friction}

This test measures the pressure-dependent friction of the rack. According to [29], it is the pressure-dependent friction that is the most dominant 
friction. The column is disconnected from the input shaft of the valve. The load cylinder is run as a position controller with a sinusoidal input with an amplitude of $0.004 \mathrm{~m}$ and $0.5 \mathrm{rad} / \mathrm{s}$. Both the force required to drive the rack and the rack position are registered. The servo valves are controlled to maintain a constant pressure in both chambers. Each measurement is made for $5,10,20,40,60$ and 80 bar in each chamber. The results of the measurements can be seen in Fig. 3.6 and the increased amplitude of the hysteresis curve with increased pressure is clearly visible. A linear relation between the friction and the sum of the cylinder pressures is then assumed in the model.

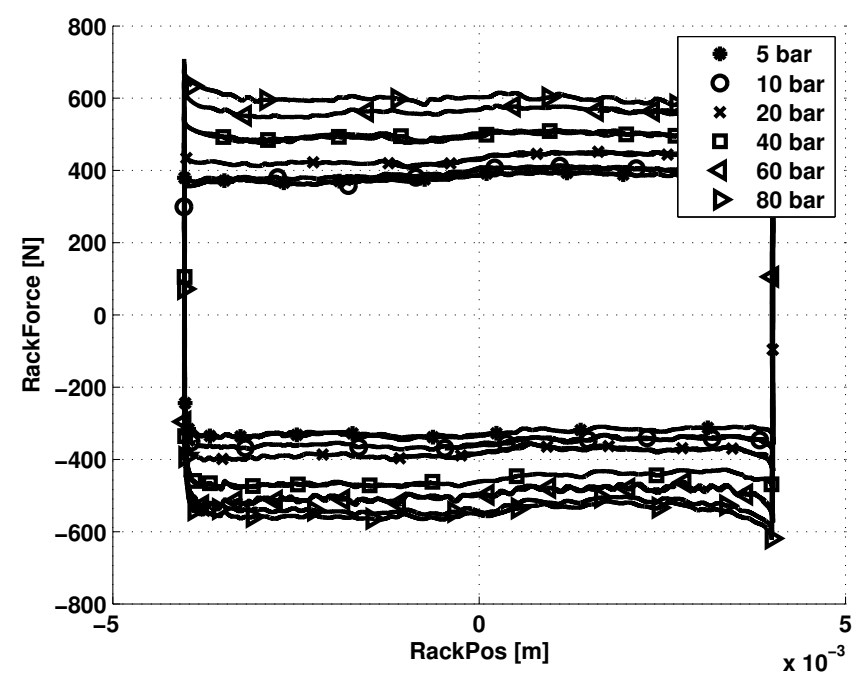

Figure 3.6 The figure shows the rack force vs. the rack position for different chamber pressures.

\section{Column friction}

The column friction is measured by again using the load cylinder as a position servo with a sinusoidal input with an amplitude of $0.004 \mathrm{~m}$ and $0.5 \mathrm{rad} / \mathrm{s}$. The steering column is attached to the valve and the steering wheel is free. The torsion bar torque then gives an indication of the friction in the upper inertia. The chamber pressures are held at 10 bar. It turned out that at zero pressure the result is very oscillative, probably due to the friction in the rack. Figure 3.7 shows the torsion bar torque 
vs. the steering wheel angle. The result is still quite oscillative but the amplitude of the hysteresis curve is still clear around $0.3 \mathrm{Nm}$.

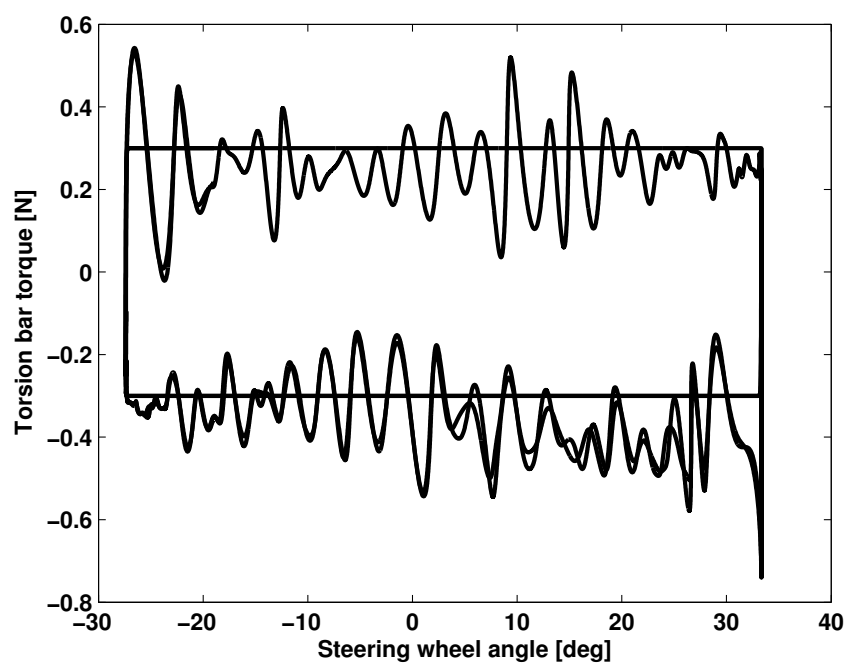

Figure 3.7 The figure shows the torsion bar torque vs. the steering wheel angle with a freely rotating steering wheel.

\section{Column and torsion bar stiffness}

The column stiffness is determined by measuring the torsion bar torque and steering wheel angle with the rack clamped. This gives the total stiffness of the upper inertia, i.e. the torsion bar and steering wheel column. The result is shown in Fig. 3.8. The inclination of the curve gives the stiffness and is set to $1.06 \mathrm{Nm} / \mathrm{deg}$. 


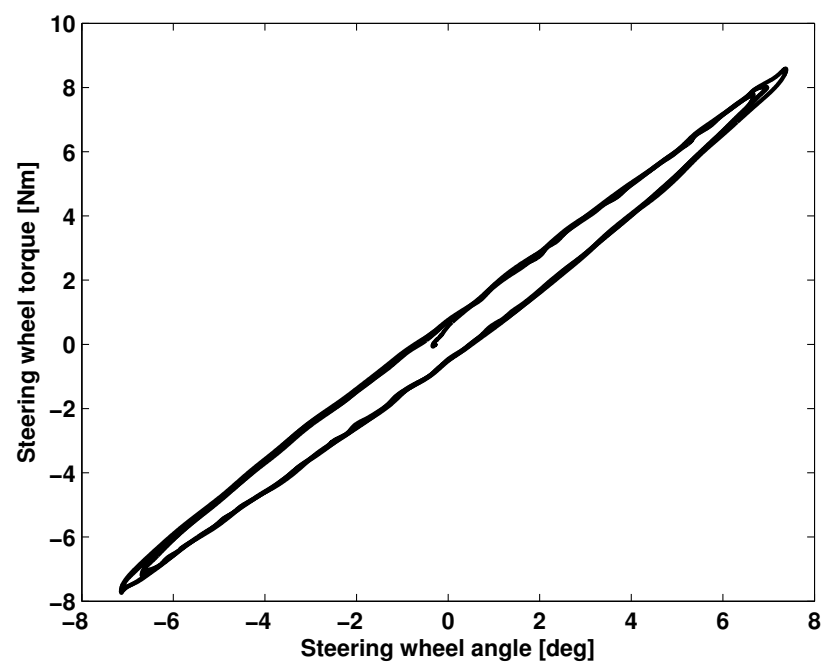

Figure 3.8 The figure shows the torsion bar torque vs. the steering wheel angle with the rack clamped.

\section{Steering wheel and column inertia}

The inertia of the upper system, i.e. the steering wheel and column, is measured by clamping the rack and applying a torque at the steering wheel. When the torque is suddenly released, the steering wheel will excite free oscillations according to:

$$
f=\sqrt{\frac{K_{T}}{J_{s w}}}
$$

The result is shown in Fig. 3.9. The frequency is $5.15 \mathrm{~Hz}$. Since the stiffness $K_{T}$ is known, the inertia can be calculated to $0.058 \mathrm{kgm}^{2}$. The damping coefficient is tuned to get a sufficient result from simulations of the same test case compared to the measurements. A damping of 0.06 was achieved in this way. What should be mentioned is that the damping is nonlinear, especially for higher steering wheel velocities, but is assumed to be linear within the operating range of this work. The same applies for the damping of the rack. 


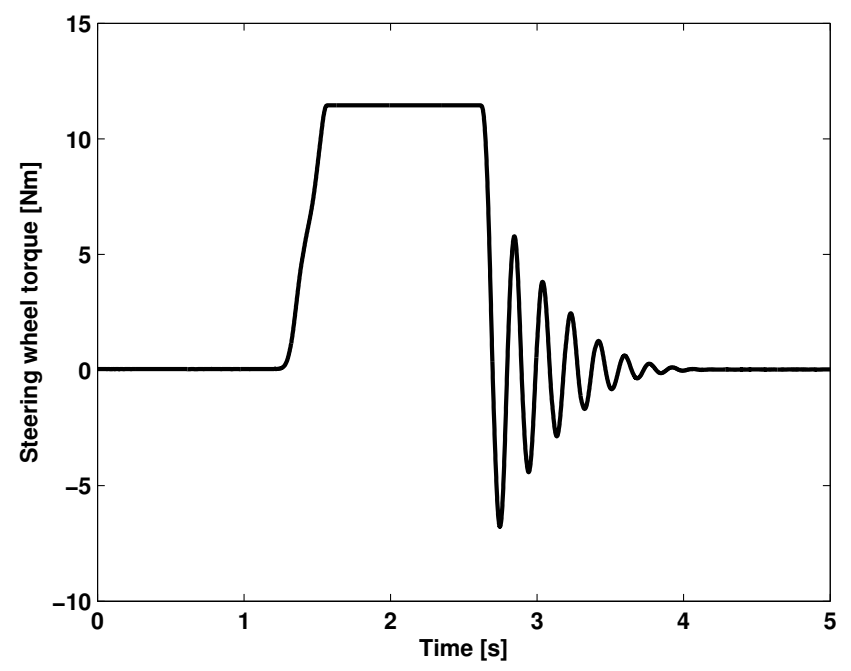

Figure 3.9 The figure shows the free oscillations of the steering wheel.

\section{System test}

The whole system is tested by manually applying a steering wheel angle with increased velocity. The vehicle model is used and set to run at 70 $\mathrm{kph}$. The steering wheel angle is limited to $\pm 30^{\circ}$ since only on-centre driving is studied. Figure 3.10 shows the measured steering wheel angle and Fig 3.11 shows the torsion bar torque. A steering wheel angle velocity of $400^{\circ} / \mathrm{s}$ was reached and a pump pressure of $\sim 40$ bar. The oil temperature is maintained between 40 and $45^{\circ} \mathrm{C}$. These measurements are later used in section 4.5 to validate the model by comparing simulated and measured results. 


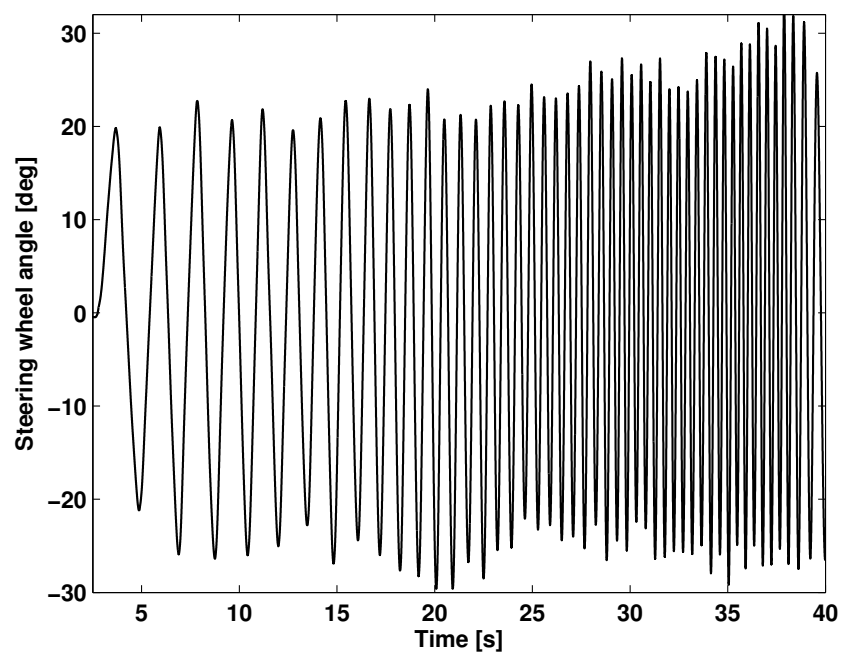

Figure 3.10 Measured steering wheel angle of the complete system.

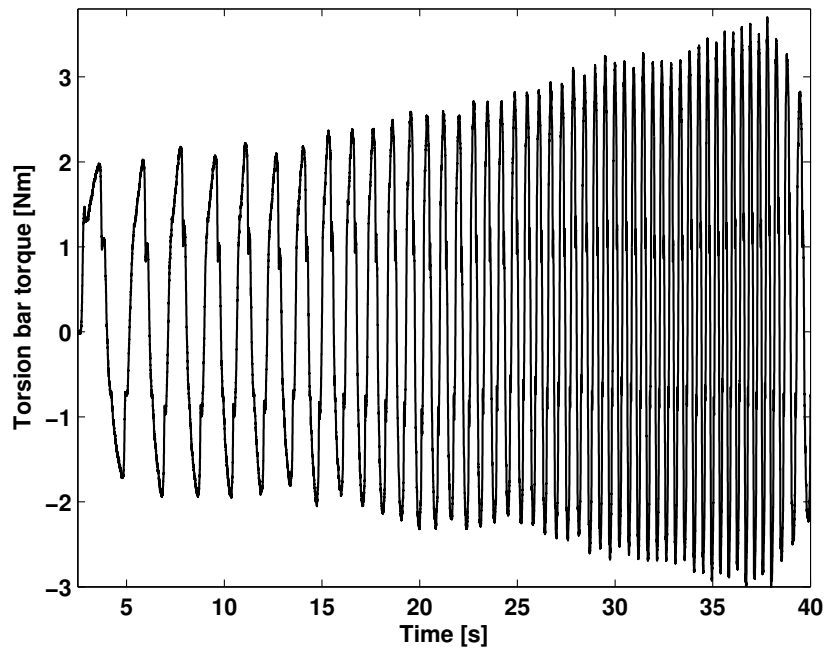

Figure 3.11 Measured torsion bar torque of the complete system. 


\section{4 \\ Modelling of the steering system}

This chapter describes the modelling of the steering system as it has been used in this work. A model can be useful in many ways but the main purpose here is to provide means to evaluate different actuator concepts. First, the system of equations is stated. These are used to derive a linear model of the steering system. The linear model gives a lot of information about parameters affecting system properties and helps understanding of the system. The nonlinear model is then used in a simulation environment. This model covers aspects not seen from a linear analysis and a complete driving cycle can be studied. For a consistent way of working and to be able to quantitatively compare concepts and the original system, the derived model represents the steering system used in the test rig. As described in chapter 3, measurements were conducted to find model parameters. The model is divided into different submodels, as can be seen in Fig. 4.1. The driver communicates with the mechanical submodel by applying a torque in order to follow a certain steering wheel angle. The mechanical submodel communicates in turn with the hydraulic and vehicle submodels. The hydraulic submodel takes the torsion bar twist and piston velocity as inputs and generates the cylinder pressures fed to the mechanical submodel. The vehicle submodel takes the road wheel angle as input and calculates the corresponding forces from the tyre-ground interaction. 


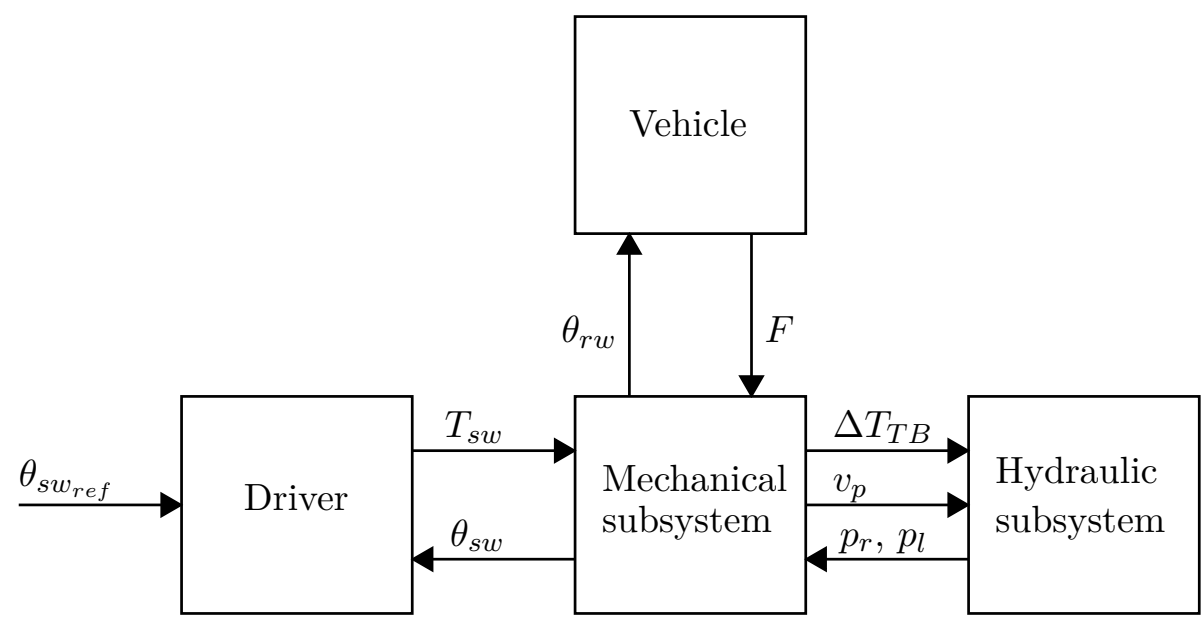

Figure 4.1 The structure of the simulation model showing the interaction between the different submodels.

\subsection{Mechanical modelling}

The mechanical subsystem can be modelled as a 2 DoF system or even up to a 5 DoF system where every inertia in the system is considered. Pfeffer [29], [30] derives a 5 DoF model with the purpose of studying the steering wheel torque. However, he also derives a 2 DoF model for the same purpose and also shows that the two models perform in a similar fashion. A 2 DoF model is also used to study the power consumption of an HPAS system, [15]. Baxter [31] also uses a simple model and ignores friction to derive expressions for steering gear feel and stiffness. Post [32] measures the friction and stiffnesses of a rack and pinion steering gear and a recirculating ball screw steering gear, and models the systems with both a high degree of freedom model and a 2 DoF model implemented with a vehicle model. He showed the importance of including nonlinear effects, such as friction, stiffness and boost curve, in order to predict the behaviour of the system. Neureder [33] studied steering wheel nibble (vibrations in the steering wheel) and derived a simple model of the steering system. Rösth [12] derived both a 2 DoF model of a passenger car steering system and a 3 DoF model of a truck steering system, both models with pressure- and speed-dependent friction. Linear models were derived to study chattering [34], and a nonlinear model to study catchup [35]. The same approach to model the mechanical subsystem is also used for EPAS systems, as shown by Badawy et al. [36], where they 
modelled a column-assisted EPAS and compared a higher and lower degree model to show similar results. Ueda et al. [37] investigated how changes in friction in different parts of the steering system affect the system characteristics. They used a 4 DoF model for this. In the early paper by Segel [38], the author derives a simplified model in order to predict the behaviour of the vehicle. The steering system is modelled with 2 DoF with Coulomb friction together with a 3 DoF linear vehicle model. The operating range where the steering system is studied in this work is similar to as e.g. [29], and it should therefore be sufficient to use a 2 DoF model for the purpose of evaluating different actuator concepts.

In order to predict the behaviour of the steering system, it is important to incorporate a friction model. The rack friction is strongly pressure-dependent, but friction also comes from the yoke, mesh, steering valve sealings and steering column. One way would be to implement a Coulomb friction. As long ago as 1966, Segel [38] stressed the importance of including friction and found that without a certain amount of Coulomb friction in the steering system, the vehicle would be unstable (for studies of a pure mechanical steering system). However, investigations by Neureder [33] suggest that the friction in the steering system behaves differently than a Coulomb friction. He found that cars exhibit nibble even at low-level forces, which contradicts the behaviour of Coulomb friction. Ueda et al. [37] also investigated friction and suggested a spring/friction model to best describe its behaviour. This means that the friction force behaves like a spring until a certain level where the force remains constant. Pfeffer [29] used the same approach and further developed the model. The equations of motion describing the steering system are expressed as:

$$
\begin{aligned}
& J_{s w} \ddot{\theta}_{s w}=T_{d}-K_{T}\left(\theta_{s w}-x_{r w} R_{T}\right)-b_{s w} \dot{\theta}_{s w} \\
& M_{r w} \ddot{x}_{r w}=P_{L} A_{p}+K_{T}\left(\theta_{s w}-x_{r w} R_{T}\right) R_{t}-b_{r w} \dot{x}_{r w}-C_{r w}
\end{aligned}
$$

$\theta_{s w}$ represents the steering wheel angle and $x_{r w}$ represents the position of the rack. The friction is modelled as an exponential spring with limited force and hysteresis, according to [29]. Figure 4.2 shows a representation of the friction model. 


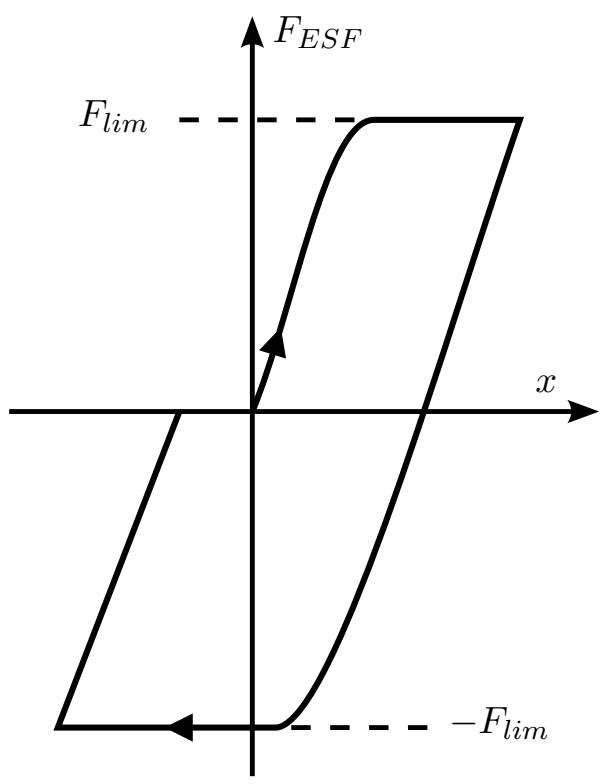

Figure 4.2 The representation of the friction model according to [29].

\subsection{Hydraulic modelling}

The hydraulic subsystem is based on the Wheatstone bridge representation seen in Fig. 2.2. It is assumed that opposite orifices in the bridge are equal in size. The model thus considers the flow equation for the four orifices and the continuity equation for each cylinder chamber and the volume between the pump and the valve. An extensive model of the hydraulic system was derived by [12]. The pump flow $q_{s}$ and load flow $q_{l}$ can be described by

$$
\begin{aligned}
& q_{s}=C_{q} A_{1} \sqrt{\frac{p_{s}-p_{L}}{\rho}}+C_{q} A_{2} \sqrt{\frac{p_{s}+p_{L}}{\rho}} \\
& q_{l}=C_{q} A_{1} \sqrt{\frac{p_{s}-p_{L}}{\rho}}-C_{q} A_{2} \sqrt{\frac{p_{s}+p_{L}}{\rho}}
\end{aligned}
$$

where $A_{1}=A\left[T_{s w}\right]$ and $A_{2}=A\left[-T_{s w}\right]$. From these equations the load pressure $p_{L}$ and the pump pressure $p_{s}$ can be derived as 


$$
\begin{aligned}
& p_{L}\left(T_{s w}, q\right)=\frac{\rho q_{s}^{2}}{8 C_{q}^{2}}\left(\left(\frac{1-q}{A\left[T_{s w}\right]}\right)^{2}-\left(\frac{1+q}{A\left[-T_{s w}\right]}\right)^{2}\right) \\
& p_{s}\left(T_{s w}, q\right)=\frac{\rho q_{s}^{2}}{8 C_{q}^{2}}\left(\left(\frac{1-q}{A\left[T_{s w}\right]}\right)^{2}+\left(\frac{1+q}{A\left[-T_{s w}\right]}\right)^{2}\right)
\end{aligned}
$$

where $q=\frac{q_{L}}{q_{s}}$. The load pressure is shown in Fig. 4.3 for both a positive and a negative load flow, which describes the static characteristic of the valve. Finally, the opening areas can be derived as

$$
\begin{aligned}
& A_{2}\left(T_{s w}\right)=\frac{q_{p}}{2 C_{q}} \sqrt{\frac{\rho}{p_{s}\left(T_{s w}\right)+p_{L}\left(T_{s w}\right)}} \\
& A_{1}\left(T_{s w}\right)=\frac{q_{p}}{2 C_{q}} \sqrt{\frac{\rho}{p_{s}\left(T_{s w}\right)-p_{L}\left(T_{s w}\right)}}
\end{aligned}
$$

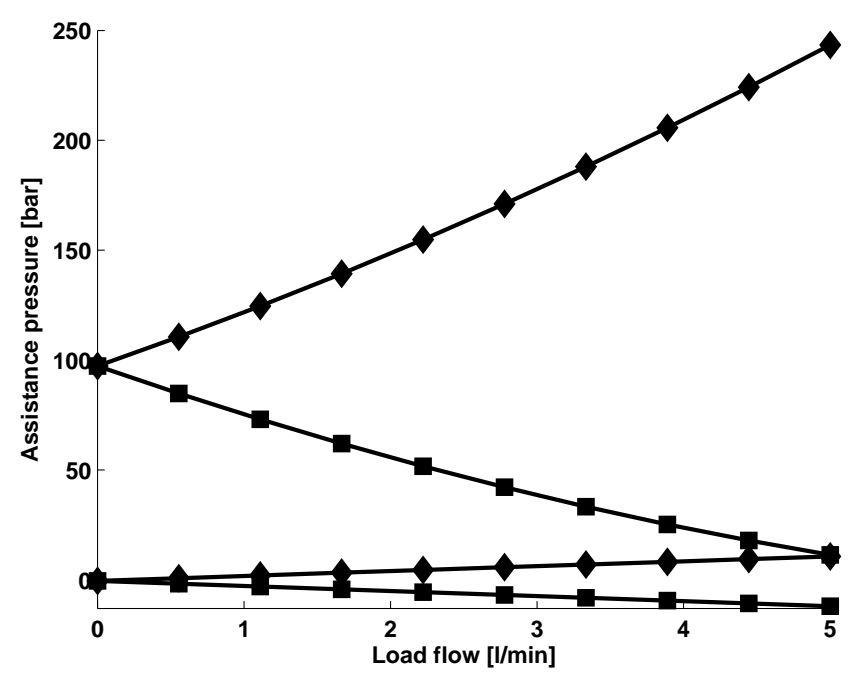

Figure 4.3 The static characteristics of the open-centre valve. The curves with square markers are for positive load flow. The curves with diamond markers are for negative load flow. 


\subsection{Linear modelling}

The linearised and Laplace transformed flow equations are defined as (capital letters are used for linearised variables):

$$
\begin{aligned}
Q_{s} & =\frac{\partial q_{s}}{\partial T_{s w}} T_{s w}+\frac{\partial q_{s}}{\partial P_{s}} P_{s}+\frac{\partial q_{s}}{\partial P_{l}} P_{l} \\
Q_{l} & =\frac{\partial q_{l}}{\partial T_{s w}} T_{s w}+\frac{\partial q_{l}}{\partial P_{s}} P_{s}+\frac{\partial q_{l}}{\partial P_{l}} P_{l}
\end{aligned}
$$

where the partial derivatives become:

$$
\begin{aligned}
& \frac{\partial q_{s}}{\partial T_{s w}}=C_{q} w_{1} \sqrt{\frac{P_{s}-P_{l}}{\rho}}+C_{q} w_{2} \sqrt{\frac{P_{s}+P_{l}}{\rho}}=K_{q 2} \\
& \frac{\partial q_{s}}{\partial P_{s}}=\frac{C_{q} T_{s w} w_{1}}{2 \sqrt{\frac{P_{s}-P_{l}}{\rho}} \rho}+\frac{C_{q} T_{s w} w_{2}}{2 \sqrt{\frac{P_{s}+P_{l}}{\rho}} \rho}=K_{c 1} \\
& \frac{\partial q_{s}}{\partial P_{l}}=-\frac{C_{q} T_{s w} w_{1}}{2 \sqrt{\frac{P_{s}-P_{l}}{\rho}} \rho}+\frac{C_{q} T_{s w} w_{2}}{2 \sqrt{\frac{P_{s}+P_{l}}{\rho}} \rho}=K_{c 2} \\
& \frac{\partial q_{l}}{\partial T_{s w}}=C_{q} w_{1} \sqrt{\frac{P_{s}-P_{l}}{\rho}-C_{q} w_{2}} \sqrt{\frac{P_{s}+P_{l}}{\rho}}=K_{q 1} \\
& \frac{\partial q_{l}}{\partial P_{s}}=\frac{C_{q} T_{s w} w_{1}}{2 \sqrt{\frac{P_{s}-P_{l}}{\rho}} \rho}-\frac{C_{q} T_{s w} w_{2}}{2 \sqrt{\frac{P_{s}+P_{l}}{\rho}} \rho}=-K_{c 2} \\
& \frac{\partial q_{l}}{\partial P_{l}}=-\frac{C_{q} T_{s w} w_{1}}{2 \sqrt{\frac{P_{s}-P_{l}}{\rho}}}-\frac{C_{q} T_{s w} w_{2}}{2 \sqrt{\frac{P_{s}+P_{l}}{\rho}} \rho}=-K_{c 1}
\end{aligned}
$$

The linearised equations of the hydraulic system now become:

$$
\begin{aligned}
& Q_{s}=K_{q 2} T_{s w}+K_{c 1} P_{s}+K_{c 2} P_{l} \\
& Q_{l}=K_{q 1} T_{s w}-K_{c 2} P_{s}-K_{c 1} P_{l} \\
& Q_{p}-Q_{s}=\frac{V_{s}}{\beta} P_{s} s \\
& Q_{l}=A_{p} X_{p} s+\frac{V_{0}}{\beta} P_{l} s
\end{aligned}
$$

where $V_{0}=\frac{V_{p 1} V_{p 2}}{V_{p 1}+V_{p 2}}$ 
The above equations now give the expression for the load pressure:

$$
\begin{aligned}
P_{L} & =\frac{K_{c 1}}{K_{c 1}^{2}-K_{c 2}^{2}} \frac{1+\frac{V_{s}}{K_{c 1} \beta} s}{\frac{s^{2}}{\omega_{0}^{2}}+\frac{2 \delta_{0}}{\omega_{0}} s+1} . \\
& \left(\begin{array}{l}
\left.\frac{1+\frac{V_{s}}{\left(K_{c 1}+\frac{K_{q 2} K_{c 2}}{K_{q 1}}\right) \beta} s}{1+\frac{V_{s}}{K_{c 1} \beta} s} K_{q 1}\left(1+\frac{K_{q 2} K_{c 2}}{K_{q 1} K_{c 1}}\right) T_{s w}-A_{p} X_{p} s\right) \\
\approx \frac{G_{K_{c}}}{K_{c}}\left(G_{K_{q}} K_{q} T_{s w}-A_{p} X_{p} s\right)
\end{array}\right.
\end{aligned}
$$

where

$$
\begin{aligned}
& \omega_{0}=\sqrt{\frac{K_{c 1}^{2}-K_{c 2}^{2}}{V_{0} V_{s}}} \beta \\
& \delta_{0}=\frac{1}{2} \frac{K_{c 1}}{\sqrt{K_{c 1}^{2}-K_{c 2}^{2}}} \frac{V_{0}+V_{s}}{\sqrt{V_{0} V_{s}}} \\
& K_{c}=\frac{K_{c 1}^{2}-K_{c 2}^{2}}{K_{c 1}} \\
& K_{q}=K_{q 1}\left(1+\frac{K_{q 2} K_{c 2}}{K_{q 1} K_{c 1}}\right)
\end{aligned}
$$

Ignoring the dynamics, Eq. 4.15 represents the static boost curve on a linear form, and will have different gains depending on the operating point, such as torque level and load flow. The complete steering system is now described with the following set of equations:

$$
\begin{gathered}
J_{s w} \theta_{s w} s^{2}=T_{d}-K_{T}\left(\theta_{s w}-R_{T} X_{r w}\right)-b_{r w} \theta_{s w} s \\
M_{r w} X_{r w} s^{2}=P_{L} A_{p}+K_{T}\left(\theta_{s w}-R_{T} X_{r w}\right) R_{T} \\
\quad-C_{r w} X_{r w}-b_{r w} X_{r w} s \\
P_{L} A_{p}=\frac{G_{K_{c}}}{K_{c}}\left(G_{K_{q}} K_{q} T_{s w}-A_{p} X_{p} s\right) A_{p}
\end{gathered}
$$

These equations can be formed into the block diagram shown in Fig. 4.4, which helps to analyse the system. From the block diagram the position servo control loop clearly appears. The driver applies a torque on the steering wheel which generates an angle. This angle is input to the control loop, i.e. the reference value. This is compared to the 
corresponding angle from the rack position. The error is the twisting of the torsion bar, which is input to the valve. The purpose of the hydraulic system is also clear, namely to control the assistance pressure. This is also affected by the movement of the rack. The pressure generates a force, which together with the equivalent steering wheel torque pushes the rack.

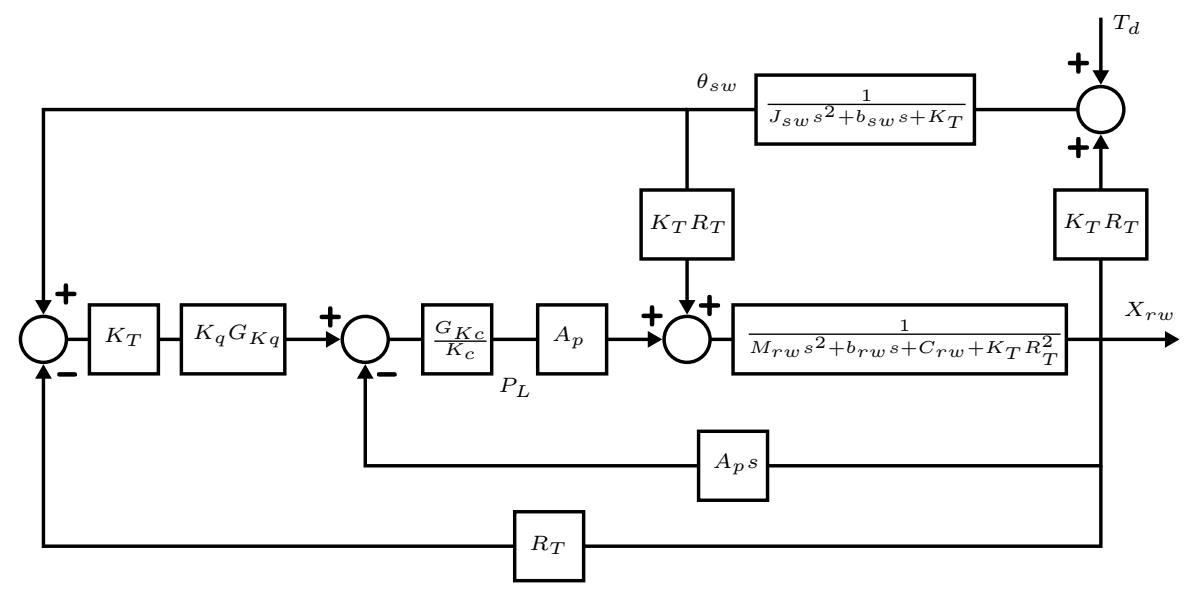

Figure 4.4 A block diagram representation of the linearised model of the open-centre steering system.

The closed loop transfer function from a steering wheel angle input to a rack displacement is defined as

$$
\frac{R_{t} X_{r w}}{\theta_{s w}}=\frac{K_{T} R_{T}^{2}+G_{K_{c} G_{K q}} A_{p} K_{T} K_{q} R_{T} / K_{c}}{M_{r w} s^{2}+\left(b_{r w}+\frac{A_{p}^{2}}{K_{c}} G_{K_{c}}\right) s+C_{r w}+K_{T} R_{T}^{2}+\frac{G_{K_{c} G_{K q} A_{p} K_{q} K_{T} R_{T}}}{K_{c}}}
$$

It is interesting to study the pressure built up by the open-centre valve since any actuator concept will replace this function. Figure 4.5 shows the pressure built up for different torsion bar torque inputs (from minimum to maximum torque) and zero load flow, i.e. when the rack is standing still. The pressure is built up fast at very low torque input but becomes rather slow as soon as the torque increases. Since the system is highly nonlinear the results vary with operating point. However, the result in Fig. 4.5 gives an indication of the behaviour of the valve.

The frequency response from a steering wheel angle input to a rack displacement (or road wheel angle) is shown Fig. 4.6 for the loop gain frequency response (open loop) and in Fig. 4.7 for the closed loop system. As mentioned previously the response is very much dependent on 

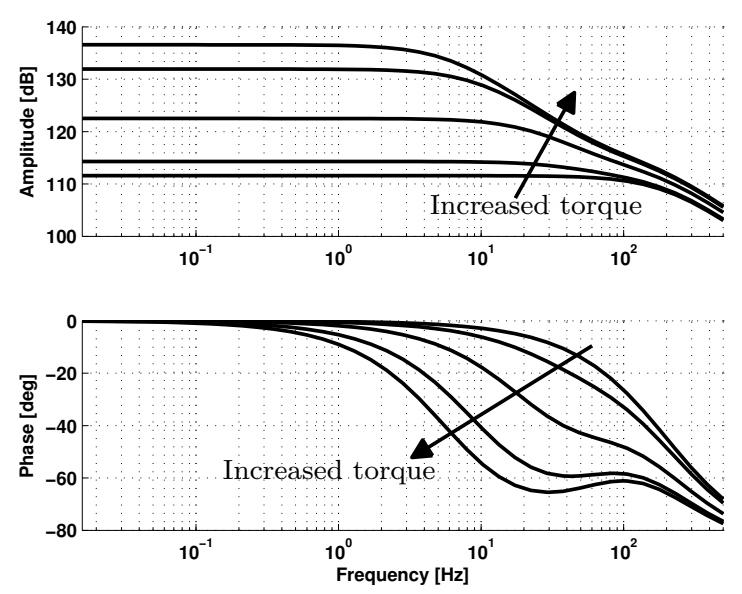

Figure 4.5 Transfer function from a torque input to load pressure for zero load flow. The upper plot shows the amplitude curve and the lower plot shows the phase curve.

the operating point. It is also dependent on the amplitude and direction of the flow. There are also unknown external parameters affecting the result. These are the stiffness and damping of the lower inertia and are dependent on the tyre-ground interaction. However, studying the frequency response of both the open loop and closed loop systems gives an indication of the system's behaviour, and same conditions will be used also for the closed-centre system. Though the valve is slow at high torque levels the higher boost gain compensates for that in the closed loop system. The frequency response of the steering system will later be compared to the frequency response of the closed-centre steering in section 6.3. 

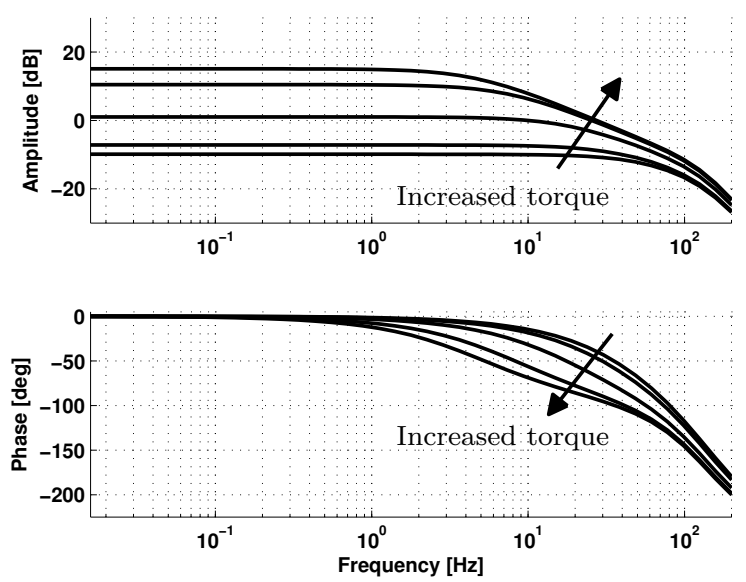

Figure 4.6 The loop gain frequency response (open loop) of the steering system for zero load flow from a steering wheel angle input to a rack displacement.
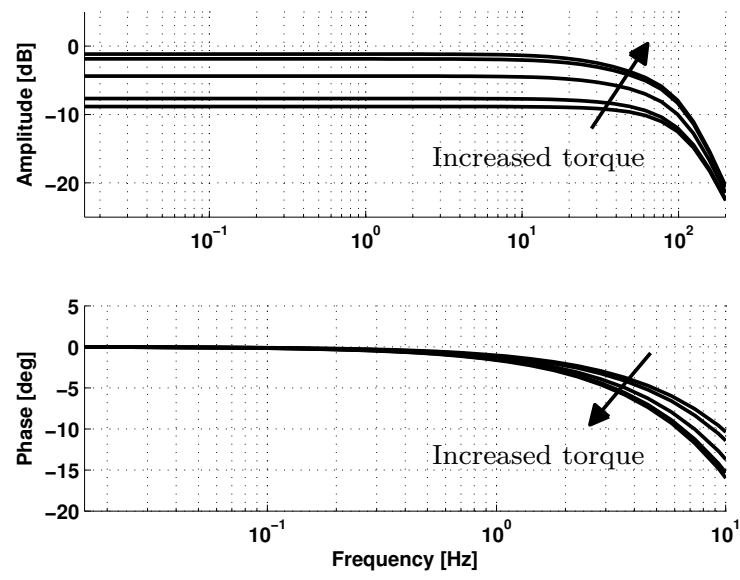

Figure 4.7 The frequency response of the closed loop system for zero load flow from a steering wheel angle input to a rack displacement.

\subsection{Simulation}

The simulation model is structured as shown in Fig. 4.1. The mechanical model is implemented with the friction models as described in section 4.1. One element is used for friction in the column with a constant value 
according to measurements described in section 3.2. Another friction element is used as a pressure-dependent friction at the rack. A linear pressure dependency is assumed. The hydraulic model is implemented using subcomponents for the four orifices and three volume components. The pump is not considered in this work and is therefore set to deliver a constant flow. The vehicle model is not considered either and an arbitrary passenger car is therefore modelled. It is necessary though to provide realistic forces on the steering rack. Low lateral accelerations are considered, which is sufficient when studying on-centre handling. A bicycle model, which is found in [26], is therefore used. The driver model in this case is a lead-lag controller set to follow a specific steering wheel angle. The output from the driver is a torque applied on the steering system. Different steering systems can therefore be compared in terms of steering wheel torque. Any differences between two systems will be detected since the steering wheel torque will have to change in order to follow the same steering wheel angle.

\subsection{Validation of steering system model}

The complete model is validated by comparing simulated results with measured results from the test run of the complete system in section 3.2. The models used are the driver model, the open-centre valve model, and the steering system model. The driver model is fed with the measured steering wheel angle as reference value and the measured rack force is applied to the steering system model. Figure 4.8 shows a comparison between the simulated and measured steering wheel angle, which shows the performance of the driver controller. The driver model is able to follow the reference with very good result. Figure 4.9 shows a comparison between the simulated and measured torsion bar torque, which is the most important indication that the model is accurate enough to be used in the evaluation process of different actuators. Figure 4.10 shows a comparison between the simulated and the measured rack position. Figure 4.11 shows a comparison between the simulated and the measured pump pressure. Figure 4.12 shows a comparison between the simulated and the measured pressure differences, i.e. the assistance pressure. All figures indicate that the model performs sufficiently well for the given driving cycle. 


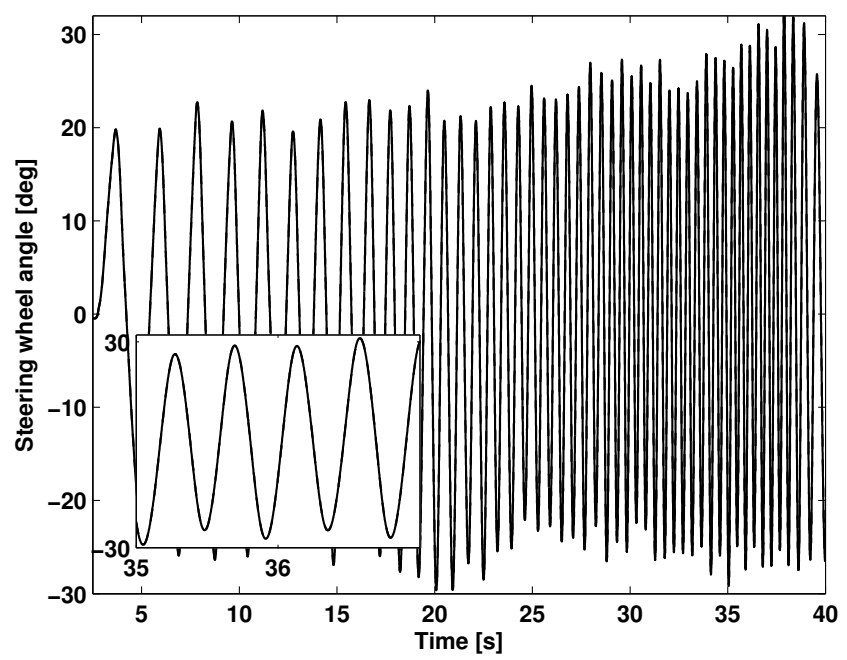

Figure 4.8 Comparison between simulated (dashed) and measured (solid) steering wheel angle.
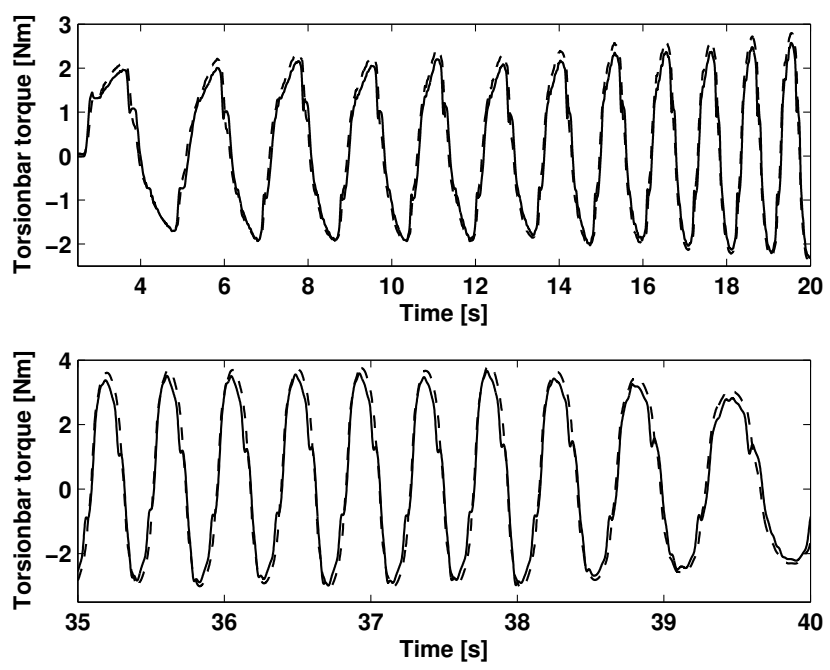

Figure 4.9 Comparison between simulated (dashed) and measured (solid) torsion bar torque. 

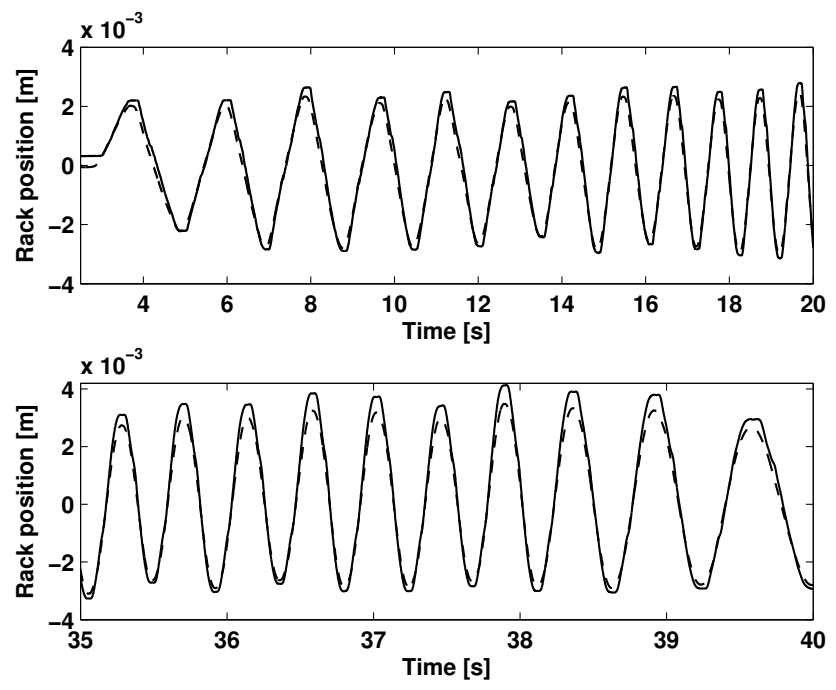

Figure 4.10 Comparison between simulated (dashed) and measured (solid) rack position.
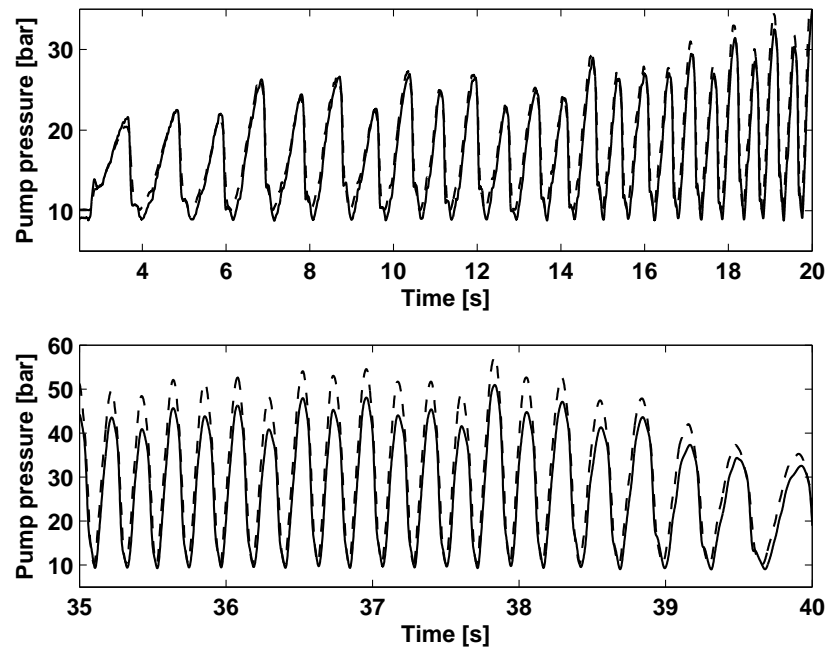

Figure 4.11 Comparison between simulated (dashed) and measured (solid) pump pressure. 

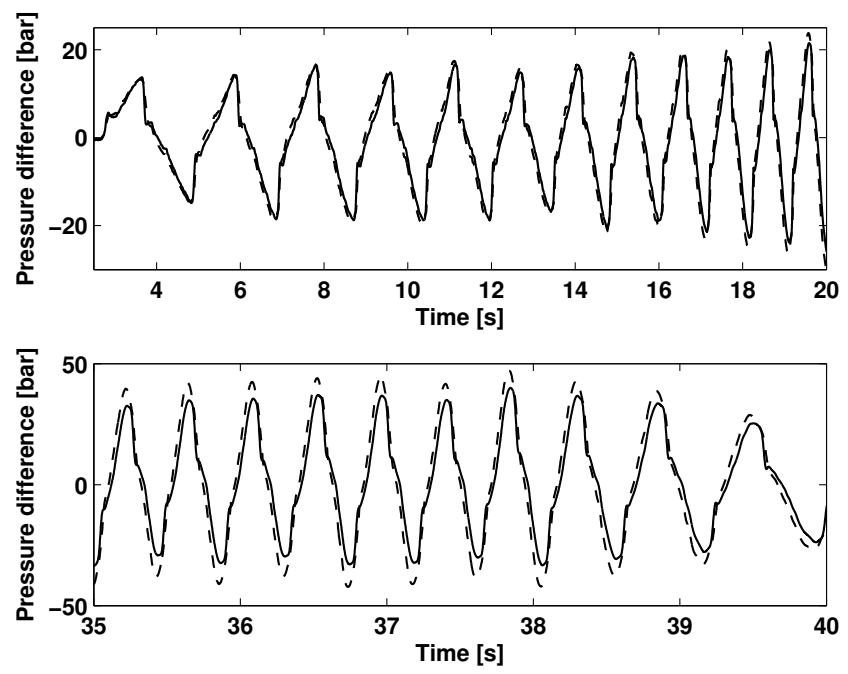

Figure 4.12 Comparison between simulated (dashed) and measured (solid) pressure differences between left and right chamber of the assistance cylinder. 


\section{5}

Pressure control

This chapter describes the self-regulated pressure control valve intended for use as a possible actuator in the steering system as well as the analysis performed to investigate the performance and suitability of the valve. The methodological approach is to derive a mathematical model of the valve. The model is in turn used in a linear analysis of the valve, revealing important aspects of the performance. The model is also used in a simulation environment together with the derived model of the steering system explained in chapter 4.

Pressure control takes place in most systems, simply for safety reasons. The pressure must not exceed certain limits. There are also system configurations that are based on a controlled pressure. One way to do this is by means of a valve-controlled system, such as pressure relief valves or pressure-reducing valves. The valve under study in this work, shown in Fig. 5.1, is in practice a combination of both types. If the pressure is too low in the controlled volume, the valve opens to supply pressure to fill up the volume until it reaches the target pressure. If the pressure is instead too high, the valve opens to tank in order to reduce the pressure in the controlled volume. The controlled pressure is sensed by the valve and compared to the target pressure. The valve is therefore self-regulated. The target pressure is set by an electronic signal and corresponds to the force applied on the spool by a solenoid. The solenoid is not part of the analysis at this point. A restrictor is placed between the load volume and the control chamber to increase damping, which will be shown in the following analysis. To provide a smooth opening the opening area consists of four holes drilled in the valve body. 


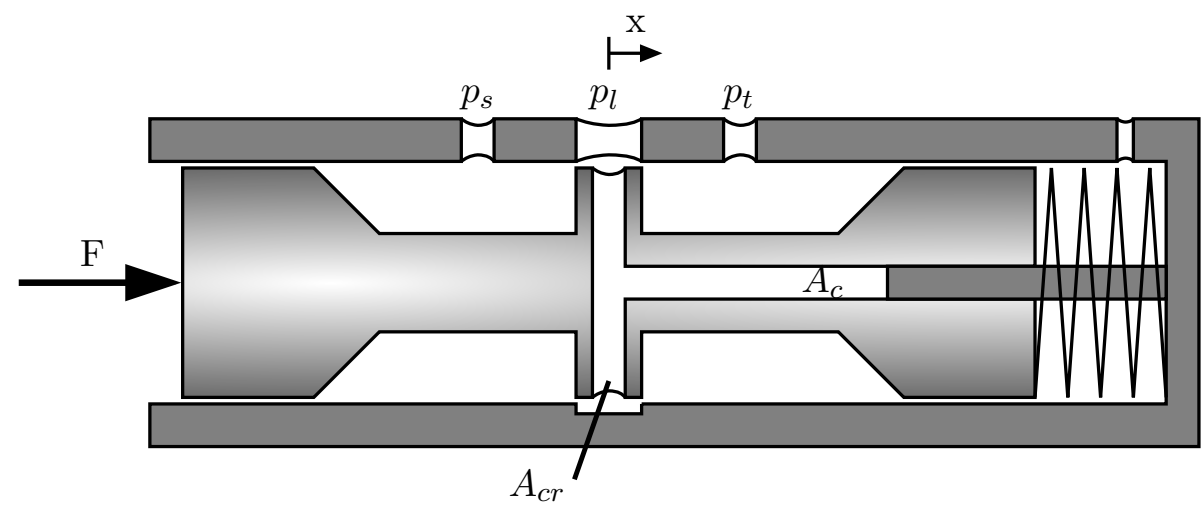

Figure 5.1 A schematic of the pressure control valve.

\subsection{Mathematical modelling of the pressure control valve}

The outlined equations describing the behaviour of the valve are based on the analysis by [39] and [40]. Other analyses of pressure controlled systems can be found in [41], where a two-stage pressure relief valve is analysed and in [42], where a pressure controlled pump is analysed. The equations consider both flow directions.

Equation of motion

$$
\begin{aligned}
m_{v} \ddot{x_{v}} & =F-p_{c} A_{c}-f_{0}-K x_{v}-b_{v}-f_{s} \\
F & =P_{r e f} A_{c}+f_{0}
\end{aligned}
$$

Load flow

$$
\begin{aligned}
& q_{v s}=C_{q} A_{s}\left(x_{v}\right) \sqrt{\frac{2}{\rho}\left(p_{s}-p_{l}\right)}-q_{c} \\
& q_{v t}=C_{q} A_{t}\left(-x_{v}\right) \sqrt{\frac{2}{\rho} p_{l}}+q_{c}
\end{aligned}
$$

Load volume

$$
q_{v s}-q_{v t}=A_{p} \dot{x}_{p}+\frac{V_{c y l}}{\beta} \dot{p}_{l}
$$




\section{Control chamber}

$$
\begin{aligned}
& q_{c}=-A_{c} v_{v}+\frac{V_{c}}{\beta} \dot{p}_{c} \\
& q_{c}=C_{q} A_{c r} \sqrt{\frac{2}{\rho}\left(p_{l}-p_{c}\right)}
\end{aligned}
$$

\section{Flow forces}

$$
f_{s}=\left|2 C_{q} A_{s}\left(x_{v}\right)\left(p_{s}-p_{l}\right) \cos (\delta)\right|-\left|2 C_{q} A_{t}\left(-x_{v}\right)\left(p_{s}-p_{l}\right) \cos (\delta)\right|
$$

\subsubsection{Static characteristic}

The static characteristic is important since it gives the control accuracy of the valve. Ideally, the pressure should not change with the flow through the valve. However, as will be seen from the dynamic analysis later on, there is a compromise between control accuracy and the stability of the valve. The static equations describing the valve for a positive spool displacement, meaning that the load side is open to supply, are the following.

$$
\begin{aligned}
& q_{v}=C_{q} w x_{v} \sqrt{\frac{2}{\rho}\left(p_{s}-p_{l}\right)} \\
& p_{\text {ref }} A_{c}-p_{l} A c-K x_{v}-K_{f}\left(p_{s}-p_{l}\right) x_{v}=0
\end{aligned}
$$

These can be rearranged into

$$
\begin{aligned}
& \Rightarrow x_{v}=\frac{A_{c}\left(p_{r e f}-p_{l}\right)}{K+K_{f}\left(p_{s}-p_{l}\right)} \\
& \Rightarrow q_{v}=\frac{K_{0} A_{c}\left(p_{r e f}-p_{l}\right)}{K_{e}} \sqrt{p_{s}-p_{l}}
\end{aligned}
$$

where

$$
\begin{aligned}
& K_{0}=C_{q} w \sqrt{\frac{2}{\rho}} \\
& K_{f}=2 C_{q} w \cos (\delta) \\
& K_{e}=K+K_{f}\left(p_{s}-p_{l}\right)
\end{aligned}
$$


Differentiating the flow gives the characteristic

$$
\begin{aligned}
& \frac{\partial q_{v}}{\partial p_{l}}=\frac{K_{0} A_{c}}{K_{e}} \sqrt{p_{s}-p_{l}}\left(-1-\frac{p_{r e f}-p_{l}}{2\left(p_{s}-p_{l}\right)}+\frac{K f\left(p_{r e f}-p_{l}\right)}{K_{e}}\right) \\
& \approx-\frac{K_{0} A_{c} \sqrt{p_{s}-p_{l}}}{K_{e}}=-\frac{A_{c} K_{q}}{K_{e}}=-\frac{1}{R_{v}} \\
& \Rightarrow R_{v}=-\frac{K_{e}}{A_{c} K_{q}}
\end{aligned}
$$

where $K_{q}=C_{q} w \sqrt{\frac{2}{\rho}\left(p_{s}-p_{l}\right)}$. The static characteristic is denoted $R_{v}$ and corresponds to the incline of the pressure-flow curve. The characteristic is very dependent on the operating point. The static characteristic of a negative spool displacement can be derived in the same way.

$$
\begin{aligned}
& \Rightarrow x_{v}=-\frac{A_{c}\left(p_{r e f}-p_{l}\right)}{K+K_{f} p_{l}} \\
& \Rightarrow q_{v}=-\frac{K_{0} A_{c}\left(p_{r e f}-p_{l}\right)}{K_{e}} \sqrt{p_{l}}
\end{aligned}
$$

where $K_{e}=K+K_{f} p_{l}$. The static characteristic is then

$$
R_{v}=\frac{K_{e}}{A_{c} K_{q}}
$$

where $K_{q}=C_{q} w \sqrt{\frac{2}{\rho}\left(p_{l}\right)}$. From the static characteristic in both cases it can be seen that in one direction the valve works as a pressure-reducing valve, while in the other direction it works as a pressure relief valve.

\subsubsection{Linearisation of the pressure control valve}

All equations describing the valve are linearised and transformed into the Laplace domain. The following equations are valid for a positive spool displacement (captital letters indicate linearised variables). 


\section{Equation of motion}

$$
\begin{aligned}
& M_{v} X_{v} s^{2}=P_{r e f} A_{c}-P_{c} A_{c}-K X_{v}-B_{v} X_{v} s \\
& \quad-K_{f}\left(p_{s}-p_{l 0}\right) X_{v}-K_{f} x_{v 0}\left(P_{s}-P_{l}\right) \\
& K_{f}=2 C_{q} w \cos (\delta) \\
& K_{e}=K+K_{f}\left(p_{s}-p_{l 0}\right) \\
& \Rightarrow M_{v} X_{v} s^{2}=P_{r e f} A_{c}-P_{c} A_{c}-K_{e} X_{v}-B_{v} X_{v} s
\end{aligned}
$$

The term $K_{f} x_{v 0}$ is small in the context and is therefore ignored.

\section{Load flow}

$$
\begin{aligned}
& Q_{v}=K_{q} X_{v}+K_{c}\left(P_{s}-P_{l}\right)-Q_{c} \\
& K_{q}=\frac{\partial q_{l}}{\partial x_{v}}=C_{q} w \sqrt{\frac{2}{\rho}\left(p_{s}-p_{l 0}\right)} \\
& K_{c}=\frac{\partial q_{l}}{\partial\left(p_{l}-p_{s}\right)}=\frac{C_{q} w x_{v 0} \sqrt{\frac{2}{\rho}}}{2 \sqrt{p_{s}-p_{l 0}}}=\frac{q_{v 0}}{2\left(p_{s}-p_{l 0}\right)}
\end{aligned}
$$

\section{Load volume}

$$
Q_{v}=A_{p} X_{p} s+\frac{V_{c y l}}{\beta} P_{l} s
$$

\section{Control chamber}

$$
\begin{aligned}
& Q_{c}=-A_{c} X_{v} s+\frac{V_{c}}{\beta} P_{c} s \\
& Q_{c}=K_{1}\left(P_{l}-P_{c}\right)
\end{aligned}
$$

By rearranging the equations above a block diagram describing the system dynamics can be derived.

$$
\begin{aligned}
X_{v} & =\frac{A_{c}}{K_{c}} \frac{P_{r e f}-P_{c}}{M_{v} s^{2}+B_{v} s+K_{e}} \\
P_{c} & =\frac{\frac{A_{c}}{K_{1}} X_{v} s+P_{l}}{1+\frac{V_{c}}{K_{1} \beta} s} \\
\left(K_{c} P_{s}-Q_{l}\right)\left(1+\frac{V_{c}}{K_{1} \beta} s\right)+ & K_{q}\left(1+\left(\frac{V_{c}}{K_{1} \beta}+\frac{A_{c}}{K_{q}}\right) s\right) X_{v} \\
& =K_{c} P_{l}\left(1+\frac{V_{c y l}}{K_{c} \beta} s\right)\left(1+\frac{V_{c}}{K_{1} \beta} s\right)
\end{aligned}
$$


Equations 5.24, 5.25 and 5.26 forms the block diagram in Fig. 5.2, with following definitions

$$
\begin{aligned}
\omega_{c} & =\frac{K_{1} \beta}{V_{c r}} \\
\omega_{m} & =\sqrt{\frac{K_{e}}{M_{v}}} \\
\delta_{m} & =\frac{B_{v}}{2} \sqrt{\frac{1}{K_{e} m}} \\
\omega_{s} & =\frac{K_{c} \beta}{V_{c y l}} \\
Q_{l} & =A_{p} X_{p} s
\end{aligned}
$$

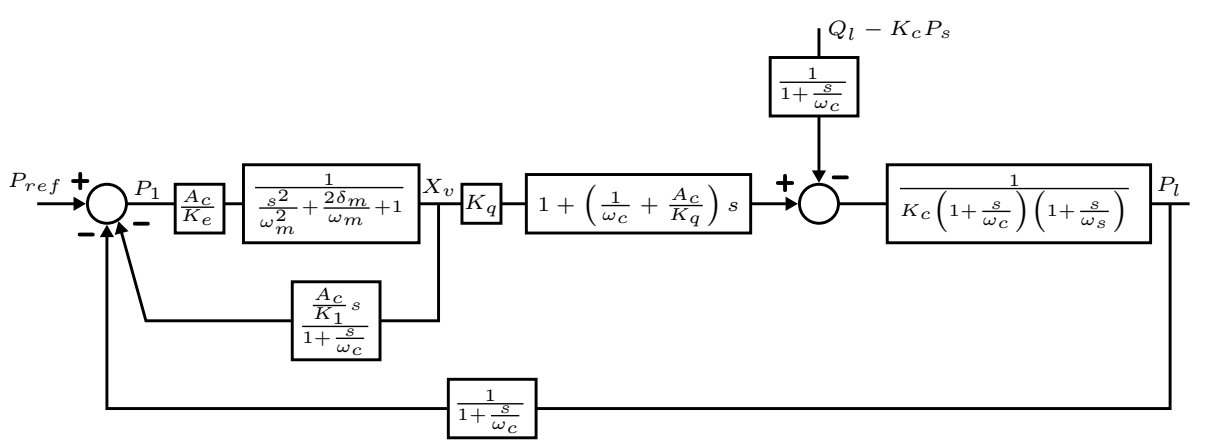

Figure 5.2 The block diagram representation of the self-regulated pressure control valve.

The derived block diagram is a general model of the valve. By designing the restrictor in different ways, a different characteristic is achieved. This was studied by both [39] and [40]. One way is to have no restrictor, or a very large one. The result of this is a very fast valve but difficult to combine with a good static characteristic. Another way is to design the restrictor in such a way that an increased damping is achieved. The approach here is to assume that the damping is difficult to control and the restrictor is therefore designed to generate the desired damping. The inner loop due to the volume change within the control chamber is 
expressed as

$$
\frac{X_{v}}{P_{1}}=\frac{\frac{A_{c}}{K_{e}}\left(1+\frac{s}{\omega_{c}}\right)}{\left(1+\frac{s}{\omega_{c}}\right)\left(\frac{s^{2}}{\omega_{m}^{2}}+\frac{2 \delta_{m}}{\omega_{m}} s+1\right)+\frac{s}{\omega_{v}}}
$$

where $\omega_{v}=\frac{K_{1} K_{e}}{A_{c}^{2}}$. If the restrictor is small enough, oil will be entrapped inside the control chamber, and the mechanical frequency will thus be replaced by a hydraulic frequency. The criteria for the restrictor is the following (see [40])

$$
K_{1} \leq 2 A_{c} \sqrt{\frac{V_{c r}}{\beta m}}
$$

The loop can then be factorised into the following expression

$$
\frac{X_{v}}{P_{1}}=\frac{\frac{A_{c}}{K_{e}}\left(1+\frac{s}{\omega_{c}}\right)}{\left(1+\frac{s}{\omega_{v}}\right)\left(\frac{s^{2}}{\omega_{h}^{2}}+\frac{2 \delta_{h}}{\omega_{h}} s+1\right)}
$$

where $\omega_{h}=\sqrt{\frac{K_{h}}{M_{v}}}, K_{h}=\frac{A_{c}^{2} \beta}{V_{c}}, \delta_{h}=\frac{\omega_{c}}{2 \omega_{h}}$. Both $\omega_{h}$ and $\omega_{c}$ are very large and can therefore be ignored in the following analysis. The block diagram of the valve can thus be simplified into Fig. 5.3.

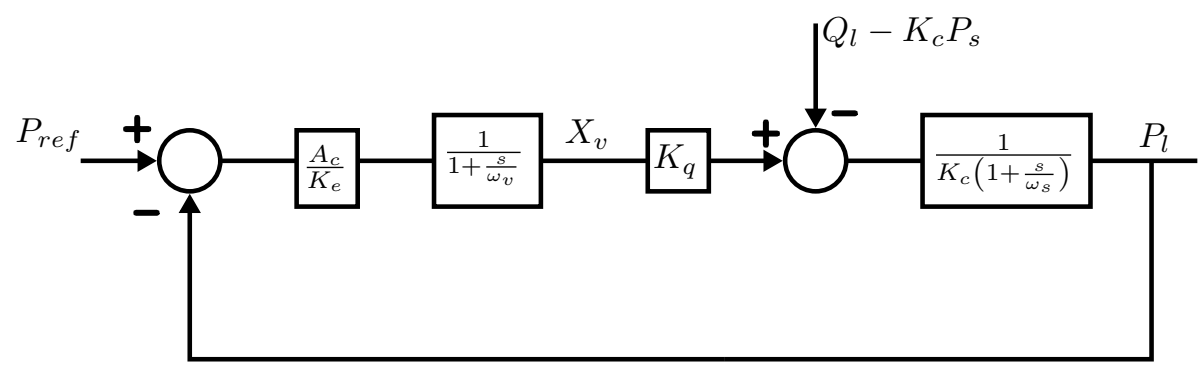

Figure 5.3 A simplified block diagram representation of the pressure control valve with a restrictor.

From the block diagram in Fig. 5.3 the loop gain is defined as

$$
\begin{aligned}
G_{o}(s) & =\frac{K_{v}}{\left(1+\frac{s}{\omega_{v}}\right)\left(1+\frac{s}{\omega_{s}}\right)} \\
K_{v} & =\frac{A_{c} K_{q}}{K_{e} K_{c}}
\end{aligned}
$$


Regarding stability, the gain margin is usually not an issue for this design, but it is rather the phase margin that controls the stability criteria. The closed loop of the valve can also be defined from the block diagram.

$$
\begin{aligned}
G_{c}(s) & =\frac{K_{s}}{\frac{s^{2}}{\omega_{0}^{2}}+\frac{2 \delta_{0}}{\omega_{0}} s+1} \\
\omega_{0} & =\sqrt{\left(K_{v}+1\right) \omega_{v} \omega_{s}} \\
\delta_{0} & =\frac{\omega_{v}+\omega_{s}}{2 \omega_{0}} \\
K_{s} & =\frac{K_{v}}{1+K_{v}}
\end{aligned}
$$

Here, $\omega_{0}$ is the resonance seen by the valve and $\delta_{0}$ its corresponding damping. The closed loop gain is $K_{s}$. A good valve design implies that $K_{v}>>1$ and therefore $K_{s} \approx 1$. This is, however, not necessary the case in this work, where the design depends on other factors. The results from the analysis are further used to design the valve and corresponding controller in chapter 6 . 


\section{6 \\ Closed-centre power steering system}

The idea behind closed-centre power steering in this work is to replace the open-centre valve with two electronically controlled pressure control valves, described in chapter 5 , that independently control the pressure in each chamber of the assistance cylinder. How they should be installed in the steering gear in practice or how any failure modes should be handled is not part of this work at this point. The same applies for the supply system. At this point it is assumed that the supply system can deliver a constant pressure and a sufficient flow. A schematic of the conceptual steering system with closed-centre valves is shown in Fig. 6.1. It is assumed that the torsion bar torque, or the steering wheel torque, can be measured, as well as the chamber pressures. These signals are fed to the controller and the control signals are the respective reference pressure to each valve. The idea in this work is to evaluate if the closed-centre system can reach the same performance as the open-centre system. For this reason, a static model of the open-centre valve is used as a reference. This model also considers the change in pressure with flow. This means that the closed-centre valve should have the same static characteristic as the open-centre valve. The dynamic performance is contributed by the dynamic characteristic of the closed-centre valve. This will of course differ compared to the original system. The effect of this is evaluated later. An overview of the system architecture is shown in Fig. 6.2. The 
first part of this chapter describes the design of the valve (section 6.1). In section 6.2 a controller is designed for the pressure control valve in order to generate the right static and dynamic characteristics. Finally, section 6.3 puts together the valve model and the model of the steering system from chapter 4 for an evaluation of the closed-centre concept through simulation.

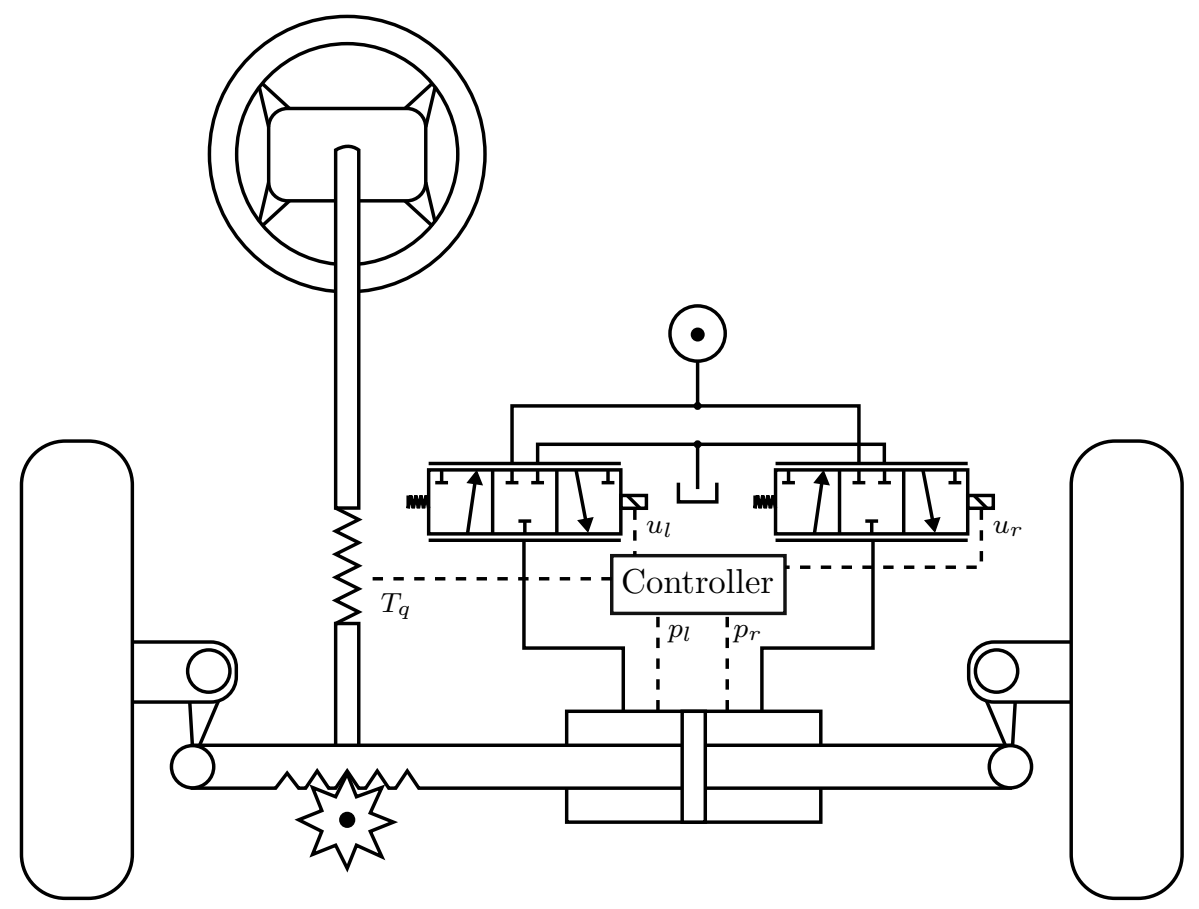

Figure 6.1 A schematic of the closed-centre steering system with individual pressure control.

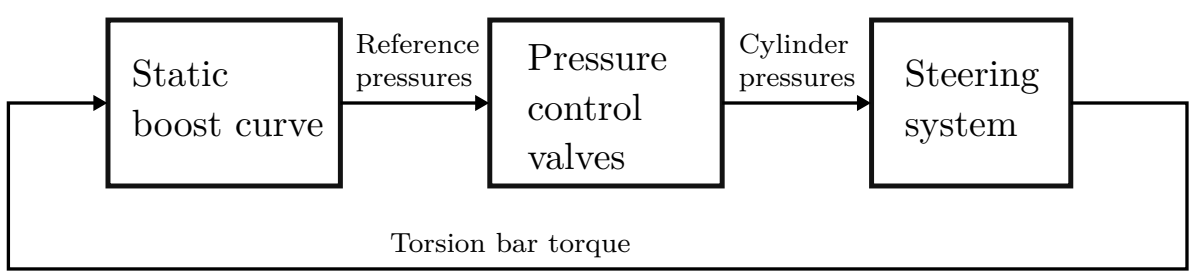

Piston velocity

Figure 6.2 Overview of the closed-centre system. 


\subsection{Valve design by optimisation}

The important parameters affecting the valve performance can be seen from the static and linear analyses in chapter 5 . These are the pressure area, spring stiffness, opening area, and damping orifice. The damping orifice is however restricted in size from the relation in 5.28. Arguably, a fast valve is desired in most systems, as is also the aim here. However, even though the solenoid design is not part of this work, it is assumed that a small solenoid is also fast (and cheap). A small solenoid can only apply a small force on the spool and therefore it is desired to keep the drive force small and at the same time design the valve to be as fast as possible. The valve is therefore designed with the help of an optimisation routine. The optimisation routine used in this work is the Complex-RF method [43], which is a further development of the original Complex method [44]. The multi-objective problem can be formulated as

$$
\begin{aligned}
& \min F(\mathbf{x})=e_{1} k_{1} f_{1}(\mathbf{x})+e_{2} k_{2} f_{2}(\mathbf{x})+\sum_{i=1}^{6} \text { pen }_{i} \\
& f_{1}(\mathbf{x})=\tau\left(\text { at } p_{l}(t=\infty)\right) \\
& f_{2}(\mathbf{x})=\max \left(F_{1}, F_{2}, F_{3}, F_{3}\right) \\
& \mathbf{x}_{\text {lower }}<\mathbf{x}<\mathbf{x}_{\text {upper }} \\
& F_{1}=F \text { at } 5 \text { bar, } q_{l}=-5 \mathrm{l} / \mathrm{min} \\
& F_{2}=F \text { at } 5 \text { bar, } q_{l}=5 \mathrm{l} / \mathrm{min} \\
& F_{3}=F \text { at } 100 \text { bar, } q_{l}=-5 \mathrm{l} / \mathrm{min} \\
& F_{4}=F \text { at } 100 \text { bar, } q_{l}=1.1 \mathrm{l} / \mathrm{min} \\
& \text { pen }_{1}=p_{l}(t=0.5)>90 \text { bar } \\
& \text { pen }_{2}=\text { max }\left(p_{l}\right)<105 \text { bar } \\
& \text { pen }_{3}=p_{\text {ref }}-p_{l}<1 \text { bar at } 5 \mathrm{bar}, q_{l}=-5 \mathrm{l} / \mathrm{min} \\
& \text { pen }_{4}=p_{\text {ref }}-p_{l}<1 \text { bar at } 5 \text { bar, } q_{l}=5 \mathrm{l} / \mathrm{min} \\
& \text { pen }_{5}=p_{\text {ref }}-p_{l}<1 \text { bar at } 100 \mathrm{bar}, q_{l}=-5 \mathrm{l} / \mathrm{min} \\
& \text { pen }_{6}=p_{\text {ref }}-p_{l}<1 \text { bar at } 100 \text { bar, } q_{l}=1.1 \mathrm{l} / \mathrm{min}
\end{aligned}
$$

The weight functions are defined as 


$$
\begin{aligned}
& e_{2}=\mathrm{e}^{-3.5 j} \\
& e_{1}=1-e_{2} \\
& j=0 . .1
\end{aligned}
$$

The parameters $k_{1}$ and $k_{2}$ are normalising factors since the objectives $f_{1}$ and $f_{2}$ are in different ranges. A simulation model of the valve is used in order to find the objective values. The objective $f_{1}$ is the time it takes to reach $90 \%$ of the final value when a step is applied to the valve. In this case, the final value is 100 bar. The objective $f_{2}$ is the maximum force required by a solenoid to drive the valve. Four extreme points are checked and these points are easily described by Fig. 6.3. The figure shows the static characteristic of the open-centre valve. In an attempt to try and mark the operating range, a constant power curve is added to Fig. 6.3 (the dashed curve). This can of course be tweaked and the chosen curve is an example. The circles mark the points where the forces $F_{1}$ to $F_{4}$ are checked. Several penalties are added to keep the valve design within certain boundaries. A penalty is added if the pressure never reaches the final value within the simulation time set, in this case within 0.5 seconds. This is to avoid extremely slow valve designs. A penalty is also added if the valve generates an overshoot of 5 bar after a step is applied. In order to make the valve actually follow the static characteristic of the open-centre valve, a simple controller is used. This is not the final controller that will be described in section 6.2. To ensure the valve design is feasible a penalty is also added if the pressure deviates too much from the reference pressure at the marked points (circles) in Fig. 6.3. The design parameters are

$$
\begin{aligned}
& \mathbf{x}(1)=d_{c} \\
& \mathbf{x}(2)=K \\
& \mathbf{x}(3)=d_{a} \\
& \mathbf{x}(4)=f_{0}
\end{aligned}
$$




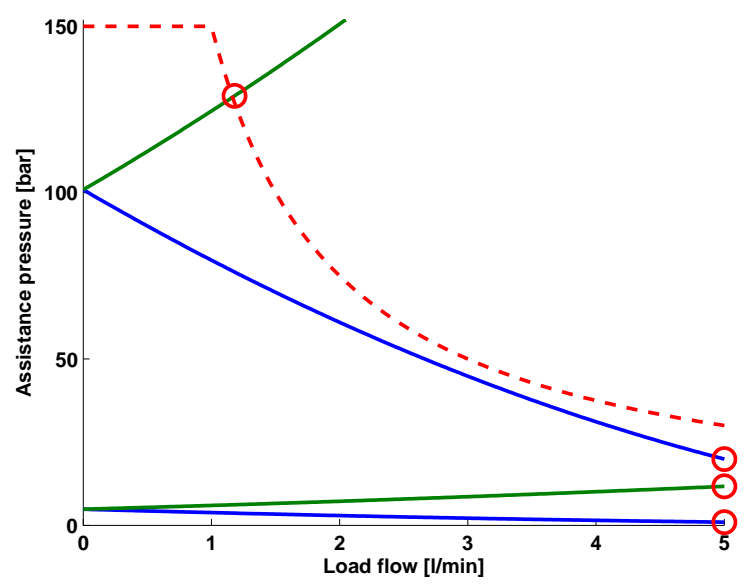

Figure 6.3 The static characteristic of the open-centre valve. The dashed line marks the operating range and the circles mark the extreme points which are used in the optimisation of the valve design.

The results of the optimisation are shown in Fig. 6.4. Here the required solenoid force for a certain response of the valve is easily seen. The chosen design is marked in the figure.

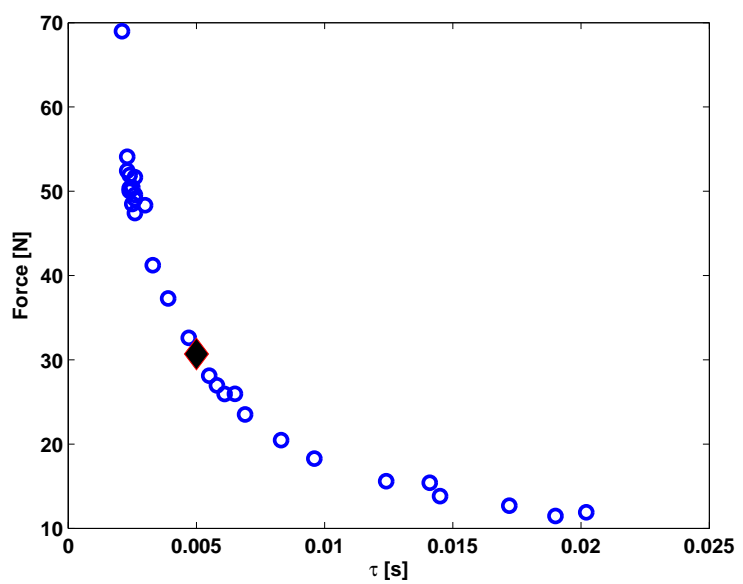

Figure 6.4 Optimisation result showing the Pareto front with drive force against valve response measured as time to reach $90 \%$ of the final value for a step input. The chosen design is marked with diamond. 


\subsubsection{Characteristics of the valve design}

From the chosen design the valve characteristic is examined. In Fig. 6.5 the static characteristic is shown for both the pressure-reducing function and the pressure relief function. Compared to the open-centre valve it has a steeper characteristic at low pressure but a better characteristic at high pressure.

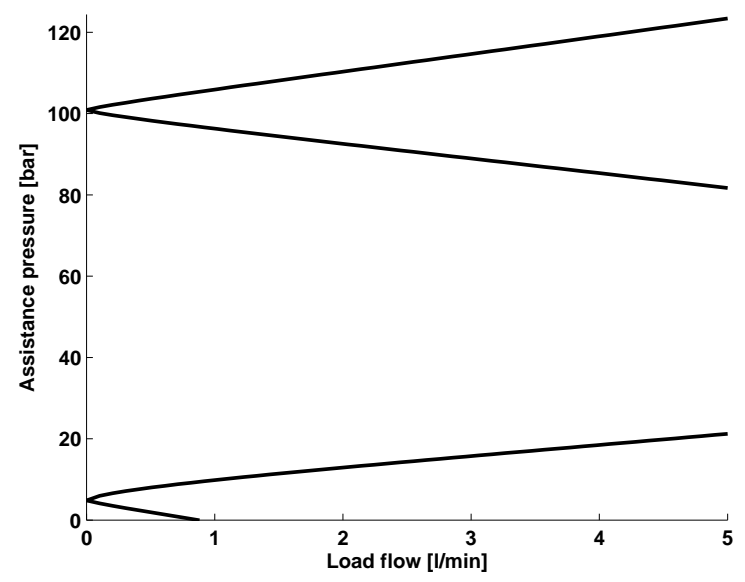

Figure 6.5 The static characteristic of the chosen design of the pressure control valve. The curves with a negative slope mark the characteristic for the pressure-reducing function. The curves with a positive slope mark the characteristic of the pressure relief function.

The chosen design is checked for stability by studying the loop gain of Eq. 5.30. Since the loop gain varies with operating point, the point which gives the highest gain is studied. The cylinder is assumed to be in centre position, which is the case for on-centre driving. Figure 6.6 shows the result and it can be seen that the phase margin would set the limitation, but the valve is far from reaching any stability margins. The reason is that the valve is designed to require a low drive force and not only take performance into consideration. 

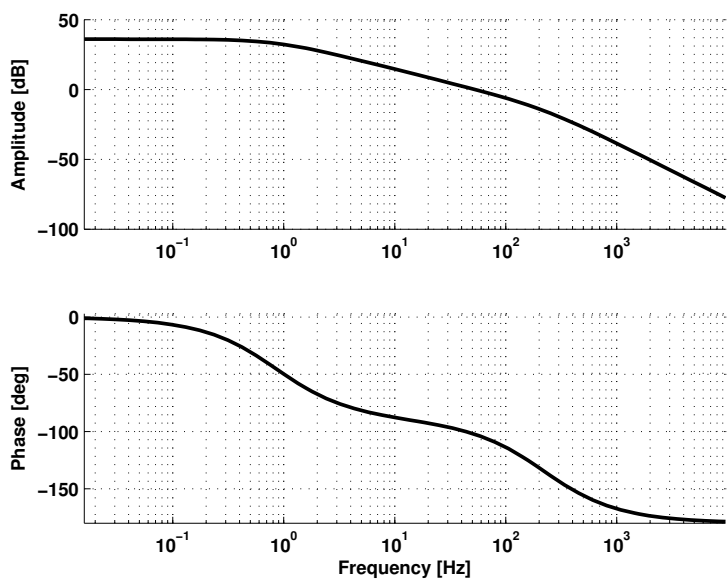

Figure 6.6 The loop gain frequency response for the pressure control valve at highest gain.

Figure 6.7 shows the performance of the valve for a step input from the simulation model. For a large step the valve reaches $90 \%$ of the final value within $5 \mathrm{~ms}$ and for a small step it reaches the final value within $6 \mathrm{~ms}$.

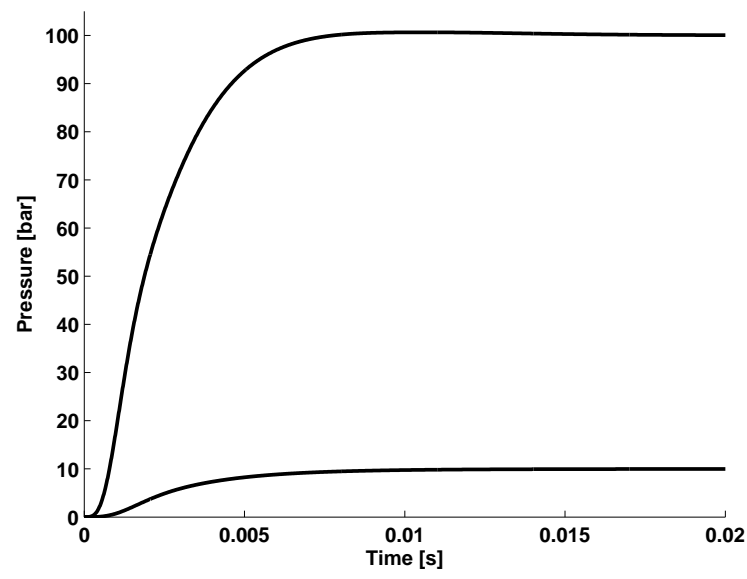

Figure 6.7 Step responses of the pressure control valve for the chosen design. 


\subsection{Controller design}

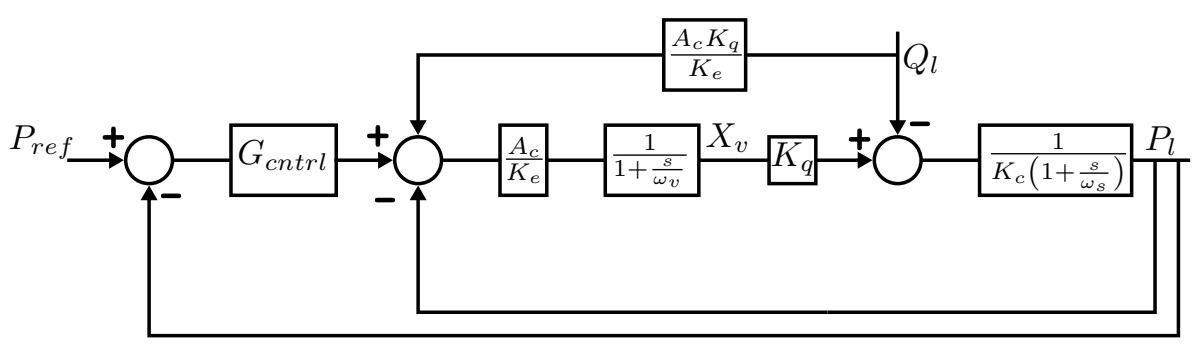

Figure 6.8 The block diagram with controller and valve.

Since the closed-centre valve should follow the static characteristic of the open-centre valve, an integrating controller is needed. An integrator in the controller may lead to an overshoot. This can affect the amplitude margin of the steering system loop and in the worst case lead to instability. This is something that must be compensated for in the controller. The controller is also set to compensate for varying system dynamics, thus generating a more predictable behaviour. The proposed controller is shown in Eq. 6.6 with the layout in Fig. 6.8 which shows the whole system with controller and valve.

$$
G_{c n t r l}(s)=\omega_{k}^{2}\left(\frac{s}{\left(s+k \omega_{k}^{2}\right) \omega_{0}^{2}}+\frac{2 \delta_{0}}{\left(s+k \omega_{k}^{2}\right) \omega_{0}}+\frac{1}{s\left(s+k \omega_{k}^{2}\right)}\right)
$$

The controller is in practice a PID controller with varying control parameters calculated from 5.32 and 5.33. What the controller does is to compensate for the valve dynamics and add an integrator and a low pass filter. The resulting loop gain is of the same order as the valve. The loop gain of the system is then

$$
G_{O_{c n t r l}}(s)=K_{s} \frac{1}{s\left(k+\frac{s}{\omega_{k}^{2}}\right)}
$$

Finally, the closed loop of the system with controller is expressed as, with $K_{s}$ assumed to be equal to one,

$$
G_{c_{c n t r l}}(s)=\frac{1}{\frac{s^{2}}{\omega_{k}^{2}}+k s+1}=\frac{1}{\frac{s^{2}}{\omega_{c n t r l}^{2}}+\frac{2 \delta_{c n t r l}}{\omega_{c n t r l}}+1}
$$


where $\omega_{c n t r l}=\omega_{k}$ and $k=\frac{2 \delta_{c n t r l}}{\omega_{c n t r l}}$. In this way the desired resonance and damping of the closed loop can be adjusted by changing $\omega_{k}$ and $k . \omega_{k}$ can be set to change with the pressure level to better resemble the opencentre valve dynamic characteristic, but is not done here. The results from simulation of the controller and valve can be found in section 8.1. In Fig. 5.3 there is a disturbance from both a change in load flow and variations in supply pressure. The variations in the supply pressure are ignored but the disturbance from the load flow is compensated for by estimating the load flow from the steering wheel velocity and using it as a feed forward with the control signal as in Eq. 6.9. Both the controller and the flow compensator contain estimated values such as $K_{q}, K_{c}$ and $K_{e}$ that both vary with pressure and spool displacement. Only the pressure is measured and therefore used when calculating those valve parameters for the controller. The spool displacement is set to some value and adjusted to obtain the desired valve performance. For the flow compensator the estimated flow is also used.

$$
e=G_{c n t r l}(s)\left(P_{r e f}-P_{l}\right)+\frac{K_{e}}{A_{c} K_{q}} Q_{l}
$$

From the block diagram in Fig. 6.8 the resulting pressure can be derived as

$$
P=\frac{G_{o} G_{c n t r l}}{1+G_{o}\left(1+G_{c n t r l}\right)} P_{r e f}-\left(\frac{\frac{1}{K_{c}\left(1+\frac{s}{\omega_{s}}\right)}\left(1-\frac{1}{1+\frac{s}{\omega_{v}}}\right)}{1+G_{o}\left(1+G_{c n t r l}\right)}\right) Q_{l}
$$

In the steering system it is the assistance pressure, i.e. the pressure difference between the two cylinder chambers, that is of importance. It can be defined as

$$
\begin{aligned}
P_{L}= & P_{1}-P_{2}=\underbrace{\frac{G_{o} G_{c n t r l}}{1+G_{o}\left(1+G_{c n t r l}\right)}}_{G_{r e f}} P_{r e f} \\
& -(\underbrace{\frac{1}{K_{c}\left(1+\frac{s}{\omega_{s}}\right)}\left(1-\frac{1}{1+\frac{s}{\omega_{v}}}\right)}_{\text {right },=G_{Q 1}}+\underbrace{\frac{\frac{1}{K_{c}\left(1+\frac{s}{\omega_{s}}\right)}\left(1-\frac{1}{1+\frac{s}{\omega_{v}}}\right)}{1+G_{o}\left(1+G_{c n t r l}\right)}}_{\text {left },=G_{Q 2}}) Q_{l}
\end{aligned}
$$


The transfer functions $G_{Q 1}$ and $G_{Q 2}$ describe the pressure change due to a flow disturbance in both chambers. The valve properties are different since they are dependent on the operating conditions, and the pressure drop is different for the two chambers.

\subsection{Closed-centre system evaluation}

The evaluation of the designed concept is evaluated through simulation of the complete system. The approach is to use the validated model of the steering system in chapter 4 and the model of the valve. A layout of the complete simulation model is shown in Fig. 6.9. The reference for the pressure control valves is the static boost curve with compensation for the load flow. The pressure control valves control the pressure in each chamber that is connected to the steering rack. A driver model is used to follow a steering wheel angle of $\pm 30^{\circ}$ and an increasing frequency up to $2 \mathrm{~Hz}$. A steering wheel angle velocity of $400^{\circ} / \mathrm{s}$ is reached. The same driver input is also used for a model of the steering system with the open-centre valve. By comparing the driver's torque for both systems an indication of the performance of the closed-centre system is achieved. The results of the comparison are presented in section 8.2.

To evaluate the closed-centre system also for high pressure levels, a spring load is used instead of the vehicle model which can be seen as a tyre working within the non-slip region during dry park manoeuvres. The same input is used and the results are shown in section 8.2. For reasons described below, a lower controller gain is used for this case.

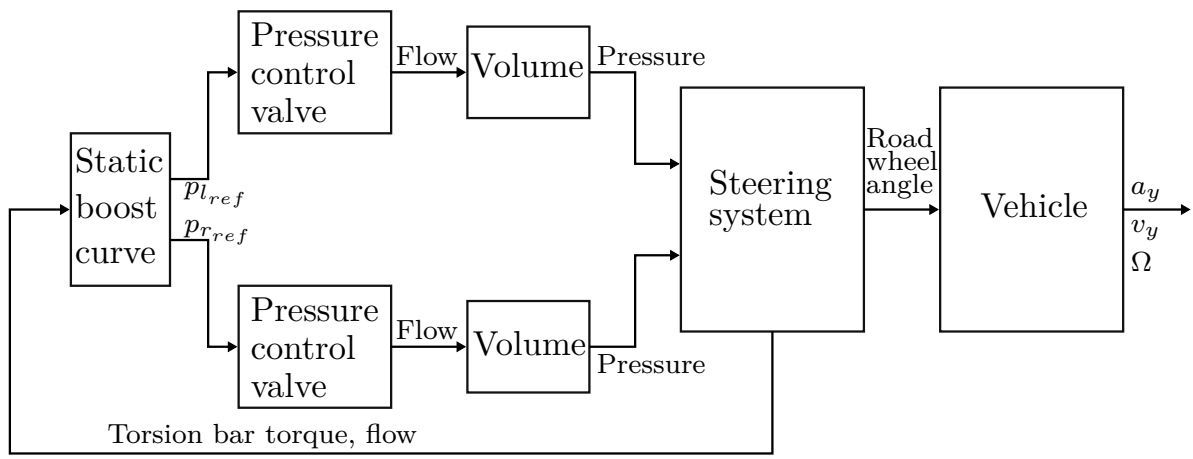

Figure 6.9 The layout of the simulation model of the closed-centre steering system. 
The first part of the evaluation is, however, to use the previous linear models of the steering system and the valve in order to examine the effect the valves have on the steering system properties. The static boost curve is in linear form described by

$$
P_{r e f}=\frac{1}{K_{c O C}}\left(K_{q O C}\left(\theta_{s w}-R_{T} X_{r w}\right) K_{T}-A_{p} X_{r w} s\right)
$$

Equation 6.11, 6.12, 4.16 and 4.17 can now form the block diagram shown in Fig. 6.10.

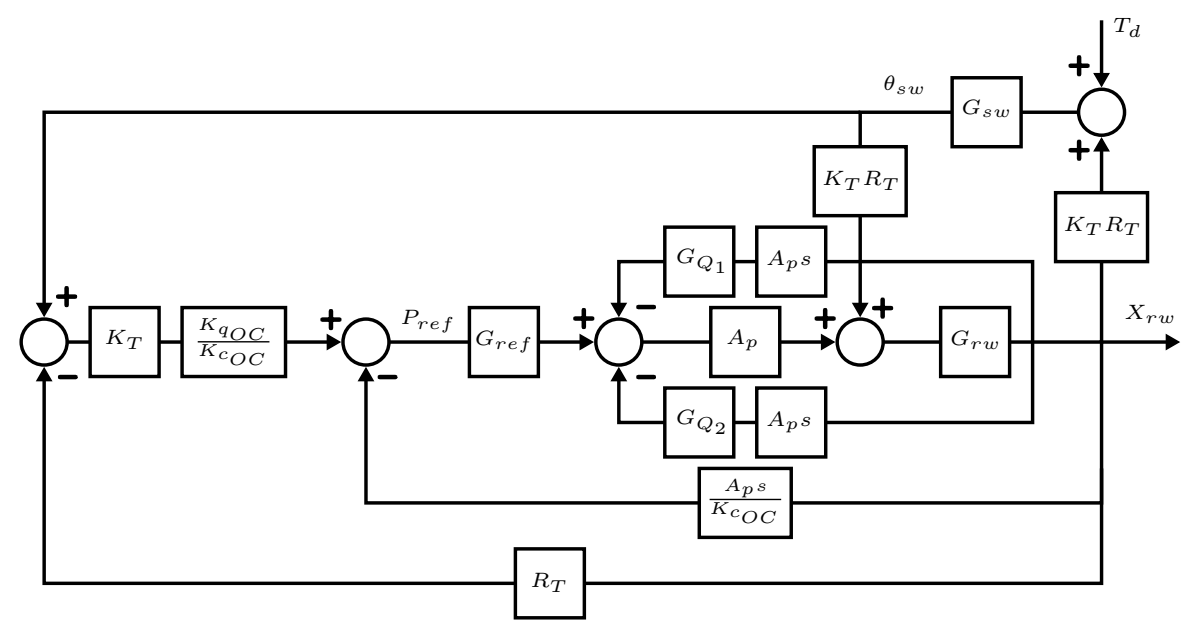

Figure 6.10 A block diagram representation of the steering system loop with the pressure control valves.

From the block diagram, the closed loop transfer function from a steering wheel angle input to rack displacement can be defined as

$$
\begin{aligned}
& \frac{R_{t} X_{r w}}{\theta_{s w}}= \\
& \frac{K_{T} R_{T}^{2}+G_{r e f} A p K_{T} K_{q_{O C}} R_{T} / K_{c_{O C}}}{M_{r w} s^{2}+\left(b_{r w}+\left(G_{Q_{1}}+G_{Q_{2}}+\frac{G_{r e f}}{K_{c O C}}\right) A_{p}^{2}\right) s+C_{r w}+K_{T} R_{T}^{2}+\frac{G_{r e f} A_{p} K_{q_{O C}} K_{T} R_{T}}{K_{c_{O C}}}}
\end{aligned}
$$

What is seen from Eq. 6.13, compared to the open-centre system, Eq. 4.19 , is that the pressure control valves contribute with additional damping, but this is purely a dynamic effect and has no influence during steady-state manoeuvres due to the integrating behaviour of the pressure control loop. To better understand the effect the pressure control 
valves have on the steering system control loop, the loop gain frequency response and the closed loop response can be studied, shown in Fig. 6.11 and 6.12 , respectively. Due to the additional lag introduced by the pressure control valves compared to the open-centre valve, a fast valve is needed for low torque levels to avoid too much phase shift in the steering system control loop. This might in turn lead to instability problems for high torque levels, where the faster valve reduces the gain margin to such an extent where instability might occur. This could be solved by varying the gain of the valve controller, but is of course a compromise between steering feel and stability issues. It is, however, reasonable to believe that at high torque levels, the steering feel is of less importance.
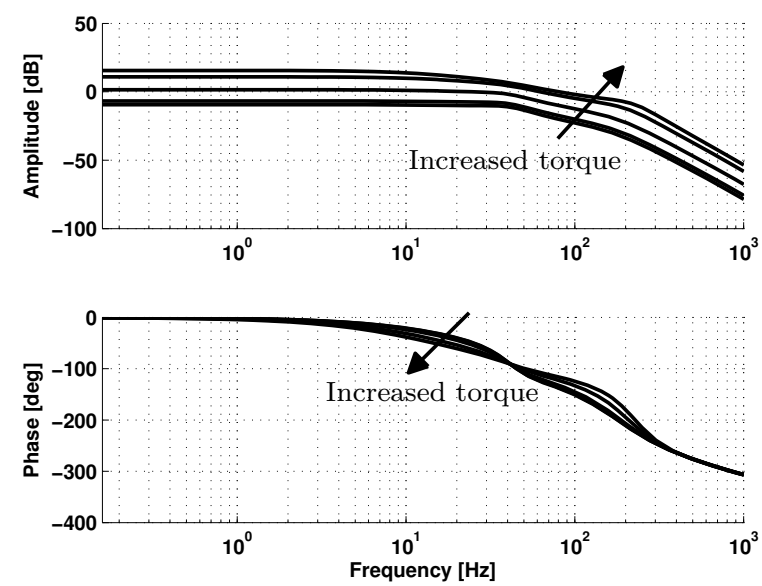

Figure 6.11 The loop gain frequency response (open loop) of the steering system with pressure control valves for zero load flow from a steering wheel angle input to a rack displacement. 

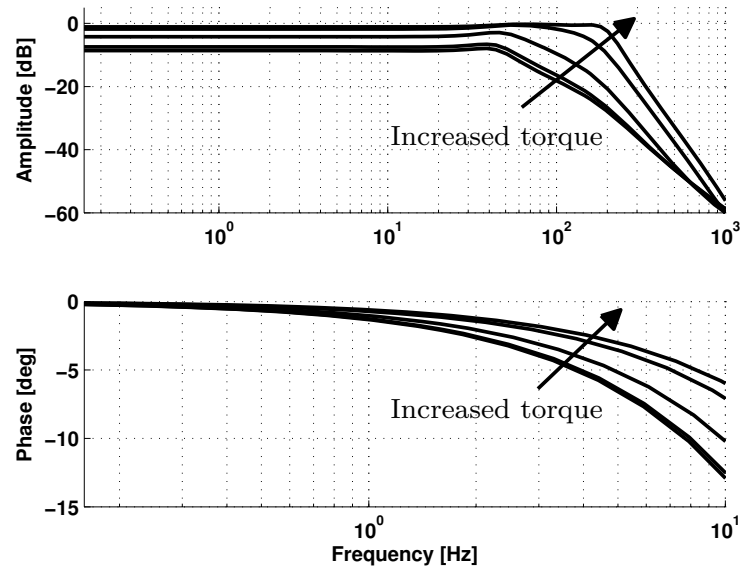

Figure 6.12 The closed loop frequency response of the steering system with pressure control valves for zero load flow from a steering wheel angle input to a rack displacement. 


\section{7 \\ Hardware-in-the- \\ loop \\ simulation}

Building a test rig of the steering system for hardware-in-the-loop simulation has many advantages [45], [46]. First and foremost, with a test rig containing parts of the real hardware a more realistic environment can be created where any conceptual actuator can be evaluated. Here, possible issues can arise that have been overseen in the simulation of the system. By having a test driver compare the original system with a conceptual closed-centre system a qualitative judgement provides valuable information regarding the performance of the system. After all, steering feel is very subjective, yet important. In this work, the test rig is partly used for a proof of concept. The aim was to develop a generic test rig for closed-centre systems. The servo valves are used to control the assistance pressure. If this is done according to an implemented model of the conceptual actuator, that lies in the software, the servo valve performance should reflect the behaviour of the concept. The actuator under study in this case is the original open-centre valve for an evaluation of the test rig itself. Two controllers were developed for the test rig. One is the force controller that takes the reference force from a vehicle model and compares it to the measured force between the load cylinder and the rack. The other controller is to control the pressure in each chamber of the assistance cylinder. 


\subsection{Force control}

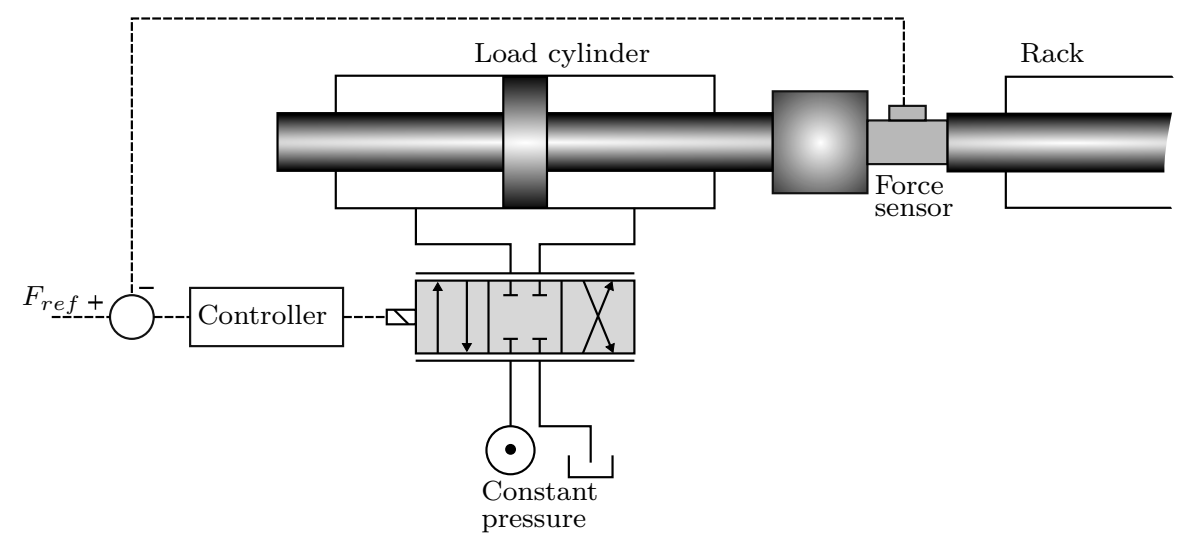

Figure 7.1 A layout of the force controller. A force sensor measures the force applied by the load cylinder on the rack. A servo valve with constant pressure is used to control the force.

A layout of the force controller is shown in Fig. 7.1. The approach is to use a linear model of the system and design a lag-controller, which is then verified in the test rig. The system studied is the load cylinder with its servo valve and an external force, corresponding to the force applied by the load cylinder on the steering rack. The governing equations of this system on linear form are the following:

$$
\begin{aligned}
& M X_{p} s^{2}=P_{L} A_{p}-B_{v} X_{p} s-F \\
& K_{q} X_{v}+K_{c}\left(P_{s}-P_{L}\right)=A_{p} X_{p} s+\frac{V_{t}}{4 \beta_{e}} P_{L} s \\
& X_{v}=G_{c n t r l}(s)\left(F_{r e f}-F\right) \frac{1}{\frac{s^{2}}{\omega_{v}^{2}}+\frac{2 \delta_{v}}{\omega_{v}} s+1}
\end{aligned}
$$

For the purpose of the linear analysis the mass and friction are ignored. The valve is assumed to have a second order dynamic. The chosen controller is a lead-filter, [47], as shown in Eq. 7.4 and the resulting performance is shown in Fig. 7.2. Some discrepancy is noted when the piston changes direction. This is probably due to the internal friction of the cylinder.

$$
G_{f c}=K_{p 0} \frac{1+\tau_{I} s}{\gamma+\tau_{I} s}
$$




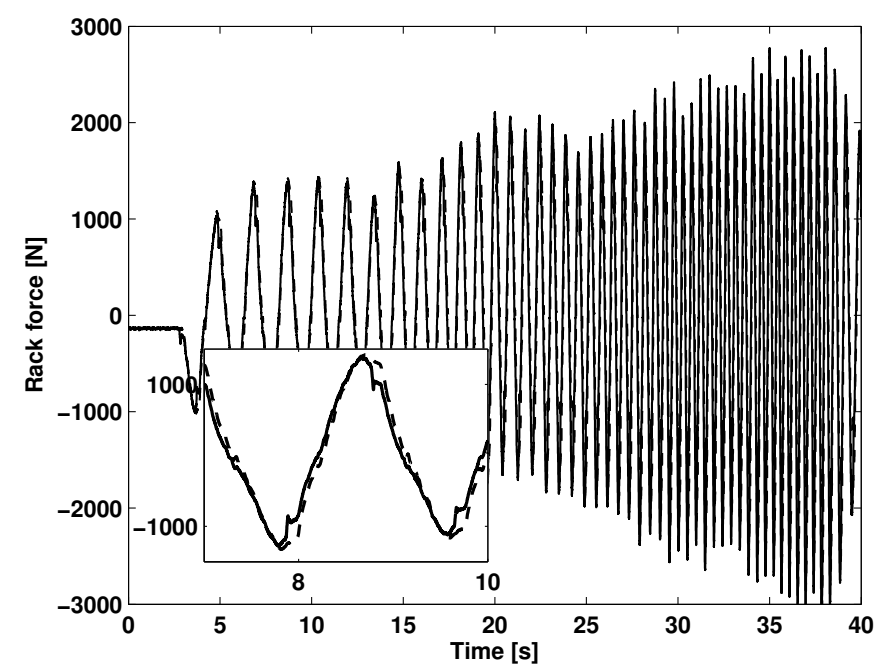

Figure 7.2 Comparison between reference force (dashed) and measured force (solid).

\subsection{Pressure control with servo valves}

The approach for control of the servo valves is similar to the one presented in chapter 6 . A static boost curve is used as reference and the dynamic characteristic is contributed by the servo valve control loop. The analysis and control structure differs, however, since another type of valve used is in the test rig than designed in chapter 6 . From the linear analysis of the open-centre steering system it was seen that the dynamic effect of the valve has no influence for low frequency input and low torque levels. This region corresponds to on-centre driving and the operating range of the test rig is therefore limited to this range. Since the steering wheel angle is applied to the test rig manually, there will most likely be a difference each test run. A direct comparison between the original system and the system with servo valves can not be made. The comparison is instead performed on a qualitative basis. This, however, is not within the scope of the work. A model-based approach is instead used to verify the test rig. A simulation model of the steering system with servo valves is derived. By studying the difference in steer- 
ing wheel torque between the open-centre system and the servo valve system for a certain difference between the reference pressure and the actual pressure for the servo valve system, an indication of the required performance is achieved. A linear analysis of the closed-centre system with servo valves is first performed to gain a better understanding of the effect valve and controller properties have on the system performance. The meter-in and meter-out valves are controlled simultaneously for each chamber and both valves will affect the pressure built-up. The analysis of the pressure built-up can be simplified into Fig. 7.3.

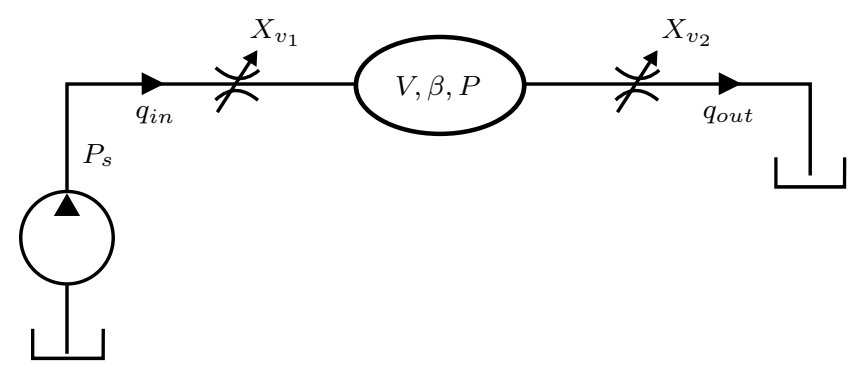

Figure 7.3 A simplified analysis of the pressure control of one chamber with servo valves.

The flow and continuity equations for the volume are expressed as (already linearised and Laplace transformed, capital letters indicate linearised variables)

$$
\begin{aligned}
& Q_{\text {in }}=K_{q_{1}} X_{v_{1}}+K_{c_{1}}\left(P_{s}-P\right) \\
& Q_{\text {out }}=K_{q_{2}} X_{v_{2}}+K_{c_{2}}(P) \\
& Q_{\text {in }}-Q_{\text {out }}=A_{p} X_{p} s+\frac{V}{\beta} P_{a} s
\end{aligned}
$$

Since one valve closes and the other opens with the same amount it is valid to define the spool displacements as

$$
X_{v_{2}}=-X_{v_{1}}=-X_{v}
$$

Equations 7.5 to 7.7 can now be formed into

$$
\begin{gathered}
\left(K_{q_{1}}+K_{q_{2}}\right) X_{v}+K_{c_{1}} P_{s}-A_{p} X_{p} s=\left(K_{c_{1}}+K_{c_{2}}\right) P_{a}+\frac{V}{\beta} P_{a} s \\
\Rightarrow K_{q} X_{v}+Q_{l}=\left(K_{c}+C_{s} s\right) P_{a}
\end{gathered}
$$


The controller needs to be of integrator type in order to follow the static characteristic of the boost curve. To compensate for some of the lag introduced by the valve and increase the damping somewhat, a lead filter is added. The suggested controller is based on the controller found in $[46]$.

$$
G_{c t r l}=\frac{K_{p 0}}{\hat{K}_{q}}\left(1+\frac{\hat{K}_{c}}{C_{s} s}\right)\left(1+T_{d} s\right)
$$

$\hat{K}_{q}$ and $\hat{K}_{c}$ are the estimated flow gain and flow-pressure coefficient, respectively. For simplicity, $\hat{K}_{q}$ and $\hat{K}_{c}$ are assumed to be perfectly estimated in the continued analysis and the valve is assumed to have a second order dynamic. A block diagram describing the pressure control loop based on Eq. 7.8 and 7.9 can be formed as shown in Fig. 7.4.

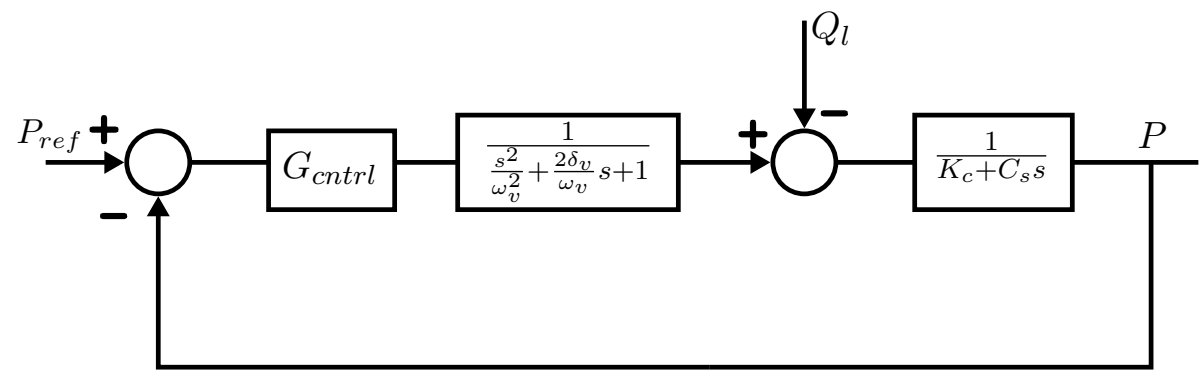

Figure 7.4 A block diagram representation of the pressure control loop with servo valves.

With accurate estimation of the valve properties the open loop from the block diagram is expressed as

$$
G_{o}(s)=\frac{K_{p 0}}{C_{s} s\left(\frac{s^{2}}{\omega_{v}^{2}}+\frac{2 \delta_{v}}{\omega_{v}} s+1\right)}\left(1+T_{d} s\right)
$$

From the block diagram in Fig. 7.4 the pressure can also be defined.

$$
P=\frac{G_{o}}{1+G_{o}} P_{r e f}-\frac{1}{\left(K_{c}+C_{s} s\right)\left(1+G_{o}\right)} Q_{l}
$$

What is of more interest is the transfer function for the assistance pressure $P_{L}$. 


$$
\begin{aligned}
P_{L}= & P_{\text {right }}-P_{\text {left }}=\underbrace{\frac{G_{o}}{1+G_{o}}}_{G_{c}} P_{\text {ref }} \\
& -(\underbrace{\frac{1}{\left(K_{c}+C_{s} s\right)\left(1+G_{o}\right)}}_{\text {right chamber },=G_{q_{1}}}+\underbrace{\frac{1}{\left(K_{c}+C_{s} s\right)\left(1+G_{o}\right)}}_{\text {left chamber, }=G_{q_{2}}}) Q_{l}
\end{aligned}
$$

The reference pressure is the static boost curve and with the open-centre valve parameters it is expressed as

$$
P_{r e f}=\frac{1}{K_{c_{O C}}}\left(K_{q_{O C}}\left(\theta_{s w}-R_{T} X_{r w}\right) K_{T}-A_{p} X_{r w} s\right)
$$

With Eq. 7.12 and 7.13, and the equations for the steering system, Eq. 4.16 and 4.17, a block diagram can be formed, as shown in Fig. 7.5.

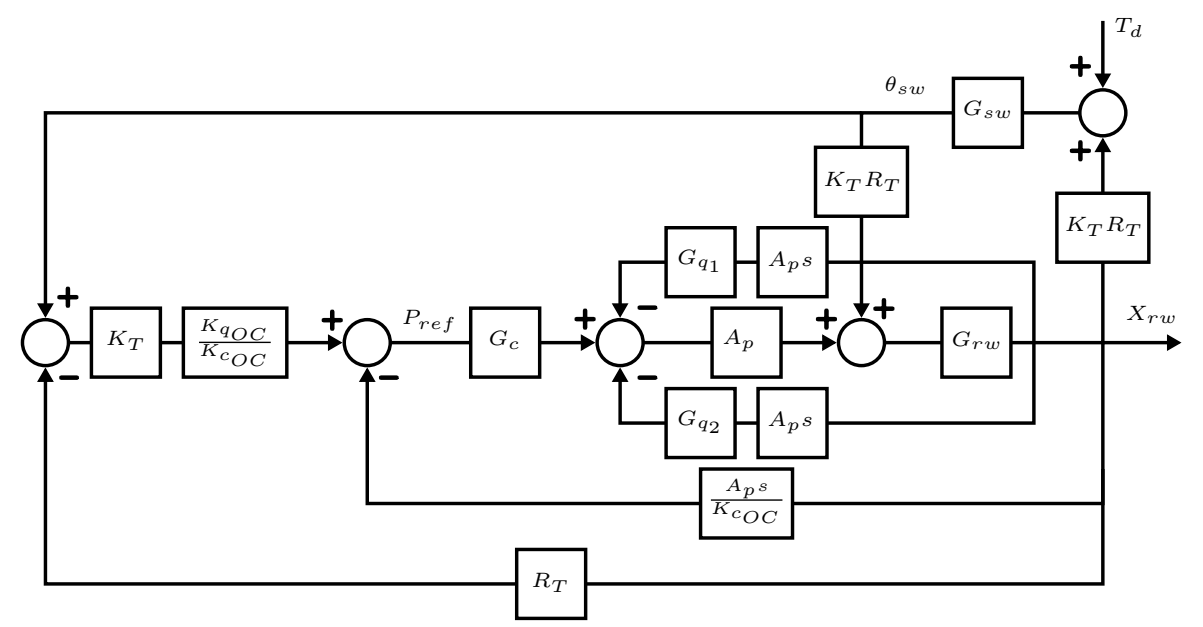

Figure 7.5 A block diagram representation of the steering system loop with servo valves.

The block diagram is similar to Fig. 6.10, where the pressure control valves are used. The closed loop transfer function from a steering wheel angle input to rack displacement can again be defined as 


$$
\begin{aligned}
& \frac{R_{t} X_{r w}}{\theta_{s w}}= \\
& \quad \frac{K_{T} R_{T}^{2}+G_{c} A p K_{T} K_{q_{O C}} R_{T} / K_{C_{O C}}}{M_{r w} s^{2}+\left(b_{r w}+\left(G_{q_{1}}+G_{q_{2}}+\frac{G_{c}}{K_{C} O C}\right) A_{p}^{2}\right) s+C_{r w}+K_{T} R_{T}^{2}+\frac{G_{c} A_{p} K_{q_{O C}} K_{T} R_{T}}{K_{C_{O C}}}}
\end{aligned}
$$

What is seen from Eq. 7.14, is a similar behaviour as in the case with pressure control valves. The loop gain frequency response and closed loop response of the steering system control loop are shown in Fig. 7.6 and 7.7 , respectively.
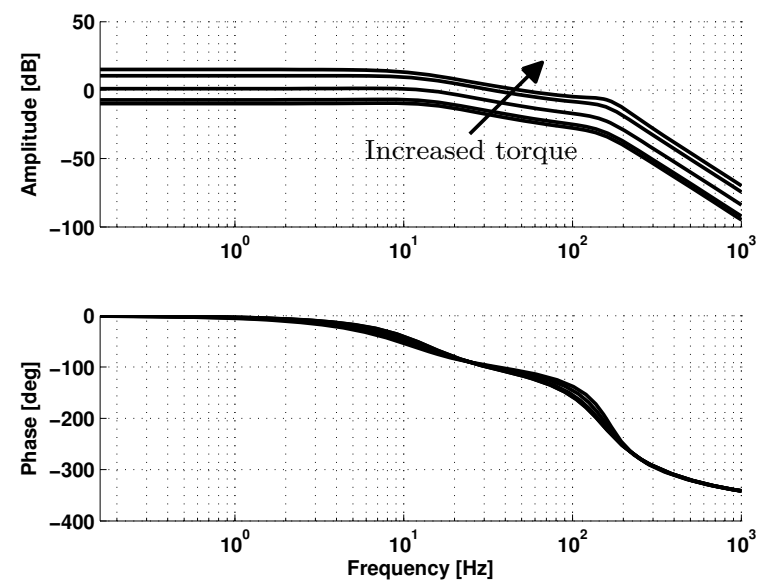

Figure 7.6 The loop gain frequency response (open loop) of the steering system with servo valves for zero load flow from a steering wheel angle input to a rack displacement. 

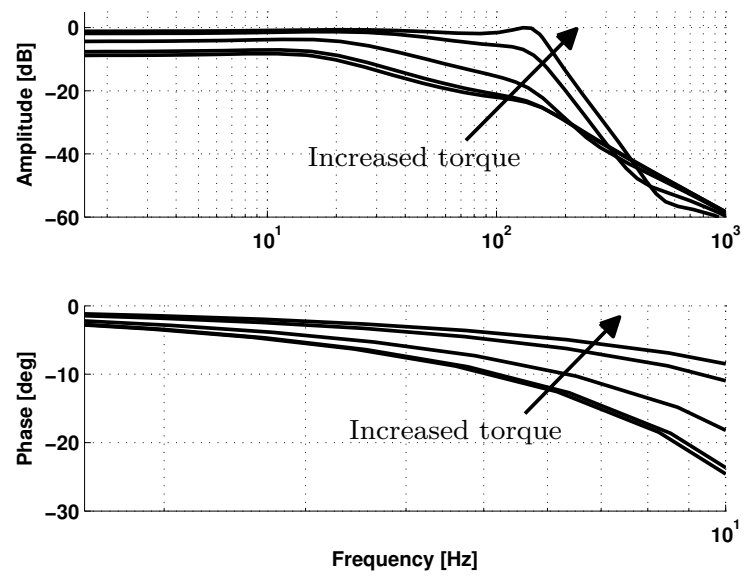

Figure 7.7 The closed loop frequency response of the steering system with servo valves for zero load flow from a steering wheel angle input to a rack displacement.

The loop gain shows an increased phase shift compared to the original system shown in Fig. 4.6, but again, the concern is rather the reduced gain margin for high torque levels. For the closed loop response, this system shows a slightly different behaviour to the original system shown in Fig. 4.7. There is an additional phase lag and a slight overshoot in the amplitude. How this behaviour affects the steering feel can only be evaluated by running the test rig. There are also nonlinear effects in the actual system, that are ignored for the linear analysis, that also might influence the behaviour of the system. The results from Fig. 7.6 and 7.7 should therefore only be seen as guidance when tuning the controller and is a valuable tool when investigating the behaviour of the system. To improve the steering feel for low torque levels, there is a margin to increase the gain without causing any instability problems. The test rig is also limited to on-centre driving, i.e. low torque levels, and the reduced gain margin at high torque levels is therefore not an issue. The case with servo valves has shown more phase shift than the case with self-regulated pressure control valves due to slower valves. The test rig should therefore provide valuable knowledge regarding closed-centre steering systems and its steering feel and provide a hindsight whether a closed-centre steering system is a feasible solution.

In the test rig, the final controller is implemented as lead-lag filter as 
in Eq. 7.15.

$$
G_{c t r l}=\frac{K_{p 0}}{\hat{K}_{q}} \frac{\frac{V}{\beta \hat{K}_{c}} s+1}{\frac{V}{\beta \hat{K}_{c}} s+\gamma} \frac{T_{d} s+1}{\alpha T_{d} s+1}
$$

From simulations and running the test rig it turned out that $\hat{K}_{c}$ could be set to a constant value due to very small variations. $K_{p 0}$ is chosen to obtain a good response and $T_{d}$ and $\alpha$ are tuned in the test rig. The reference model works around low pressure levels, especially for on-centre driving. This creates a difficulty for the closed-centre valves since they lose performance with such a low pressure drop. To overcome this, the pressure in each chamber is raised by 50 bar. This will not affect the pressure difference over the assistance cylinder but merely the friction level. The friction is nevertheless an unknown factor and should not be regarded when evaluating the actuator performance. It also turned out that the servo valve is very nonlinear around the zero spool position and due to the oversize of the valves they will work with very small spool displacements. This created difficulties when controlling the pressure. The valve spools are therefore shifted to work around a small opening position where their behaviour is more linear. This has no other effect for the scope of this work than to improve the response of the control loop.

For the simulation model a sinusoidal input in steering wheel angle with an amplitude of $20 \mathrm{deg}$ and an increasing frequency up to $2 \mathrm{~Hz}$ is used. The simulation results are shown below. Figure 7.8 shows the comparison between the reference pressure and actual pressure of the servo valves. Some discrepancy exists for higher frequency input. More interesting, is however, to compare the pressure from the servo valve system with that of the open-centre system, as in Fig. 7.9. Here the discrepancy is much lower, which resulted in the difference between the steering wheel torque for both systems shown in Fig. 7.10. The difference is very low and exists only during movement of the steering wheel. If the test rig can reach similar performance, the conclusion is that the test rig can be used to evaluate different actuator concepts. The results from the test rig are shown in section 8.3. 


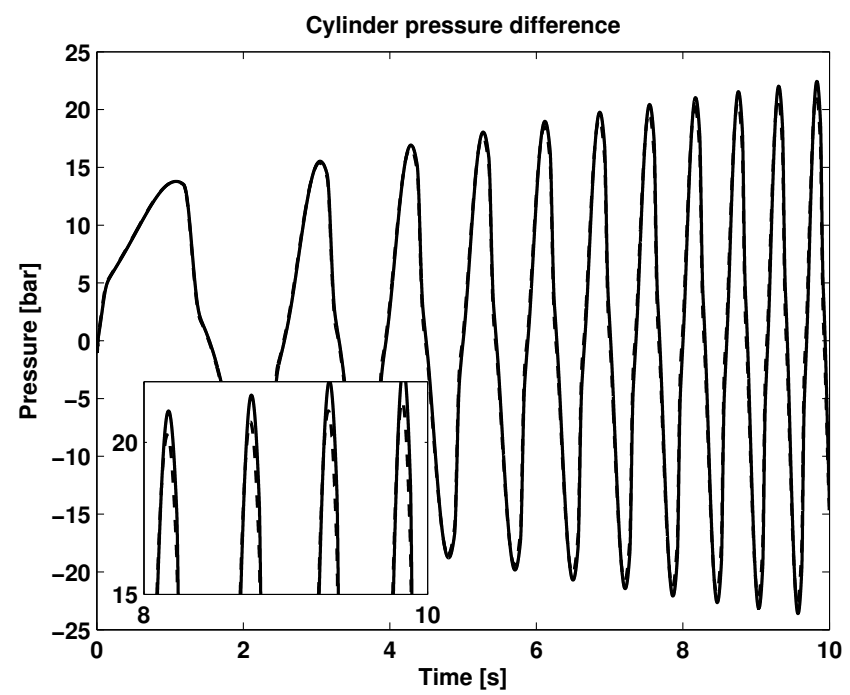

Figure 7.8 Comparison of simulated data between reference pressure (dashed) and actual pressure (solid) for the servo valve system.

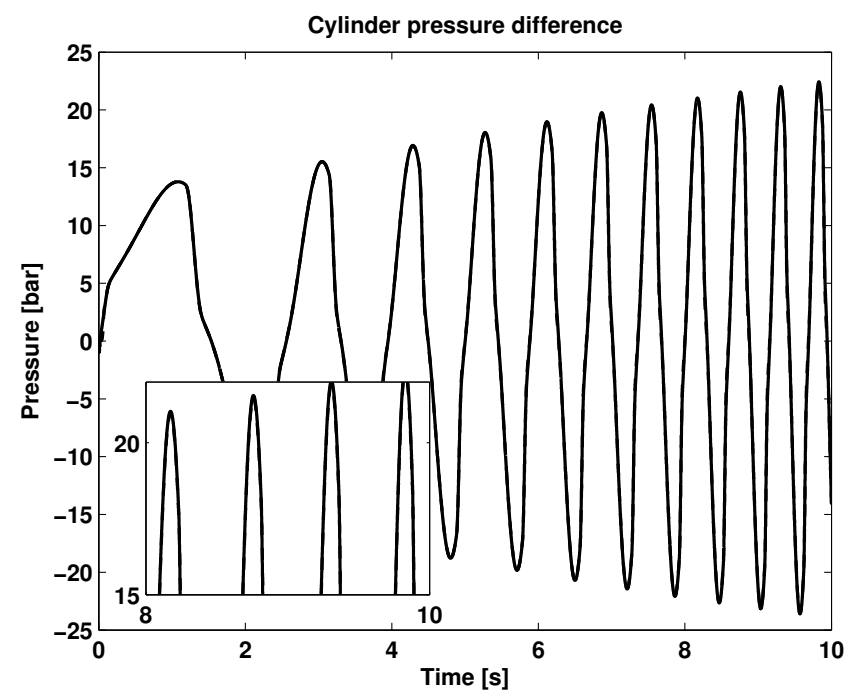

Figure 7.9 Comparison of simulated data between the open-centre valve system (dashed) and the servo valve system (solid). 


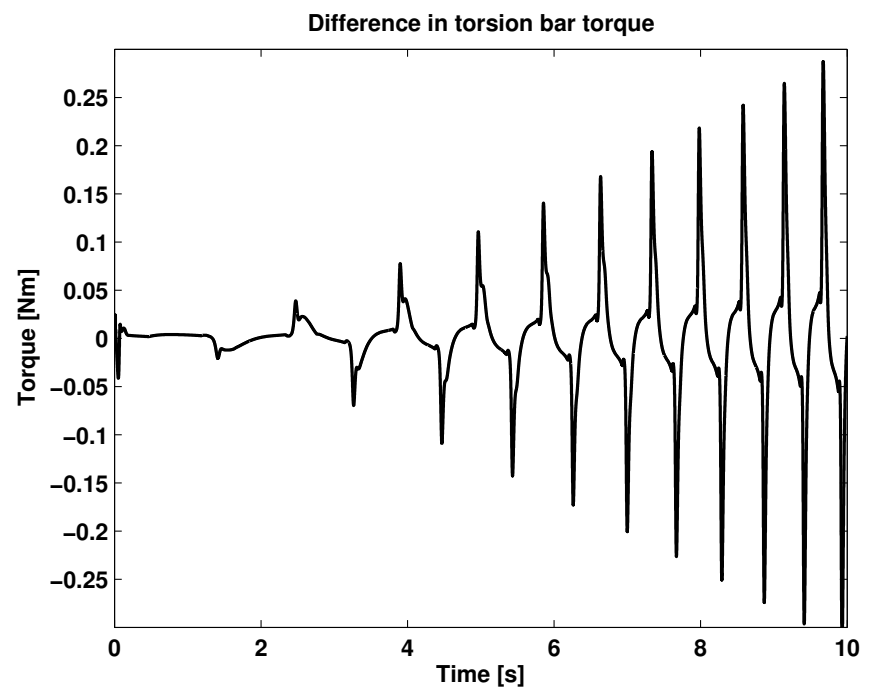

Figure 7.10 Simulated steering wheel torque difference between the open-centre system and the servo valve system. 


\section{8 \\ Results}

This chapter presents the most important results from the final design of the pressure control valve with additional controller as well as results from the test rig with closed-centre steering.

\subsection{Results from controller design}

The results in Fig. 8.1 show the performance of the valve and additional controller compared to the open-centre valve for a step input. The input corresponds to a step in torsion bar torque with an amplitude of $2 \mathrm{Nm}$. This is the most interesting and important area since it corresponds to on-centre driving where deviations in steering system characteristics are most apparent. It is also this region where the open-centre valve has its best performance, as was seen from the analysis in section 4.3 . 


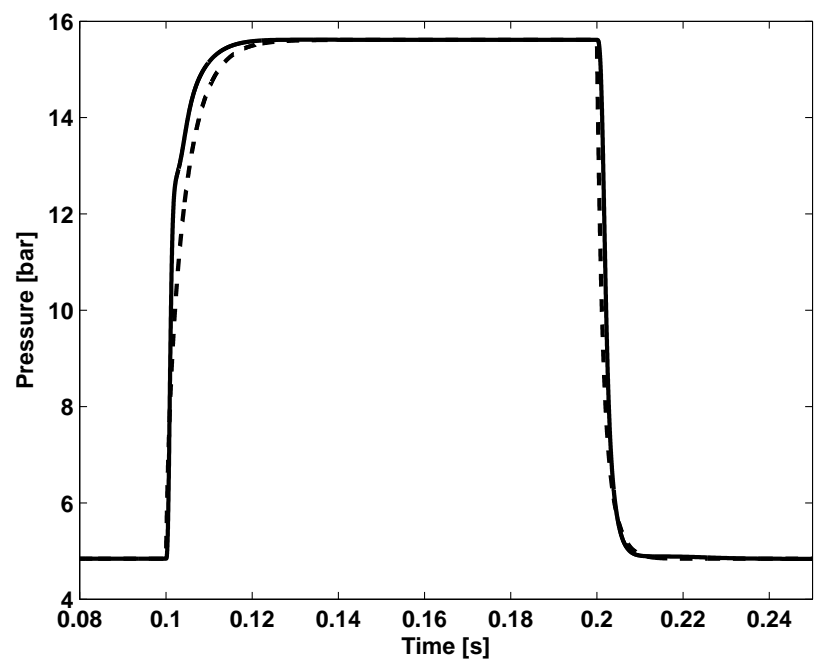

Figure 8.1 Step respons of the pressure control valve with the controller from the simulation model. The dashed curve shows the open-centre valve and the solid curve the closed-centre valve.

\subsection{Results from closed-centre steering system simulation}

The following figures present the results from simulation of the complete closed-centre steering system as described in section 6.3. Figure 8.2 shows a comparison of the assistance pressure between the open-centre valve and the closed-centre valve. The figure shows also the difference in pressure between the two systems, and it reaches 1 bar at maximum for the given steering cycle. Figure 8.3 shows the comparison of the steering wheel torque, i.e. the torque applied by the driver, between the open-centre system and the closed-centre system. The torque fed back to the driver is the channel of information through which the driver can appreciate differences in the steering system. To what extent a driver can appreciate a difference in torque level is subjective and it can be assumed that a certain level of torque difference is acceptable and not noticeable by a driver. However, the difference in Fig. 8.3 between the two systems is small, as can be seen from Fig. 8.4. The figure shows both the torque error in time and against the steering wheel angle velocity. Only for higher frequency input does the torque error increase. Finally, 
Fig. 8.5 shows a comparison between the two systems of the pressure in each chamber of the assistance cylinder. The figure also shows the difference in pressure between the two systems.
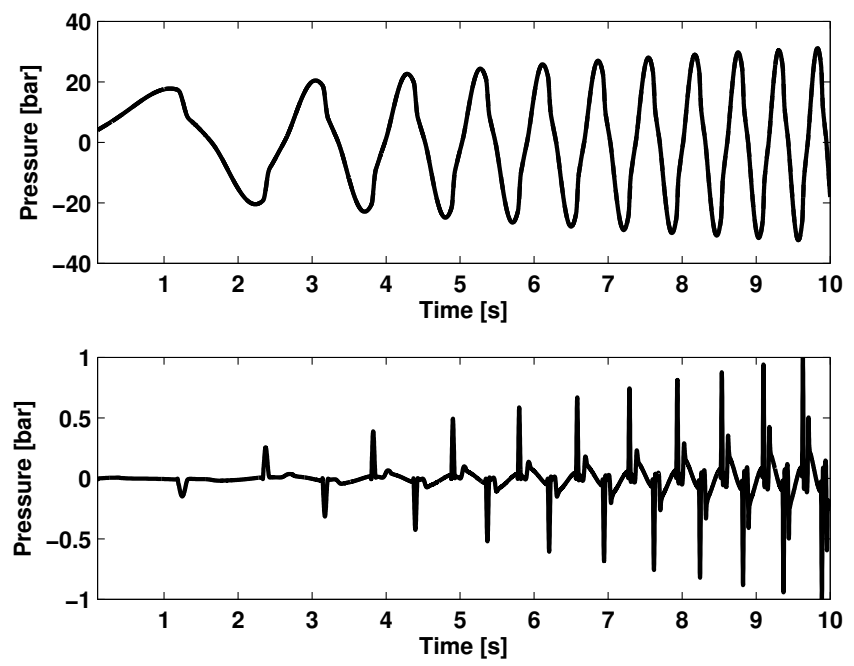

Figure 8.2 Comparison of the assistance pressure between the opencentre valve (dashed) and the closed-centre valve (solid) in the upper plot. The lower plot shows the difference in pressure between the two systems. 


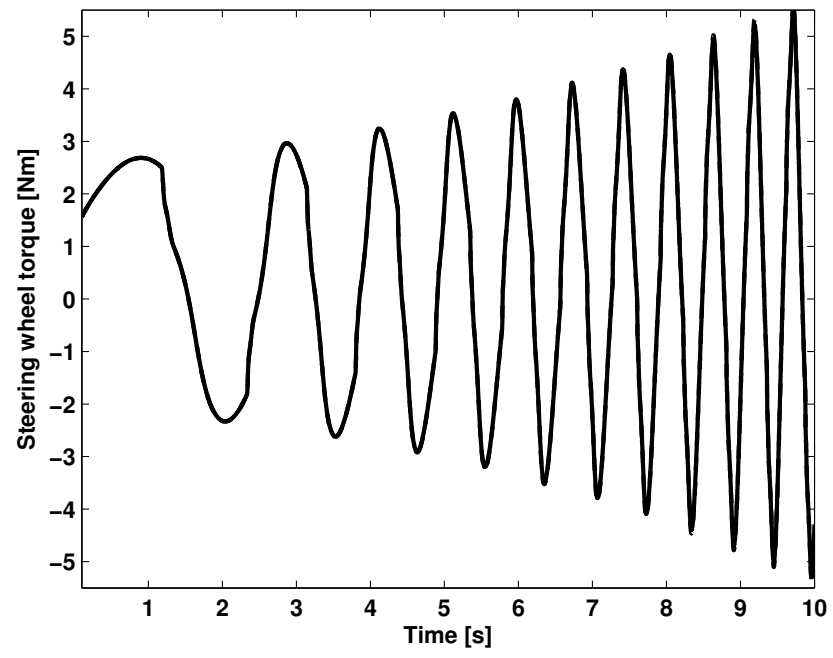

Figure 8.3 Comparison of the steering wheel torque between the opencentre system and the closed-centre system.
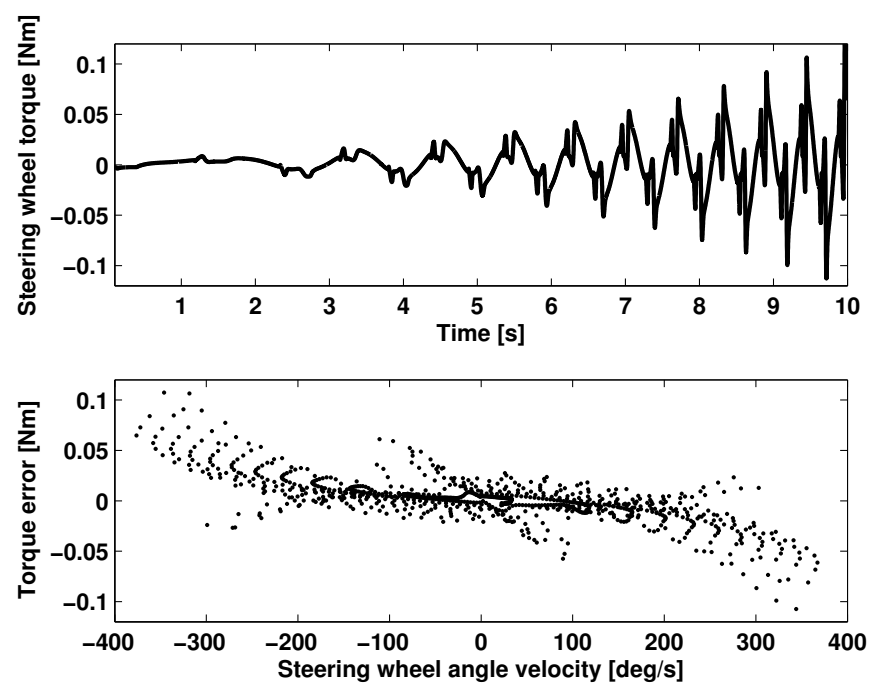

Figure 8.4 Difference in steering wheel torque between the open-centre system and the closed-centre system. The upper figure shows the torque difference in time and the lower figure shows the torque difference against the steering wheel angle velocity. 

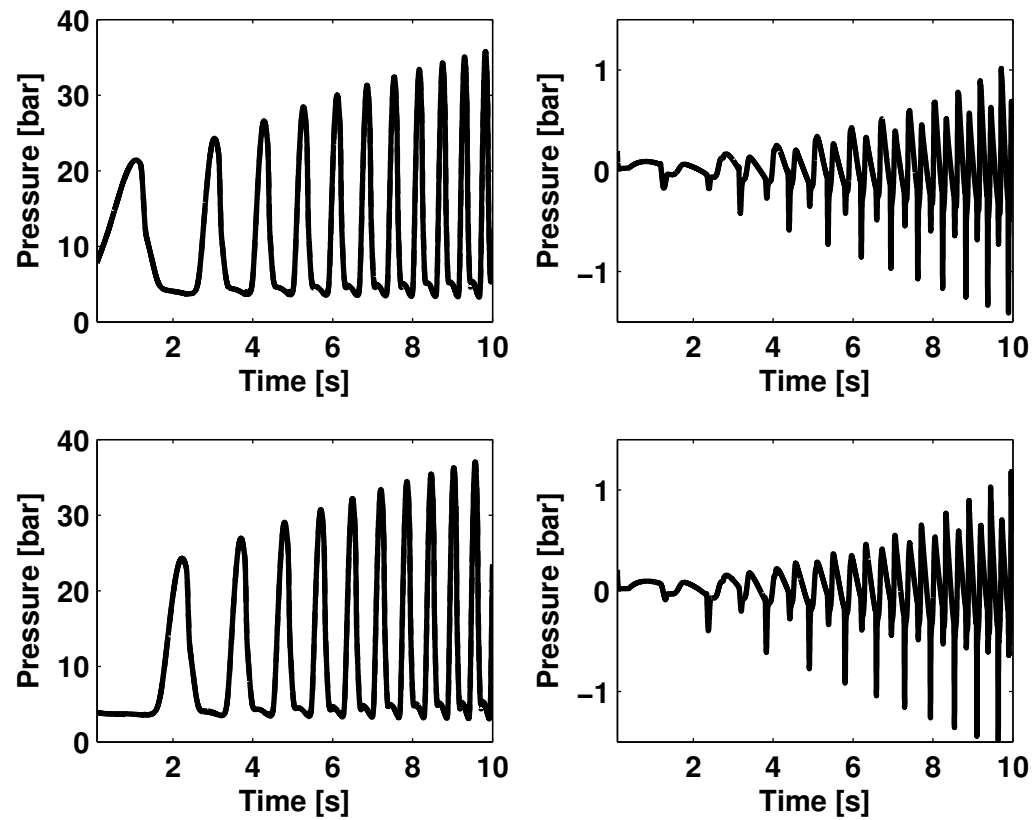

Figure 8.5 Comparison of the pressure in the left chamber (upper left plot) and the right chamber (lower left plot) between the open-centre valve (dashed) and the closed-centre valve (solid). The right plots show the respective difference in pressure between the two systems.

\section{Dry Park}

Figure 8.6 shows the comparison between the open-centre system and closed-centre system for the spring load seen as a dry park case. Some discrepancy can be seen around the low pressure area where the opencentre valve is faster and around the high pressure area where the opencentre valve is slower than the closed-centre valve. 


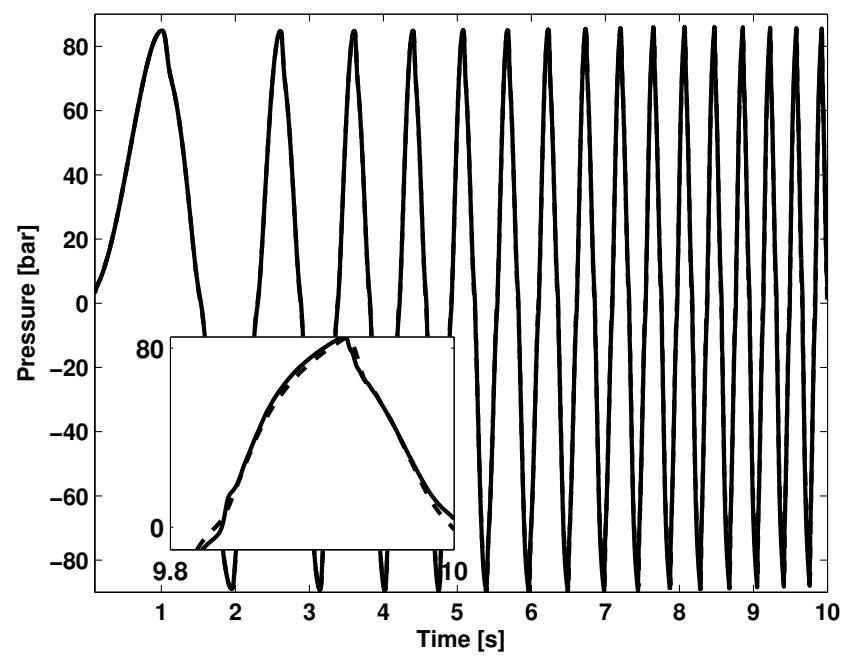

Figure 8.6 Comparison of the load pressure between the open-centre valve (dashed) and the closed-centre valve (solid).

\subsection{Results from closed-centre steering in the test rig}

\subsubsection{Step response}

In order to tune control parameters and verify the performance of the servo valves a step response is conducted for each chamber with the rack in a locked position. The result for a step from 50 bar to 100 bar and from 100 bar to 50 bar are shown in Fig. 8.7. The controller reaches $63 \%$ of its final value in $8-9 \mathrm{~ms}$ in both directions. 

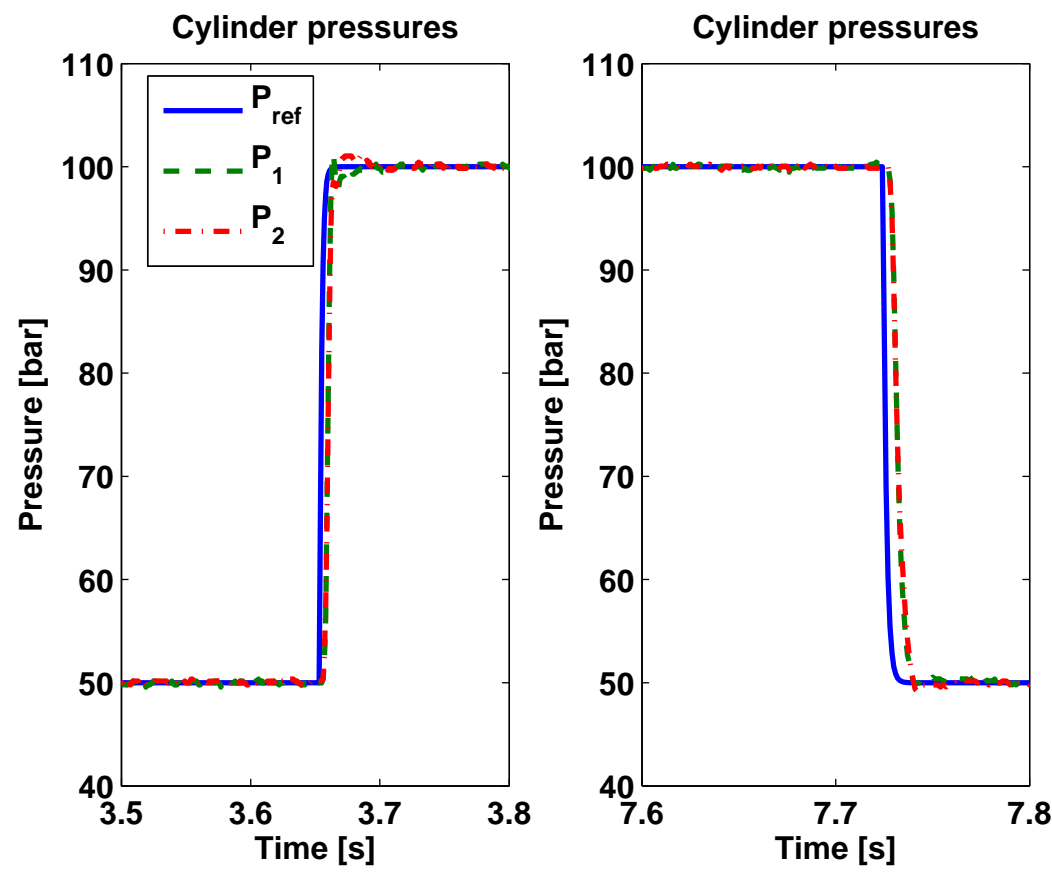

Figure 8.7 Step responses of the pressure controller from test rig.

\subsubsection{On-centre driving}

The software vehicle speed is set to a constant value of $70 \mathrm{kph}$. Figure 8.8 shows the pressure difference in the assistance cylinder. The servo valves are able to follow the reference pressure satisfactorily. The jerks in reference pressure are a result of the measured torsion bar torque and are filtered out by the servo valves. 


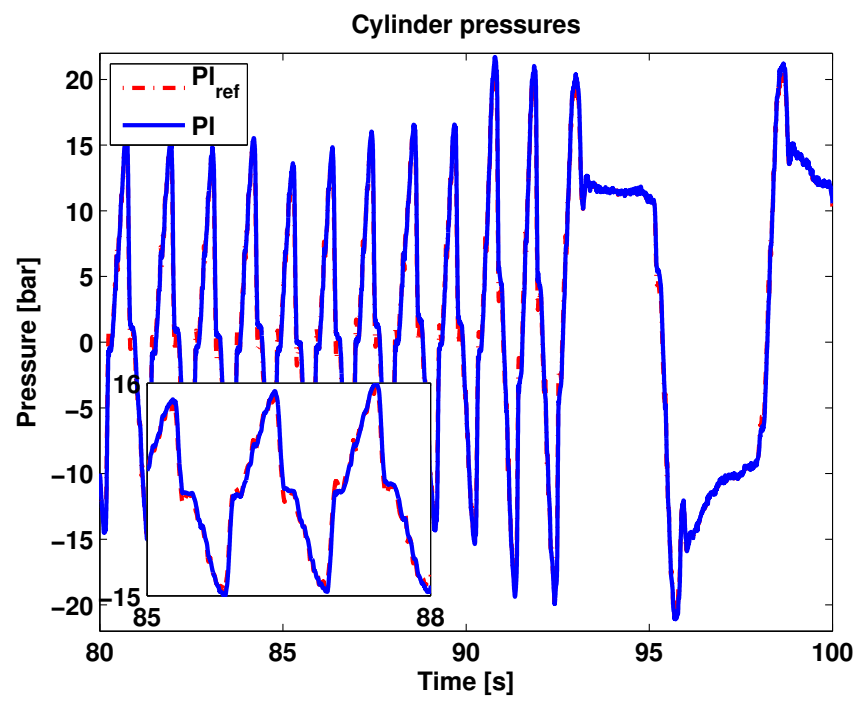

Figure 8.8 Measured cylinder pressures from the test rig. 


\section{9 \\ Discussion}

The aim of this work was to investigate the possibility to use an electronically controlled self-regulated pressure control valve as actuator in a power steering system. A model-based approach was used where a model of the valve was derived for in-depth analysis of its behaviour. A model of the steering system is also derived and validated against measurements from a test rig. The validated model of the steering system gives confidence to the simulation results of the complete closed-centre steering system. These two models are put together for a complete simulation of the closed-centre steering system. In many cases the simulation model has been used to gain knowledge of the system.

Many parts of the work should be seen as suggestions for a methodological approach rather than quantitative results. The valve has been designed with the help of an optimisation routine, which uses outer boundaries that will affect the outcome of the optimisation. These boundaries are primarily connected to the operating range of the steering system. This is a subjective matter. The operating range might differ for different cases, different vehicles, etc. The final valve is also set to follow the static behaviour of the open-centre valve used in the test rig. This also has an effect on the optimisation result. The optimisation generated a clear Pareto front where the maximum response of the valve is given for any available drive force. The exact requirement regarding the valve performance is difficult to predict beforehand. The controller can increase the performance as well. One approach is to make a comparison against the open-centre valve, which is fast at low pressure levels, and slow at high levels. It would, however, be more accurate to ask the question; what performance is needed from a steering feel point 
of view? Once again, this is a highly subjective matter. It is not stated that the performance of the open-centre valve is what is needed. An oversized valve might be generated. The approach has therefore been to choose a valve design with a good compromise between performance and drive force and evaluate it in the simulation environment.

What has been excluded from the valve design at this point is the solenoid. The solenoid would contribute both by increasing the total mass of the moving part of the valve, i.e. the spool and core, and also a time lag from an input signal to a force. It has been assumed that if the required drive force is kept low, a small solenoid would be sufficient and therefore also fast. There is also a hysteresis effect from the solenoid but since an integrating controller is used the effect should not give any issues. The next step in the work would be to actually add a model of a solenoid to the valve and study the effects, especially the effects the time lag and increased mass of the moving part have.

During the process of developing and evaluating the closed-centre system, it has been clear that the open-centre system has a very good characteristic. It has very little time lag and the response is direct. Since the actuation of the valve is controlled by the twisting of the torsion bar, which is controlled by the driver, a change in flow will immediately take place and affect the pressure rate. In a closed-centre system the valve has to react first, i.e. the spool has to begin moving first before the flow can change. The complete closed-centre system has been very sensitive to any overshoot of the pressure and a very smooth control of the pressure was necessary to avoid torque ripples. The reason for this is probably due to the fact that the boost gain (which is derived from the test rig) is very high. The boost gain corresponds to the slope of the boost curve. An overshoot of the pressure could momentarily raise the boost gain and force the system towards instability. There is probably also a lack of damping in the system. The system studied is in practice the test rig which is only constituted by the rack and pinion. Any friction from the suspension and wheel assembly is therefore missing. The tyre model is also fairly simple and a linear behaviour is assumed. Another boost curve would lead to other requirements of the valve. The linear analysis of the closed-centre valves in the steering system control loop, showed that a fast valve is probably needed at low torque levels in order to avoid too much phase shift, which might affect the steering feel. As mentioned, the studied valve has a greater phase shift compared to the open-centre valve. At high torque levels, a faster valve than the 
original valve, reduces the gain margin which might lead to instability problems. There is, thus, a compromise between steering feel and instability issues. It is, however, justified to believe that the steering feel is of less importance for high torque levels, which only take place during parking manoeuvres.

The analysis of the steering system is limited to on-centre driving. It is during on-centre driving where the steering feel is most evident and the behaviour of the closed-centre system is important here. Small rack displacements are therefore assumed and the performance of the closedcentre valve at lock-to-lock (the rack is at the end position) where the chamber volumes are very small has not yet been studied. The volume has a substantial effect on both performance and stability of the valve and the gain would probably need to be adjusted accordingly.

The results from simulation of the closed-centre steering system are promising. The pressure control valves are able to follow the reference but more importantly the dynamic behaviour allows the closed-centre system to have a similar characteristic to the open-centre system. This is seen from the comparison between the steering wheel torque from the open-centre system and the closed-centre system. The difference in torque is very small in both systems, even if some discrepancy exists for higher frequency input. This is a dynamic effect, since an integrating controller is used and no static error exists, and how a driver would appreciate the difference is a relative question. Would a driver accept a closed-centre steering system?

The external valve controller relies on additional pressure sensors but guarantees a predictable static behaviour. The controller also compensates for the valve dynamics and this means that the valve properties must be known. Valve properties would in reality have a certain tolerance that might affect the performance of the controller. A sensitivity analysis would answer this question. Further, the valve properties depend on both pressure and spool displacement. The spool displacement is not measured and the valve properties are only varied with pressure. Measuring the spool position might improve the controller and is something that could be investigated further, as well as how a displacement sensor might be installed.

The results from the test rig show that the servo valves are capable of following the reference value with good results. The critical region is around zero assistance pressure, where the servo valves are slower than the open-centre valve. From the simulation, however, it is seen that 
this should have little affect on the steering wheel torque. This could not be verified in the test rig since it would require measurement of the steering wheel torque and that the same input is always applied. One way to overcome this issue would be to use an electric motor to apply the steering wheel angle with high accuracy. For higher pressure, the servo valves would eventually be faster than the open-centre valve, also causing a discrepancy in steering wheel torque. The effect of having a valve with a different dynamic characteristic than the open-centre valve on steering feel is a possible subject for further study. There is also an issue in using the measured torsion bar torque as input. Any twisty moves or noise would be amplified in the pressure control loop and might cause problems. Filtering the signal, on the other hand, might give too much phase shift of the steering system loop and eventually lead to an unstable system, as well as affecting the steering feel. The jerky behaviour of the reference pressure around low pressure region is probably due to friction in the load cylinder. This is sensed by the torsion bar torque sensor and fed to the pressure control loop. In this case, the servo valves act as a filter for this behaviour. The friction in the load cylinder is sensed in the steering wheel. Nevertheless, the friction is the same for the reference system and should not be considered here.

It is of interest to discuss whether such a valve would also work for heavy vehicles. The conditions are different. A higher load flow is required, which might necessitate a higher drive force, but this depends on the intended operating range. Cylinder volumes are larger, though, which would mean that a slower valve is acceptable. 


\section{0}

\section{Conclusions}

What can be concluded from this work is that a self-regulating pressure control valve can perform sufficiently close to the open-centre valve. Simulation results have proven that the difference in steering wheel torque during on-centre driving between the two systems is very low and should be negligible. The method used to design and evaluate the concept has also been proven to work. The test rig has also shown that a closed-centre system is a feasible solution, although an experienced driver should make such a judgement regarding the steering feel. With slower servo valves in the test rig than the designed self-regulating pressure control valves, the test rig consitutes a proof that also the faster actuator is a feasible solution, regarding on-centre driving. 


\section{1 \\ Outlook}

The work in this thesis is highly motivated by the industry. There is a clear trend within the vehicle industry, both for passenger cars and heavy vehicles, to implement more active safety functions but also to strive towards autonomous vehicles. This will also incorporate the steering system and the need for an active steering system, which can be controlled by an external signal. Since heavy vehicles must rely on hydraulic power to turn the wheels due to the power requirement, finding a solution that enables active steering for a hydraulic power steering system is motivated. Existing solutions on the market make use of the open-centre system already installed in the vehicle. Although this resolves the problem with active steering, it still has the disadvantage of poor energy efficiency. A closed-centre system with electronically controlled valves would overcome this issue as well. Even if this work so far has shown that a closed-centre solution can perform as well as the open-centre system, more research is needed to fully understand all the effects and derive a concept that could be installed in a vehicle. Different concepts will be studied to see what solution fits different vehicle types best. One is a two-stage valve that would generate a much better static characteristic than the single-stage valve studied in this work. The benefit would be a wider operating range and use in larger vehicles. It would also be interesting to study the possibility to exclude the pressure sensors. The pressure sensors guarantee the accuracy of the valves but come with additional cost and fault modes. A valve solution that would work without the sensors would perhaps be cheaper and more fault tolerant but with a higher requirement on the valve itself. The next step will also involve how the closed-centre valves should be in- 
stalled in a vehicle and also how to handle different failure modes. The supply system has so far only been considered to be able to deliver a constant pressure and sufficient flow. This must of course be studied further and is an important aspect from packaging perspectives. The energy consumption of the closed-centre system is of most importance when motivating the solution compared to open-centre based solutions and further work is needed in this area as well. The passenger car industry has moved towards pure electric power steering systems with lower energy consumption and electronic control of the actuator. However, a comparison between a closed-centre solution and an EPAS system is still of interest when considering energy consumption and the high power density of hydraulic systems. Further work is still possible with the test rig to improve both the performance and the steering feel of the rig, i.e. to handle nonlinear effects such as friction in the load cylinder, but also how to incorporate the test rig in the evaluation process of different actuator concepts. 


\section{Bibliography}

[1] Andreas Eidehall. "Tracking and threat assessment for automotive collision avoidance". $\mathrm{PhD}$ thesis. Linköping University, 2007.

[2] Matthias Schorn et al. "Nonlinear Trajectory Control for Automatic Steering of a Collision Avoiding Vehicle". In: American Control Conference. 14 - 16 June 2006.

[3] N. Minoiu Enache et al. "Driver steering assistance for lane departure avoidance". In: Control Engineering Practice 17 (2009), pp. 624-651.

[4] Gábor Kovács et al. "Lane-Departure Detection and Control System for Commercial Vehicles". In: IEEE International Conference on Intelligent Vehicles. 1998.

[5] J. Ackermann, T. Bünte, and D. Odenthal. "Advantages of active steering for vehicle dynamics control". In: 32nd International Symposium on Automotive Technology and Automation. 1999.

[6] Jürgen Ackermann. "Active Steering for Better Safety, Handling and Comfort". In: Proceedings of Advances in Vehicle Control and Safety. 1998.

[7] Roy McCann and Son Nguyen. "Jackknife Avoidance in Large Trucks Using Active Front Steering". In: SAE Paper 2004-012639. 2004.

[8] Philip Koehn and Michael Eckrich. "Active Steering - The BMW Approach Towards Modern Steering Technology". In: Steering and Suspension Technology Symposium. 2004-01-1105. Detroit, Michigan, USA, 2004. 
[9] Wolfgang Reinelt et al. "Active Front Steering (Part 2): Safety and Functionality". In: SAE World Congress. SAE number 200401-1101. Detroit, MI, USA, 2004.

[10] Meihua Tai, Pushkar Hingwe, and Masayoshi Tomizuka. "Modeling and Control of Steering System of Heavy Vehicles for Automated Highway Systems". In: IEEE/ASME Transactions on Mechatronics 9 (Dec. 2004), pp. 609-618.

[11] Jürgen Guldner et al. Robost control design for automatic steering based on feedback of front and tail lateral displacement.

[12] Marcus Rösth. "Hydraulic Power Steering System Design in Road Vehicles; Analysis, Testing and Enhanced Functionality". PhD thesis. Division of Fluid and Mechanical Engineering Systems, Linköping University, 2007.

[13] A. Bootz. "Evolutionary Energy Saving Concepts for Hydraulic Power Steering Systems". In: 5th International Fluid Power Conference. 2006.

[14] James E. Forbes, Steven M. Baird, and Thomas W. Weisgerber. "Electrohydraulic Power Steering - An Advanced System for Unique Applications". In: International Congress and Exposition. 870574. Detroit, Michigan, USA, 23-27 February 1987.

[15] Peter E. Pfeffer et al. "Energy Consumption of Electro-Hydraulic Steering Systems". In: SAE 2005 World Congress $\&$ Exhibition. Apr. 2005.

[16] Yoshiharu Inaguma, Keiji Suzuki, and Kyousuke Haga. "An Energy Saving Technique in an Electro-Hydraulic Power Steering (EHPS) System". In: SAE Paper 960934. 1996.

[17] Jochen Gessat. "Electrically Powered Hydraulic Steering Systems for Light Commercial VehiclesS". In: SAE 2007 Commercial Vehicle Engineering Congress and Exhibition. 2007-01-4197. 2007.

[18] S. Müller, A. Kugi, and W. Kemmetmüller. "Analysis of a closedcenter hydraulic power steering system for full steer-by-wire functionality and low fuel consumption". In: The Ninth Scandinavian International Conference on Fluid Power, SICFP'052. 2005. 
[19] Wolfgang Kemmetmüller, Steffen Müller, and Andreas Kugi. "Mathematical Modeling and Nonlinear Controller Design for a Novel Electrohydraulic Power-Steering System". In: IEEE/ASME Transactions on Mechatronics 12.1 (Feb. 2007), pp. 85-97.

[20] Wolfgang Kemmetmüller, Andreas Kugi, and Steffen Müller. "Modeling and Nonlinear Control of an Electrohydraulic ClosedCenter Power-Steering System". In: Proceedings of the 44th IEEE Conference on Decision and Control, and the Europeand Control Conference 2005. Seville, Spain, Dec. 2005.

[21] Wentao Yu and William Szabela. "Energetic Efficiency Analysis and Performance Evaluation for a Closed Center Steering System". In: SAE 2007 Commercial Vehicle Engineering Congress 83 Exhibition. 2007-01-4217. 2007.

[22] Urs Wiesel et al. "A method for evaluating the fuel saving potential of different hybrid steering system configurations in heavy vehicles". In: VDI-Berichte 2068. 2009.

[23] M. Rösth, J. Pohl, and J.-O. Palmberg. "Active Pinion - Cost Effective Solution for Enabling Steering Intervention in Road Vehicles". In: The Bath Workshop on Power Transmission 8 Motion Control, PTMC'03. Bath, United Kingdom, Sept. 2003.

[24] Willy Klier, Gerd Reimann, and Wolfgang Reinelt. "Concept and Functionality of the Active Front Steering System". In: Convergence International Congress $\& 3$ Exposition On Transportation Electronics. 2004-10-18. 2004.

[25] Steffen Müller. "Zukünftige verbrauchsarme Servolenkungen für volle Steer-by-Wire-Funktionalität". In: ATZ - Automobiltechnische Zeitschrift 106 (2004), pp. 310-318.

[26] Thomas D. Gillespie. Fundamentals of vehicle dynamics. Society of Automotive Engineers, 1992.

[27] Giancarlo Genta and Lorenzo Morello. The Automotive Chassis Volume 1: Component Design. Springer, 2009.

[28] Richard Stone and Jeffrey K. Ball. Automotive Engineering Fundamentals. SAE International, 2004.

[29] Peter E. Pfeffer. "Interaction of Vehicle and Steering System Regarding On-Center Handling". PhD thesis. Deparment of Mechanical Engineering, University of Bath, 2006. 
[30] Peter E. Pfeffer et al. "Modelling of a Hydraulic Steering System". In: Fisita World Automotive Congress. 2006.

[31] John Baxter. "Analysis of Stiffness and Feel for a Power-Assisted Rack and Pinion Steering Gear". In: SAE Technical Paper 880706. 1988.

[32] J.W. Post and E.H. Law. "Modeling, Characterization and Simulation of Automobile Power Steering Systems for the Prediction of On-Center Handling". In: International Congress $\mathcal{E}$ Exposition. Feb. 1996.

[33] U. Neureder. "Investigation into Steering Wheel Nibble". In: Institution of Mechanical Engineers, Journal of Automobile Engineering 216 (2002), pp. 297-277.

[34] M. Rösth and J.-O. Palmberg. "Robust design of power steering system with emphasis on chattering phenomena". In: The 10th Scandinavian International Conference on Fluid Power, SICFP'0\%. 2007.

[35] M. Rösth and J.-O. Palmberg. "Modeling and Validation of Power Steering Systems with Emphasis on Catch-up Effect". In: The 9th Scandinavian International Conference on Fluid Power, SICFP'05. 2005.

[36] Aly Badawy et al. "Modeling and Analysis of an Electric Power Steering System". In: SAE International Congress and Exposition, Steering and Suspension Technology Symposium. 1999-010399. Detroit, Michigan, Mar. 1999.

[37] Etsuhiro Ueda et al. "The Development of Detailed Steering Model for On-Center Handling Simulation". In: International Symposium on Advanced Vehicle Control (AVEC). 2002, pp. 657662 .

[38] Leonard Segel. "On the Lateral Stability and Control of the Automobile as Inluenced by the Dynamics of the Steering System". In: ASME Journal of Engineering for Industry (1966), pp. 283-295.

[39] Herbert E. Merritt. Hydraulic Control Systems. John Wiley \& Sons, USA, 1967.

[40] Jan-Ove Palmberg. Tryckstyrning (in Swedish). Tech. rep. Division of fluid and mechanical engineering systems, Linköping University, 1983. 
[41] Jan-Ove Palmberg, Bo Andersson, and Christer Malmros. "Analysis and synthesis of hydraulic pressure regulators". In: Applied Control $\&$ Identification, IASTED. Copenhagen, Denmark, 1983.

[42] Jan-Ove Palmberg and Ding Kang-Zhi. "Modelling and simulation of pressure-controlled pumps". In: International Journal of Modelling 85 Simulation 7 (1987).

[43] P. Krus and J. Andersson. "Optimizing optimization for design optimization". In: Proceedings of DETC'2003, ASME Design Automation Conference. Chicago, 2003.

[44] M.J. Box. "A new method of constrained optimization and a comparison with other methods". In: The Computer Journal 8 (1965), pp. $42-52$.

[45] Mikael Sannelius. "On Complex Hydrostatic Transmissions". PhD thesis. Linköping University, 1999.

[46] Christer Ramdén. "Experimental methods in valve characteristic assessment". PhD thesis. Linköping University, 1999.

[47] Torkel Glad and Lennart Ljung. Reglerteknik. Studentlitteratur, 2006. 